\title{
EFEITOS DE REGULADORES VEGETAIS E DE FERTILIZANTES NA REMISSÃO DE SINTOMAS DE DECLÍNIO DOS CITROS
}

\author{
AMALIA SILVEIRA BERNARDES \\ Engenheira Agrônorna
}

Orientador : Prof. Dr. PAULO ROBERTO DE CAMARGO E CASTRO

Dissertação apresentada à Escola Superior de Agricultura "Luiz de Queiroz", da Universidade de São Paulo, para obtenção do título de Mestre em Agronomia, Área de Concentração : Fisiologia e Bioquímica de Plantas.

PIRACICABA

Estado de São Paulo - Brasil

Fevereiro - 1994 
Ficha catalggrafica preparada pela Seço de Livros da Divisas de Eitiloteca e Documentaça - FCLerusf

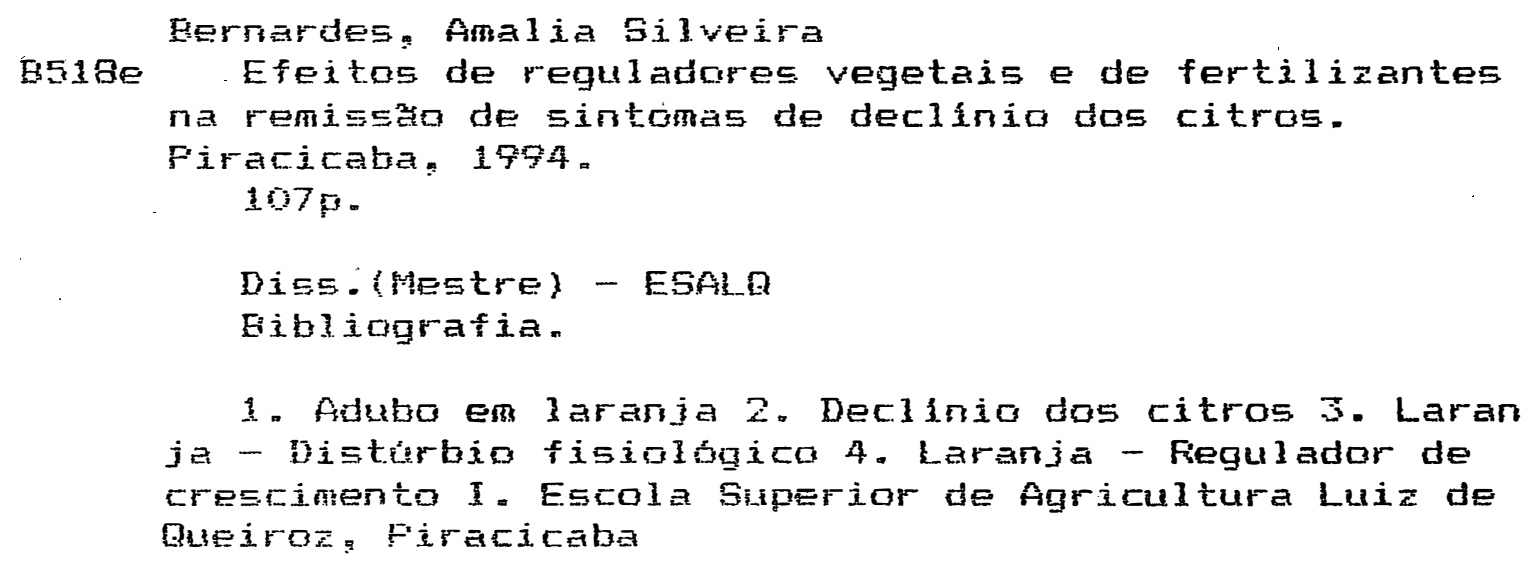




\title{
EFEITOS DE REGULADORES VEGETAIS E DE FERTILIZANTES NA REMISSÃO DE SINTOMAS DE DECLÍNIO DOS CITROS
}

\author{
AMALIA SILVEIRA BERNARDES
}

Aprovada em : 18.05 .1994

Comissão julgadora :

Prof. Dr. Paulo Roberto de Camargo e Castro ESALQ/USP

Prof. Dr. Antonio Roque Dechen ESALQ/USP

Dr. Joaquim Teófilo Sobrinho IAC/SAESP

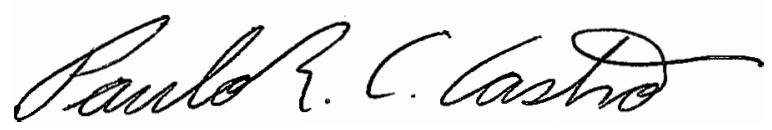

Prof. Dr. PAULO ROBERTO DE CAMARGO E CASTRO Orientador 
A meus pais e irmãos, pelo estímulo e confiança que me impulsionaram a contornar os obstáculos.

Àqueles que trabalham na terra com amor e sabedoria. 


\section{AGRADECIMENTOS}

Ao Prof. Dr. Paulo Roberto de Camargo e Castro, pela orientação e apoio.

Aos colegas do Curso de Pós-Graduação em Fisiologia e Bioquímica de Plantas, pela amizade e aprendizado conjunto.

Aos funcionários do Departamento de Botânica da ESALQ, pelo auxílio durante o Curso e a condução do experimento.

Aos Senhores Carlos Acácio de Campos, Oscar de Campos, Maurício Mendes, e todos aqueles que colaboraram com a condução do experimento na Fazenda Urutuba.

Ao Pesquisador Dr. Nivaldo Guirado, do Instituto Agronômico de Campinas, pela colaboração na instalação do ensaio na Fazenda Urutuba.

Ao Sr. Salvador Parducci, da Microquímica, e Sr. Carios Gilberto Rosin, do laboratório IBRA, pela colaboração e apoio para que o experimento se realizasse.

Aos Professores do Departamento de Matemática e Estatística da ESALQ, em especial Dra. Clarice G.B. Demétrio, Dr. Cassio R.M. Godoy e Prof. Iza Ferreira Alves, pelo apoio em diversas etapas da elaboração da dissertação. 
Aos Professores do Departamento de Agricultura da ESALQ, Prof. Marcos Silveira Bernardes, pela orientação na metodologia de fotografias hemisféricas, Dr. José Dias Costa e Dr. Gil M.S. Câmara, pelo auxílio na fase de elaboração do texto.

Ao Pesquisador Dr. Toshio Igue, do Instituto Agronômico de Campinas, pela orientação na análise estatística dos resultados, e por sua grande atenção e disponibilidade.

Ao Sr. Wagner Rodrigues dos Santos, do Instituto Agronômico de Campinas, pela obtenção dos índices DRIS a partir da análise foliar das laranjeiras.

Ao funcionário Sr. Hamilton José Orsini, do Departamento de Engenharia da ESALQ, Setor de Topografia, pela colaboração com instrumentos para o cálculo dos índices de área foliar.

A ESALQ, pela possibilidade de nosso crescimento e aprendizado.

Ao Instituto Agronômico de Campinas, pelos relevantes servị̧os à difusão científica.

A todos aqueles que contribuíram, direta ou indiretamente, para a realização deste trabalho. 


\section{SUMÁRIO}

Página

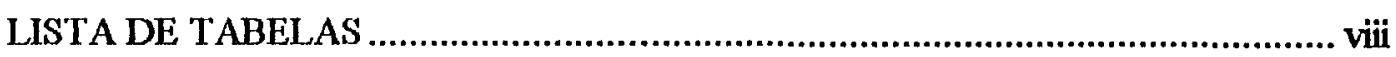

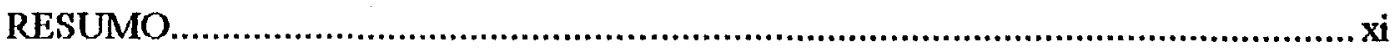

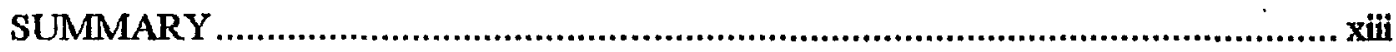

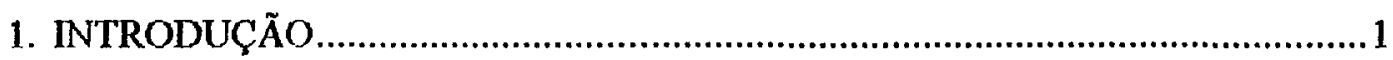

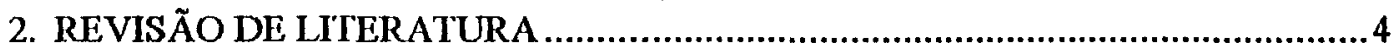

2.1. Caracterização do declínio dos citros ......................................................

2.1.1. Absorção de água pelo tronco das árvores ..........................................5

2.1.2. Teor de zinco no lenho................................................................6

2.2. Possíveis condições de ocorrência do declínio...............................................8

2.3. Estado nutricional de plantas cítricas afetadas pelo declínio..............................14

2.3.1. Interpretação da análise foliar pelo DRIS ........................................20

2.4. Associação do declínio com agentes patogênicos..........................................22

2.5. Tentativas de controle e recuperação de plantas ...............................................25

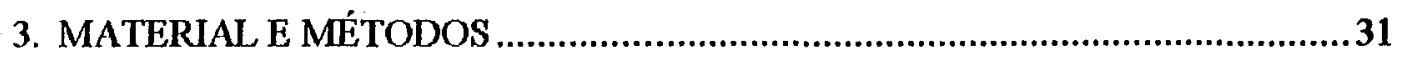

3.1. Caracterização do local do experimento .......................................................31

3.2. Cultivar e seleção de árvores utilizadas ......................................................34

3.3. Teste de absorção de água pelo tronco ....................................................34

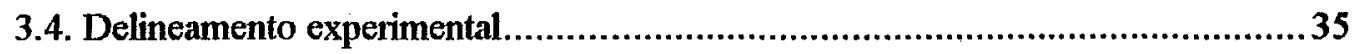

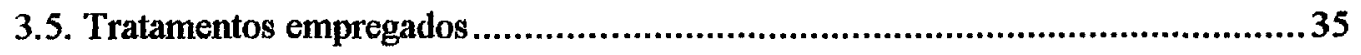

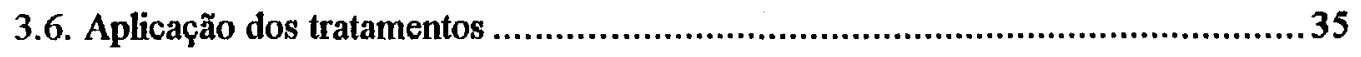

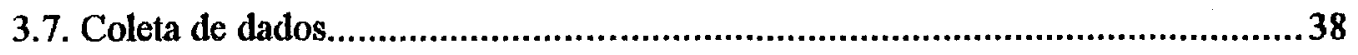

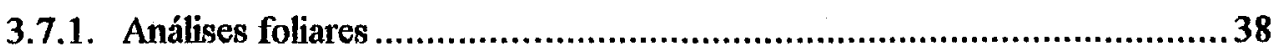

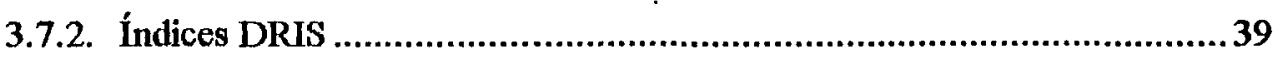




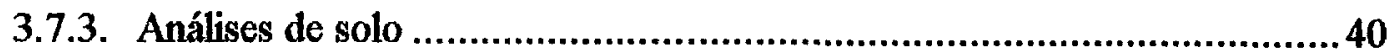

3.7.4. Análise do teor de zinco no lenho.......................................................41

3.7.5. Teste de absorção de água pelo tronco ..............................................41

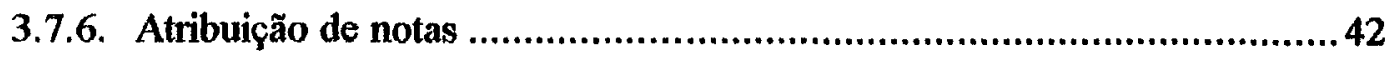

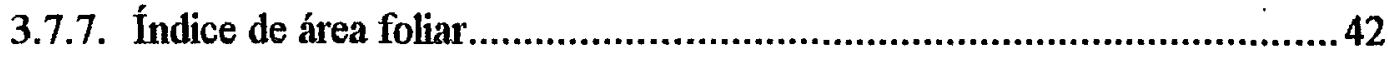

3.7.8. Correlação notas - índice de área foliar......................................................4 44

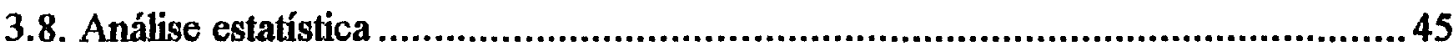

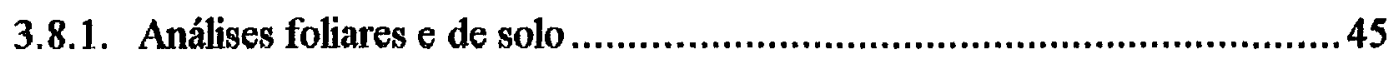

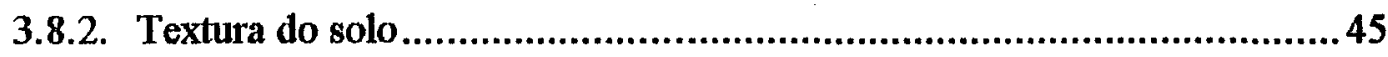

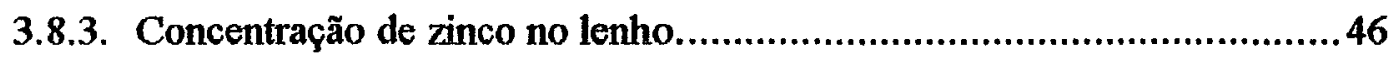

3.8.4. Absorção de água pelo tronco ................................................................. 46

3.8.5. Notas pela aparência visual ............................................................... 46

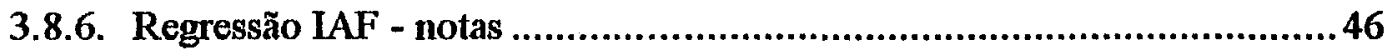

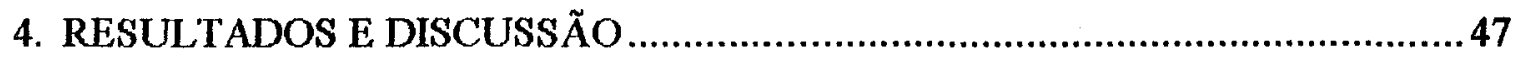

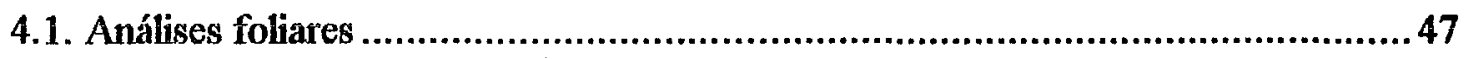

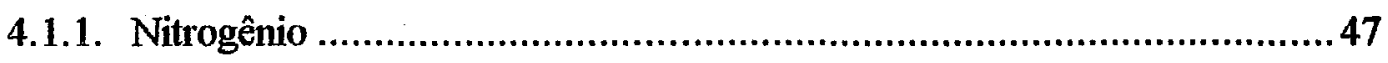

4.1.2. Fósforo e potássio ...........................................................................50

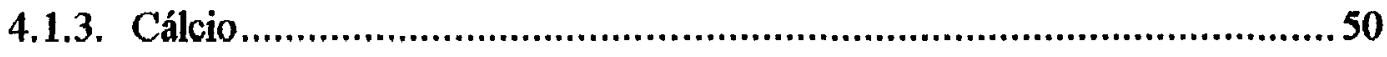

4.1.4. Magnésio e enxofre .............................................................................51

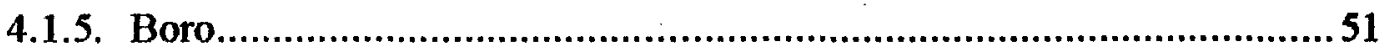

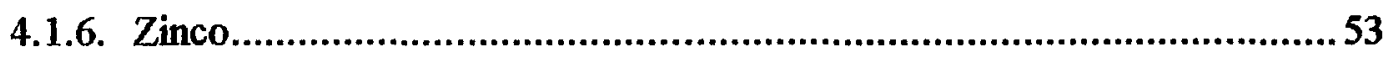

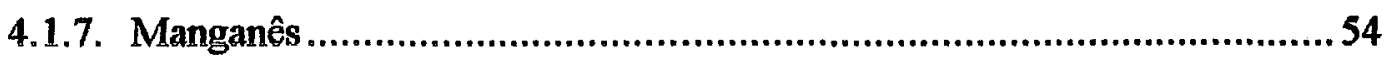

4.1.8. Ferro, cobre e alumínio …....................................................................55

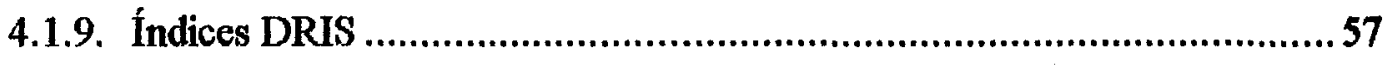

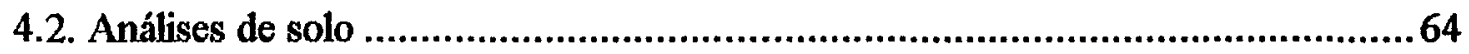


4.2.1. Porcentagem de saturação de bases ...................................................64

4.2.2. Textura do solo................................................................... 77

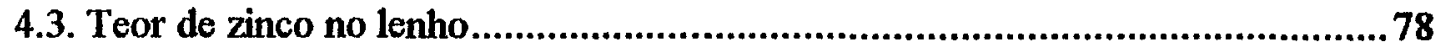

4.4. Teste de absorção de água pelo tronco ................................................. 80

4.5. Avaliação visual das árvores............................................................... 82

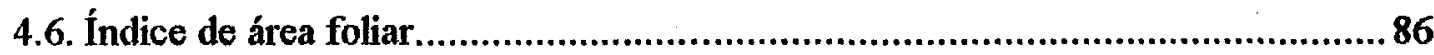

4.7. Correlação notas - índices de área foliar ................................................87

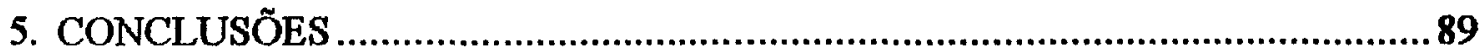

REFERÊNCIAS BIBLIOGRÁFICAS......................................................... 91 


\section{LISTA DE TABELAS}

Tabela

Página

1 Porcentagens de amostras foliares com deficiência (1980-1982). 15

2 Porcentagens de amostras foliares com deficiência(1983).......................... 16

3 Porcentagens de amostras foliares com deficiência (1983-1984). .................. 17

4 Porcentagens de amostras foliares com deficiência (1985-1986). .................. 17

5 Interpretação das faixas de valores de indices DRIS obtidos de análises de folhas de citros.

6 Dados climatológicos do posto meteorológico da Empresa Champion Papel e Celulose.

7 Tratamentos empregados e suas respectivas doses.

8 Composição dos produtos aplicados às árvores do ensaio

9 Médias e análise de variância das concentrações de nitrogênio, fósforo, potássio, cálcio, magnésio e enxofre, em porcentagem, para as análises foliares de junho de 1989.

10 Médias e análise de covariância das concentrações de nitrogênio, fósforo, potássio, cálcio, magnésio e enxofre, em porcentagem, para as análises foliares de abril de 1990.

11 Médias e análise de variância das concentrações de boro, zinco, manganês, ferro, cobre e alumínio, em ppm, para as análises foliares de junho de 1989.

12 Médias e análise de covariância das concentrações de boro, zinco, manganês, ferro, cobre e alumínio, em ppm, para as análises foliares de abril de 1990

13 Índices DRIS para o nitrogênio, da análise foliar de abril de 1990 57

14 Índices DRIS para o fósforo da análise foliar de abril de 1990. 58 
15 Índices DRIS para o potássio, da análise foliar de abril de 1990 .......................58

16 Índices DRIS para o cálcio, da análise foliar de abril de 1990........................59

17 Índices DRIS para o magnésio, da análise foliar de abril de 1990....................59

18 Índices DRIS para o enxofre, da análise foliar de abril de $1990 . . . \ldots \ldots \ldots \ldots \ldots . . . . . .60$

19 Índices DRIS para o boro, da análise foliar de abril de 1990........................60

20 Indices DRIS para o ferro, da análise foliar de abril de 1990 .......................61

21 Índices DRIS para o manganês, da análise foliar de abril de 1990 ..................61

22 Índices DRIS para o zinco, da análise foliar de abril de 1990........................62

23 Índices de balanço nutricional, obtidos a partir da análise foliar de abril de 1990

24 Médias e análise de variância da porcentagem de saturação de bases e dos teores de fósforo, em ppm, do solo das amostras de junho de 1989.

25 Médias e análise de covariância da porcentagem de saturação de bases e dos teores de fósforo, em ppm, do solo das amostras de novembro de 1990

26 Médias e análise de variância dos índices de $\mathrm{pH}$ do solo, em $\mathrm{CaCl}_{2}$, e da capacidade de troca catiônica, em meq/100 $\mathrm{cm}^{3}$ de solo, obtidos a partir de amostras retiradas em junho de 1989.

27 Médias e análise de covariância dos índices de $\mathrm{pH}$ do solo, em $\mathrm{CaCl}_{2}$, e da capacidade de troca catiônica, em meq/100 $\mathrm{cm}^{3}$ de solo, obtidos a partir de amostras retiradas em novembro de 1990.

28 Médias e análise de variância da porcentagem de matéria orgânica, e dos teores de potássio, em $\mathrm{meq} / 100 \mathrm{~cm}^{3}$ de solo, das amostras retiradas em junho de 1989.

29 Médias e análise de covariância da porcentagem de matéria orgânica, e dos teores de potássio, em meq $/ 100 \mathrm{~cm}^{3}$ de solo, das amostras retiradas em novembro de 1990. 
30 Médias e análise de variância dos teores de cálcio e de magnésio, em meq $/ 100 \mathrm{~cm}^{3}$ de solo, das amostras retiradas em junho de 1990 .

31 Médias e análise de covariância dos teores de cálcio e de magnésio, em meq $/ 100 \mathrm{~cm}^{3}$ de solo, das amostras retiradas em novembro de 1990.

32 Médias e análise de variância da acidez potencial do solo, em meq/ $100 \mathrm{~cm}^{3}$ de solo, e da relação cálcio/magnésio, das amostras retiradas em junho de 1989.

33 Médias e análise de covariância da acidez potencial do solo, em meq/ $100 \mathrm{~cm}^{3}$ de solo, e da relação cálcio/magnésio, das amostras retiradas em novembro de 1990 .

34 Médias e análise de variância das relações cálcio/potássio e magnésio/ potássio,obtidas a partir das amostras de solo de junho de 1989.

35 Médias e análise de covariância das relações cálcio/potássio e magnésio/ potássio, obtidas a partir das amostras de solo de novembro de 1990.

36 Médias e análise de variância da porcentagem de areia e de argila nas amostras de solo retiradas no início do experimento, em junho de 1989.

37 Teores de zinco no lenho, em ppm, obtidos de amostras a $20 \mathrm{~cm}$ acima da região de enxertia, em abril de 1990, e análise de variância.

38 Volume de água absorvida, em $\mathrm{ml} / 10$ segundos, no teste de absorção de água realizado em outubro de 1990, e análise de variância.

39 Notas obtidas da avaliação visual de 20 de outubro de 1989, e análise de variância.

40 Notas obtidas da avaliação visual de 02 de abril de 1990, e análise de variância.

41 Notas obtidas da avaliação visual de 26 de outubro de 1990, e análise de variância.

42 Índice de área foliar calculado pelo método de fotografias hemisféricas e notas correspondentes para oito árvores do ensaio. 


\title{
EFEITOS DE REGULADORES VEGETAIS E DE FERTILIZANTES NA REMISSĀO DE SINTOMAS DE DECLÍNIO DOS CITROS
}

\author{
Autora : AMALIA SILVEIRA BERNARDES \\ Orientador : PROF. DR. PAULO ROBERTO DE CAMARGO E CASTRO
}

\section{RESUMO}

O declínio é responsável pela morte de aproximadamente 10 milhões de plantas cítricas anualmente no Estado de São Paulo, causando aumento do custo de produção, devido a necessidade de erradicação das plantas afetadas, e replantio no pomar. A substituição de porta-enxertos, recomendada como possível medida preventiva para esta anomalia de etiologia desconhecida, apresenta algumas desvantagens para o citricultor, como desuniformidade na época de colheita, ou perda das características de resistência a outras moléstias e a condições desfavoráveis de água no solo, conferidas pelo limoeiro 'Cravo', atualmente o cultivar mais utilizado como porta-enxerto e aparentemente o mais suscetível ao declínio dos citros.

Com o objetivo de avaliar a resposta de laranjeiras com declínio à aplicação de reguladores vegetais e de fertilizantes, como alternativa para o controle desta anomalia, foi conduzido um experimento em um pomar na região de Mogi-Guaçu, Estado de São Paulo, onde foram empregados os tratamentos : ácido giberélico+ácido 2,4-diclorofenoxiacético; ácido giberélico+ácido naftalenacético; ácido giberélico+ácido naftalenacético+Grex-Citrus; Agromil+Biofix; Aminofértil-1+Aminofértil-2; controle com sintomas de declínio; controle 
sem declínio. As árvores foram diagnosticadas quanto ao declínio, pelo teste de absorção de água pelo tronco e avaliação visual. Os tratamentos foram aplicados em quatro épocas, a intervalos de quatro meses, aproximadamente, entre julho de 1989 e junho de 1990 . Foram realizadas análises foliares e de solo, no ínicio e ao término do ensaio, em todas as árvores envolvidas. Juntamente com a segunda análise foliar, foram retiradas amostras do lenho de cada árvore, para análise do teor de zinco. Foram efetuadas avaliações visuais com atribuição de notas pelo estado da copa das plantas, em três épocas durante o ensaio, após as aplicações dos tratamentos. Um segundo teste de absorção de água pelo tronco, foi realizado ao final das aplicações. Oito das quarenta e duas árvores do ensaio foram fotografadas com a finalidade de cálculo do índice de área foliar pelo método de fotografias hemisféricas, e foi testada a correlação dos índices obtidos, com as notas atribuídas às árvores fotografadas.

De acordo com as notas atribuídas, o volume de água absorvida pelo tronco, e o teor de zinco no lenho, nenhum dos produtos aplicados resultou em recuperação significativa das laranjeiras com declínio. A textura do solo sob árvores com declínio não diferiu da textura do solo sob árvores sem declínio. O tratamento com Aminofértil1+Aminofértil-2 apresentou maiores teores de boro e de zinco nas folhas, em relação ao controle com declínio. $\mathrm{O}$ tratamento com ácido giberélico+ácido 2,4-diclorofenoxiacético apresentou teor foliar de cálcio mais elevado e de manganês mais baixo, em relação ao controle com declínio. $O$ tratamento com ácido giberélico+ácido naftalenacético+Grex-Citrus apresentou menor teor de nitrogênio nas folhas, e maior teor de zinco, em relação ao controle com declínio. $O$ tratamento controle com declínio apresentou maiores teores de nitrogênio $e$ de zinco nas folhas, em relação ao controle sem declínio. $O$ tratamento controle sem declínio manteve volume de água absorvida pelo tronco significativamente maior do que o do controle com declínio e de todos os demais tratamentos, também com declínio. Os índices de área foliar calculados pelo método de fotografias hemisféricas apresentaram-se significativamente correlacionados com as notas atribuídas pela avaliação visual das árvores. 


\title{
EFFECT OF PLANT GROWTH REGULATORS AND FERTILIZERS ON THE REMISSION OF SYMPTOMS OF CITRUS DECLINE
}

\author{
Author : AMALIA SILVEIRA BERNARDES \\ Adviser : PROF. DR. PAULO ROBERTO DE CAMARGO E CASTRO
}

SUMMARY

The disease known as "declinio" in Brazil causes great damage in citrus groves, with great expenses to the grower who needs to replace dead trees in the orchard. The effective measure to prevent citrus decline at this time is the change of rootstocks. The most used rootstock, 'Rangpur' lime, is seemingly the most suscepitible to ciirus decline. However, the replacement by resistant rootstocks may bring about drawbacks since they can be susceptible to other diseases or unfavourable soil conditions.

Treatments with gibberellic acid + 2,4-dichlorophenoxyacetic acid; gibberellic acid + naphthalenacetic acid; gibberellic acid + naphthalenacetic acid + Grex-Citrus (a fertilizer); Agromil + Biofix (fertilizers); Aminofertil-1 + Aminofertil-2 (fertilizers), were applied for the purpose of estimating the effect of plant growth regulators and fertilizers on decline-affected orange trees as an altemative control of this disorder. The treatments were compared to control plants, with or without decline.

The trees showing visual symptoms were diagnosticated by water injection into the trunk with a syringe. Applications were spread on each tree every four months from 
July 1989 to June 1990. Samples of each tree were taken for leaf and soil analyses, before the start of the experiment and after finishing it. Wood samples were taken at the same time as the last leaf samples, for zinc level analysis. The trees were rated with grades from 1 to 5 related to the severity of their visual symptoms, three times during the experiment, after applications. Another water uptake test with syringe injection was conducted after all product applications. Hemispherical photographs of eight trees were taken for determining leaf area index and its correlation with the scale values of the visual ratings.

Significant recovery of the decline-affected trees was not obtained by any of the products applied. Soil texture under decline-affected trees was not significantly different from soil texture under healthy trees. Aminofertil-1 + Aminofertil-2 applications resulted in higher leaf boron and zinc levels than in decline-affected control trees. Gibberellic acid + 2,4-dichlorophenoxyacetic acid treatment resulted in higher leaf calcium levels and lower leaf manganese levels than in decline-affected control trees. Gibberellic acid + naphthalenacetic acid + Grex-Citrus resulted in higher leaf zinc levels and lower leaf nitrogen levels than in decline-affected control trees. Nitrogen and zinc levels in the leaves were significantly higher in decline-affected control trees than in healthy control trees. Healthy control trees took up significantly higher amount of water than did all decline-affected trees, treated or untreated. Calculated leaf area indexes were significantly correlated with rating grades given to the trees. 


\section{INTRODUÇÃo}

A anomalia de plantas cítricas denominada declínio foi detectada no Brasil desde o princípio da década de 1970, em diversos pomares dos Estados de São Paulo, Minas Gerais, Bahia e Sergipe.

As plantas são afetadas geralmente após os três anos de idade, ou após a primeira produção, havendo redução significativa da absorção de água, com a ocorrência de obstruções dos vasos do xilema. Do murchamento parcial de alguns ramos a moléstia evolui até a morte da árvore (ROSSETTI \& BERETTA, 1988) .

Levantamentos realizados nas principais regiões citrícolas do Estado de São Paulo, principal produtor de citros, mostraram que em 1982-1983, cerca de $4,6 \%$ da população total de aproximadamente 100 milhões de árvores adultas estava afetada pelo declínio (ARRUDA et al.,1986).

Até o momentó não se conhece a etiologia desta moléstia. Diversos experimentos têm sido conduzidos visando determinar um agente causal, ou recuperar plantas afetadas.

A substituição de árvores com declínio por mudas cujos cultivares de porta-enxertos são tolerantes ou menos suscetíveis ao declínio, parece atualmente a única medida efetiva para o controle desta anomalia. Os cultivares para porta-enxertos 
considerados apropriados são a laranjeira 'Caipira', as tangerineiras 'Cleopatra' e 'Sunki', e o tangelo 'Orlando' (BERETTA et al., 1988b; GUIRADO et al., 1988 e GUIRADO et al., 1991).

Tem sido observado que a taxa de aumento da incidência de declínio é maior em plantas cítricas enxertadas sobre limoeiro 'Cravo' (TEÓFILO SOBRINHO \& FIGUEIREDO, 1984 e GUIRADO \& SILVERIO, 1992). A partir dos anos 60 o limoeiro 'Cravo' tornou-se quase que o único porta-enxerto utilizado na citricultura paulista. Levantamentos realizados nos viveiros em 1961 e 1970 mostraram que a participação do limoeiro 'Cravo' havia crescido de 77\% para 99\%.

Atualmente quase toda a agroindústria citrícola paulista está apoiada sobre este porta-enxerto que, a partir da década de 70 , vem sendo afetado pelo declínio dos citros, o que vem causando a perda anual de oito a dez milhões de plantas e elevando os custos de produção e de colheita (POMPEU JÚNIOR, 1991). Segundo o mesmo autor, as excepcionais características do limoeiro 'Cravo' fazem com que ele continue a predominar nos novos plantios. As médias dos dados coletados em viveiros no período de 1984 a 1988 mostraram que o limoeiro 'Cravo' representava $72 \%$ dos porta-enxertos. Após, vinham a tangerineira 'Cleopatra' com 24\%, a laranjeira 'Caipira' com 1\%, seguidos pelo limoeiro 'Volkameriano', tangerineira 'Sunki', laranjeira 'Azeda', citrumelo 4475, $P$. trifoliata, tangelo 'Orlando' e citranges 'Troyer' e 'Carrizo'.

Como a substituição de porta-enxertos pode acarretar algumas desvantagens para o citricultor, entre elas : a produção tardia, menor rendimento, menor resistência à seca, a condições adversas e a outras moléstias, além de ser um processo oneroso, outras alternativas para o controle do declínio têm sido experimentadas.

Com a finalidade de verificar a resposta de plantas com declínio à aplicação de reguladores vegetais e de fertilizantes, este experimento foi instalado em 
pomar com grande incidência deste distúrbio. O subdesenvolvimento das plantas atingidas pode estar relacionado à deficiência hídrica e nutricional, consequência do desequilibrio provocado pelo distúrbio na absorção pelas raízes e translocação para a parte aérea, de água, hormônios e nutrientes. Este distúrbio levaria à ocorrência de baixos teores de auxinas endógenas ou outros hormônios responsáveis pelo crescimento vegetal.

Este ensaio visa avaliar o estado nutricional e a possibilidade de remissão de sintomas de declínio em plantas cítricas, em estágio inicial da anomalia, após a aplicação exógena de reguladores vegetais e de fertilizantes. 


\section{REVISÃO DE LITERATURA}

\subsection{Caracterização do declínio dos citros}

Os sintomas de declínio se manifestam geralmente após a primeira produção dos citros. O primeiro sintoma visível é a paralisação do crescimento, e em estágios mais avançados há um desfolhamento parcial ou total dos ramos, que pode progredir até a morte da planta (ROSSETTI \& BERETTA,1988).

As raízes são afetadas, reduzindo-se o número de radicelas quando comparadas com as raízes de plantas sadias. O sintoma de deficiência de zinco nas folhas geralmente está associado com esta moléstia ( PRATES, 1988 ; ROSSETTI, 1981 e ROSSETTI, 1984 ).

As características específicas das plantas com declínio em relação às sadias são acúmulo de sais de zinco e compostos fenólicos no tronco, acima da região de enxertia ( ROSSETTI, 1981 ; SYVERTSEN et al., 1980 ; WUTSCHER et al., 1977 e YOUNG et al., 1980 ); baixa absorção de água pelo tronco, ramos e raízes ( BERETTA, 1986 ; BRLANSKY et al., 1984 ; LEE et al., 1984a e WUTSCHER, 1989a); e obstruções amorfas nos vasos do xilema ( BERETTA, 1986 ; BRLANSKY et al., 1984 ; BRLANSKY et al., 1985 e ROSSETTI et al.,1985 ), o que provoca uma disfunção destes vasos, correlacionada aos sintomas na copa das plantas afetadas. Esta 
anomalia apresenta grandes semelhanças com a anomalia conhecida por "blight" nos Estados Unidos e com o "declinamiento" na Argentina ( BERETTA et al., 1988a ; BRLANSKY et al., 1984 e BRLANSKY et al., 1985 ). Tanto para o declínio como para "blight", as obstruções amorfas constituem-se de calose, lignina, substâncias pécticas, gomas, proteínas e lipídeos ( BERETTA et al., 1988a ).

CHILDS (1979) demonstrou que o potencial hídrico ou a pressão da seiva nas raizes de árvores com "blight", na Flórida, era o mesmo que em árvores sadias, no entanto este potencial era muito mais baixo nas folhas das árvores afetadas por "blight" do que nas folhas das árvores sadias. Ainda, havia mais água nas raízes de árvores afetadas do que em sadias, sendo estes aspectos indicativos de que "blight" pode incapacitar o transporte adequado de água e nutrientes mesmo quando há água disponível em abundância para as raízes.

\subsubsection{Absorção de água pelo tronco das árvores}

O teste de absorção de água pelo tronco tem sido utilizado como um dos métodos diagnósticos de declínio dos citros (COHEN, 1974). A princípio realizado durante um período de 24 horas, no qual a água é injetada pela força gravitacional, o método foi modificado para um teste rápido utilizando-se pressão manual e uma seringa (LEE et al., 1984a). Por este método, árvores sadias absorvem um mínimo de $10 \mathrm{ml} \mathrm{em}$ 30 segundos, enquanto que árvores com declínio normalmente não absorvem água, ou chegam a absorver 1 a $2 \mathrm{ml}$ em 30 segundos. Pelo teste de 24 horas, as árvores são consideradas afetadas pelo declínio se absorvem menos de $50 \mathrm{ml}$ de água no período. 
LEE et al. (1984a) citam que com o teste por injeção gravitacional, algumas árvores sadias podem absorver pouca água, fornecendo falsas diagnoses; a injeção por pressão manual com seringa evita este problema, sendo que a absorção aparentemente só depende da presença ou não de elementos de vasos desobstruídos.

\subsubsection{Teor de zinco no lenho}

Durante os primeiros meses de 1976, WUTSCHER et al. (1977) coletaram amostras de lenho de plantas sadias e com declínio, na Flórida. Em seis dos dez locais amostrados, as concentrações de zinco no lenho eram significativamente maiores em árvores afetadas pelo declínio. As médias dos teores de zinco variavam de 13 a 26 ppm nas árvores afetadas, e de 2 a 6 ppm nas árvores sadias, nos locais onde foi constatada diferença estatisticamente significativa nos teores de zinco. Os autores enfatizam, no entanto, a importância de se comparar amostras de plantas afetadas e sadias de um mesmo local, visto que há uma certa variação nos teores de zinco no lenho de plantas sadias de um local para outro, o que anularia o estabelecimento de um padrão único para diagnosticar o declínio nas plantas cítricas.

WUTSCHER \& HARDESTY (1979b) encontraram teores médios de zinco no lenho, de 25 ppm em plantas com "blight" e de 5 ppm em plantas sadias.

YOUNG et al. (1980) obtiveram a partir de análises do tronco, teores médios de 14 ppm de zinco em árvores com "blight" e 3 ppm em árvores sadias.

ROSSETTI (1981) relatou resultados de pesquisas do Instituto Biológico do Estado de São Paulo, então conduzidas, onde foram obtidos teores médios de sais de 
zinco no tronco, em ppm, de 9,2 e 6,4, respectivamente, para plantas com declínio e sadias.

LIMA (1984) encontrou teores médios de zinco no lenho, de 9,3 ppm em plantas com declínio e 1,4 ppm em plantas sadias.

BRLANSKY et al. (1984) relataram teores médios de 2,4 a 2,6 ppm de zinco no tronco de árvores sadias e de 6,7 a 8,5 ppm em árvores com "blight" na Flórida; de 4,3 a 7,9 ppm em árvores sadias e de 8,6 a 30,7 ppm em árvores com declínio no Brasil; de 0,94 a 2,30 ppm em sadias e de 3,30 a 5,65 ppm em árvores com "declinamiento" na Argentina.

WUTSCHER (1989a) realizou um levantamento a longo prazo (por um período de 12 anos), de concentrações de zinco no lenho de laranjeiras, afetadas ou não por "blight". As concentrações de zinco variavam de 14 a 20 ppm nas árvores afetadas, e de 2 a 3 ppm nas sadias.

GIROTO (1990) encontrou concentrações de 25 ppm de zinco no lenho de laranjeiras com declínio, e 17 ppm em laranjeiras sadias.

Estes resultados de pesquisas mais recentes confirmam a observação apresentada por WUTSCHER et al. (1977) de que há variações nas concentrações de zinco no tronco das plantas de um local para outro, independentemente da ocorrência de declínio. 


\subsection{Possiveis condições de ocorrência do declínio}

MARAIS (1990) cita que foram obtidas evidências circunstanciais de que tipos de solo ( solos rasos, ou com camada de impedimento (BURNETT et al., 1982); solos com baixo teor de matéria orgânica, baixa fertilidade, ou alto teor de dolomita ou cal; solos compactados ), práticas culturais (certas fontes de nitrogênio nos fertilizantes, estresse hídrico por irrigação deficiente) e desordens nutricionais, foram relacionados à alta incidência de "blight". TUBELIS et al. (1988) citam que a taxa de aumento na incidência do declínio variou com o tipo de solo. Em levantamento em pomares cítricos do Estado de São Paulo, foi constatado que a taxa de aumento da incidência do declínio em laranjeira 'Pera' diferia para os diversos tipos de latossolo, sendo maior para o latossolo vermelho escuro - fase arenosa, seguindo taxas intermediárias nos latossolos vermelho amarelo - orto; roxo e vermelho escuro-orto; sendo a menor taxa de aumento de declínio encontrada em latossolo vermelho amarelofase arenosa.

Na região de Barretos, Estado de São Paulo, em latossolo vermelho escuro - fase arenosa, há uma das mais altas incidências de declínio dos citros do Estado, geralmente correlacionada a uma baixa disponibilidade hídrica e uma seca intensa (ORTOLANI et al., 1991).

NEMEC (1983) observou que a incidência de "blight" na Flórida é mais severa em solos rasos do que em solos profundos. Estudos sobre a temperatura, potencial hídrico e oxigênio a várias profundidades em solos rasos e profundos de dois pomares, sugerem que o desenvolvimento de raízes de citros estaria sujeito a maior estresse na região próxima à superfície do solo, especialmente em solos rasos, que restringem o crescimento da raiz à regiâo acima da camada de impedimento, onde 
ocorrem maiores flutuações no potencial hídrico e no teor de oxigênio, causadas pela drenagem deficiente, do que em solos mais profundos. NEMEC et al. (1983), em outra investigação, ao removerem árvores do solo, encontraram menor massa radicular em árvores afetadas por "blight" do que em árvores sadias.

Um levantamento posterior de NEMEC et al. (1984) em solos rasos com camada de impedimento de argila, na Flórida, revelou que naquela área não havia diferenças significativas nas propriedades dos solos sob plantas sadias ou afetadas por "blight". Entretanto, os autores sugeriram que o crescimento de raízes confinado à zona acima da camada de argila provavelmente levaria a um detrimento da nutrição, tornando as plantas mais suscetíveis a parasitas não específicos, como Fusarium solani.

No início do presente ensaio, aproximadamente $40 \%$ das árvores amostradas cresciam em solo que se apresentava com concentrações tóxicas de alumínio abaixo de $20 \mathrm{~cm}$ de profundidade, o que impede o desenvolvimento normal de raízes nesta camada de solo. As concentrações tóxicas de alumínio funcionam como uma camada de impedimento ao crescimento de raízes, prejudicando o estado nutricional das plantas.

ALLMARAS et al. (1988), em uma revisão sobre a influência da compactação do solo na sanidade de raízes, colocam que a compactação pode intensificar os danos no metabolismo e crescimento da raiz, provocados por fatores como deficiência ou excesso de água no solo, deficiência de oxigênio $\left(\mathrm{O}_{2}\right)$, resistência mecânica, distúrbios nutricionais. As raízes, que necessitam de energia proveniente da respiração para cumprir com as diversas atividades fisiológicas, que incluem absorção de água e de nutrientes, produção de substâncias de reserva e de hormônios, crescem não raro em ambientes desfavoráveis à respiração, causados pelas operações agrícolas dentro do 
pomar. Os autores citam diversos trabalhos que demonstram um aumento do crescimento de populações de fungos patogênicos na rizosfera de plantas submetidas a condições estressantes de solo, como deficiência de $\mathrm{O}_{2}$.

Além do distúrbio nas próprias raízes, o ambiente onde elas crescem pode interferir no desenvolvimento da parte aérea, que obviamente é dependente da atividade radicular.

Em culturas de citros, geralmente os sistemas radiculares de mais de uma árvore se mesclam nas entrelinhas, com grande concentração de radicelas a considerável distância do colo das plantas (MAGALHÃES, 1988). Em vista destes dados, o emprego racional de práticas culturais no pomar de citros, como gradagens, capinas, trânsito de tratores no tratamento fitossanitário, é de grande importância para a obtenção de sucessos na produtividade.

As radicelas, além de se encontrarem a distâncias de até 4 metros do tronco, estão concentradas nos primeiros $15 \mathrm{~cm}$ de profundidade do solo, em uma proporção de aproximadamente $45 \%$ do total de radicelas da árvore (MOREIRA, 1988). Daí a conclusão de que o manejo de um pomar deve considerar a fundamental importância da preservação de um sistema radicular saudável, evitando-se a exposição de solo e corte de radicelas resultantes de gradagens na entrelinha.

O trânsito frequente de máquinas pesadas no pomar, mesmo não danificando diretamente as radicelas, pode causar distúrbios no crescimento e atividade radiculares, pela compactação do solo. 
Cohen ${ }^{1}$, citado por WUTSCHER (1988a), encontrou áreas livres de "blight" em solos com alto teor de matéria orgânica margeados por solos calcáreos com severa incidência de "blight". Uma alta incidência da anomalia também foi constatada em solos com escavações de valas, terraplenados, e que receberam calagem pesada, incidência esta bem maior do que em áreas não perturbadas ( WUTSCHER, 1988b ). Uma maior severidade da anomalia foi observada ao longo de estradas e canais de drenagem (COHEN, 1982). LIMA (1983) observou uma porcentagem maior da incidência de declínio em plantas adjacentes a carreadores dentro do pomar. Este autor também relatou uma maior porcentagem de plantas afetadas pelo declínio, adjacentes a plantas anteriormente afetadas pela anomalia.

Há evidências bastante fortes de que o tipo de solo e tratamentos de solo influenciem a incidência de "blight", assim como fatores nutricionais (CASTRO, 1991; WUTSCHER, 1986 ; WUTSCHER, 1988a e WUTSCHER \& HARDESTY, 1979b).

Estudos de longo prazo na Flórida têm demonstrado que não há diferença significativa no teor de nitrogênio amoniacal do solo sob árvores sadias ou afetadas por "blight" ( WUTSCHER \& HARDESTY, 1979a ); os níveis de nitrito são bem baixos e não apresentam diferenças entre plantas sadias ou com "blight", sendo que a pequena diferença entre os níveis de nitrato não poderiam sustentar a hipótese de uma relação causal com a anomalia, relacionando-se mais com diferenças

${ }^{1} \mathrm{COHEN}, \mathrm{M}$. Nonrandom distribution of trees with citrus blight. In: CONF. INT. ORG. CITRUS VIROL., 8., Australia, 1979. Proceedings. Riverside, California, E.C. Calavan; S.M. Garnsey; L.W. Timmer, coord.,1980. p.260-263. 
da propriedade dos solos. Anderson \& Bistline², citados por ALBRIGO (1984) não encontraram correlação entre o nivel de nitrogênio na fertilização e a incidência de "blight".

Um ensaio foi conduzido para determinar os efeitos de doses recomendadas e excessivas de fontes nitrogenadas ( uréia, nitrato de amônio e hidróxido de amônio ) em citros ( NEMEC et al., 1989a ). Doses mais elevadas de nitrato de amônio e hidróxido de amônio ( $11,8 \mathrm{~kg}$ de $\mathrm{N} /$ árvore ) causaram sintomas semelhantes ao "blight" na folhagem. A absorção de água foi reduzida com altas doses de qualquer das fontes de nitrogênio ( $13,7 \mathrm{~kg}$ de N/árvore como uréia; $11,8 \mathrm{~kg} \mathrm{e} \mathrm{15,9 \textrm {kg }}$ de N/árvore como nitrato de amônio; e 1,4 kg de N/árvore como hidróxido de amônio ), e um aumento das obstruções filamentosas nos vasos de xilema também foi observado. Com doses mais baixas de nitrato de amônio ( $2,6 \mathrm{~kg} \mathrm{e} 7,9 \mathrm{~kg}$ de N/árvore ) e

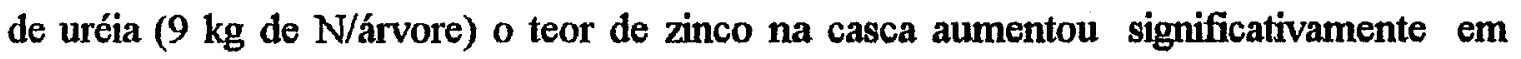
relação às plantas controle. No entanto, obstruções amorfas dos vasos ( características deste declínio ) não aumentaram com estes tratamentos. Com este experimento demonstrou-se que a administração de fertilizantes contendo doses excessivas de nitrogênio pode causar sintomas semelhantes ao declínio chamado "blight", no entanto não se pode concluir que estes fertilizantes nitrogenados causem "blight".

WUTSCHER (1986) relatou que, quando a ocorrência de "blight" em um pomar está claramente correlacionada com as características do solo, os teores de ferro, manganês, zinco e cobre nas radicelas das árvores afetadas, são significativamente mais baixos do que nas árvores sadias.

${ }^{2}$ ANDERSON, C.A. \& BISTLINE, F.W. Rate of nitrogen fertilization and incidence of blight in three orange groves on the Ridge. Proceedings of the Florida State Horticultural Society, 91: 59-61, 1978. 
WUTSCHER (1989b) demonstrou uma correlação altamente significativa entre valores mais altos de $\mathrm{pH}$ e de teor de cálcio do solo, e a ocorrência de "blight" na planta, em cinco locais da Flórida, concordando com resultados de um trabalho anterior (WUTSCHER \& LEE, 1988 ) realizado em um local isolado. Com relação aos demais nutrientes ( fósforo, potássio, magnésio, sódio, ferro, manganês, zinco e cobre ) houve diferenças pequenas entre amostras de solo sob árvores sadias e em declínio. Os teores de cálcio foram consistentemente maiores mesmo em solos sob árvores no estágio anterior ao aparecimento de sintomas de "blight", quando comparados com os teores sob árvores completamente sadias.

A maioria das combinações de enxerto/porta-enxerto cultivadas comercialmente são afetadas pelo declínio; no entanto a ocorrência desta anomalia prevalece em árvores formadas com a combinação laranjeira 'Pera' sobre limoeiro 'Cravo'.

LIMA (1983), em levantamento da incidência de declínio em 87 hectares de uma fazenda em Mogi-Guaçu, Estado de São Paulo, encontrou maior taxa de incidência em laranjeiras sobre porta-enxertos de limoeiro 'Cravo' do que sobre portaenxertos de Poncirus trifoliata e de laranjeira 'Caipira'.

Um levantamento da Coordenadoria de Assistência Técnica Integral, da Secretaria da Agricultura do Estado de São Paulo, realizado em 1988 em 124 propriedades citrícolas da região de Campinas, com um total de aproximadamente dois milhões de plantas inspecionadas, revelou que $\mathbf{5 , 8 5 \%}$ destas estavam afetadas pelo declínio dos citros. Não se constatou a ocorrência de declínio em pomares dos cultivares 'Pera'/'Cleopatra' ; 'Pera'/laranjeira 'Caipira' ; 'Valencia'/'Sunki' ; 'Ponkan'/'Cravo' ; tangor 'Murcote/'Cravo' ; lima ácida 'Tahiti' ; 'Ponkan'/'Cleopatra' e 'Tahiti'/'Cleopatra' (PRATES, 1989). 
CASTRO (1991) sugeriu que a tolerância maior de certos cultivares de porta-enxertos provavelmente se deve a uma maior capacidade de renovar o sistema vascular de translocação inorgânica, quando há obstrução pela ocorrência do declínio, ou a um menor volume de elementos vasculares afetados e obstruídos, afetando menos o seu funcionamento.

\subsection{Estado nutricional de plantas cítricas afetadas pelo declínio}

Em levantamento do estado nutricional de plantas cítricas em 47 propriedades do Estado de São Paulo, durante o período de agosto de 1980 a outubro de 1982, foram comparadas amostras de folhas de plantas sadias e de plantas afetadas pelo declínio ( PRATES et al., 1983a ). Os resultados encontram-se na Tabela 1.

Nota-se que tanto as plantas sadias como as com declínio apresentam elevada porcentagem de amostras deficientes quanto aos nutrientes fósforo e zinco. Uma diferença marcante entre as porcentagens de amostras deficientes em potássio em plantas sadias (25\%) e em plantas com declínio (64\%), sugere um estudo mais aprofundado.

Em levantamento semelhante, no período de março a novembro de 1983 (PRATES et al., 1984b), em 32 propriedades citrícolas do Estado de São Paulo, o estado

nutricional das plantas sadias ou afetadas pelo declínio foi avaliado, como mostra a Tabela 2, seguindo os mesmos padrões para níveis mínimos adequados dos nutrientes, de PRATES et al. (1983a). 
Tabela 1 - Porcentagens de amostras foliares com deficiência (1980-1982).

\begin{tabular}{|c|c|c|c|c|c|}
\hline \multirow[t]{2}{*}{ Nutrientes } & $\begin{array}{c}\text { Plantas } \\
\text { sadias } \\
\end{array}$ & $\begin{array}{c}\text { Plantas } \\
\text { com declínio }\end{array}$ & \multirow[t]{2}{*}{ Nutrientes } & $\begin{array}{c}\text { Plantas } \\
\text { sadias } \\
\end{array}$ & $\begin{array}{c}\text { Plantas } \\
\text { com declínio }\end{array}$ \\
\hline & & & & \multicolumn{2}{|c|}{$\%$} \\
\hline$N$ & 38 & 27 & $\mathrm{Fe}$ & 0 & 0 \\
\hline $\mathrm{P}$ & 62 & 67 & $\mathrm{Mn}$ & 9 & 0 \\
\hline $\mathrm{K}$ & 25 & 64 & $\mathrm{Cu}$ & 36 & 20 \\
\hline $\mathrm{Ca}$ & 15 & 9 & $\mathrm{Zn}$ & 70 & 61 \\
\hline $\mathrm{Mg}$ & 26 & 27 & $\mathrm{~B}$ & 53 & 39 \\
\hline S & 19 & 20 & & & \\
\hline
\end{tabular}

Obs.1: Foram considerados como niveis minimos adequados para os nutrientes : $N=2,20 ; P=0,12$; $\mathrm{K}=1,00 ; \mathrm{Ca}=3,00 ; \mathrm{Mg}=0,30 ; \mathrm{S}=0,20(\mathrm{em} \%) ; \mathrm{Fe}=60 ; \mathrm{Mn}=25 ; \mathrm{Cu}=6 ; \mathrm{Zn}=25 ; \mathrm{B}=50$ (em ppm).

Obs.2: Foram amostradas 53 plantas sadias e 132 plantas com declínio.

Destaca-se novamente uma marcante diferença entre a porcentagem de amostras deficientes em potássio em sadias e com declínio. Há uma elevada porcentagem de amostras deficientes em fósforo, tanto em plantas sadias como com declínio.

PRATES et al. (1985) ainda realizaram um levantamento do estado nutricional de plantas cítricas sadias e afetadas pelo declínio, no período de dezembro de 1983 a agosto de 1984, que pode ser avaliado na Tabela 3. Neste ensaio, tanto plantas sadias como afetadas pelo declínio apresentaram elevada porcentagem de amostras deficientes em nitrogênio, fósforo, enxofre, boro e zinco. 
Tabela 2 - Porcentagens de amostras foliares com deficiência (1983).

\begin{tabular}{|c|c|c|c|c|c|}
\hline \multirow[t]{2}{*}{ Nutrientes } & $\begin{array}{l}\text { Plantas } \\
\text { sadias } \\
\end{array}$ & $\begin{array}{c}\text { Plantas } \\
\text { com declínio }\end{array}$ & \multirow[t]{2}{*}{ Nutrientes } & $\begin{array}{c}\text { Plantas } \\
\text { sadias } \\
\end{array}$ & $\begin{array}{c}\text { Plantas } \\
\text { com declínio }\end{array}$ \\
\hline & \multicolumn{2}{|c|}{$\%$} & & \multicolumn{2}{|c|}{$\%$} \\
\hline $\mathrm{N}$ & 44 & 61 & $\mathrm{Fe}$ & 6 & 0 \\
\hline $\mathrm{P}$ & 78 & 89 & Mn & 6 & 5 \\
\hline $\mathrm{K}$ & 19 & 73 & $\mathrm{Cu}$ & 12 & 2 \\
\hline $\mathrm{Ca}$ & 22 & 13 & $\mathrm{Zn}$ & 56 & 42 \\
\hline $\mathrm{Mg}$ & 31 & 24 & $\mathrm{~B}$ & 34 & 23 \\
\hline$S$ & 41 & 19 & & & \\
\hline
\end{tabular}

Obs.: Foram amostradas 32 plantas sadias e 62 plantas com declínio.

Os resultados de amostras coletadas entre 1985 e 1986 por PRATES et al. (1989), são apresentados na Tabela 4.

Nota-se elevada porcentagem de plantas deficientes em boro (PRATES et al., 1989), tanto sadias como com declínio. Neste levantamento, assim como no realizado entre dezembro de 1983 e agosto de 1984 ( PRATES et al., 1985 ), não houve correlação significativa entre deficiências nutricionais e a incidência de declínio. 
Tabela 3 - Porcentagens de amostras foliares com deficiência (1983-1984).

\begin{tabular}{|c|c|c|c|c|c|}
\hline \multirow[t]{2}{*}{ Nutrientes } & $\begin{array}{c}\text { Plantas } \\
\text { sadias } \\
\end{array}$ & $\begin{array}{c}\text { Plantas } \\
\text { com declínio }\end{array}$ & \multirow[t]{2}{*}{ Nutrientes } & $\begin{array}{c}\text { Plantas } \\
\text { sadias }\end{array}$ & $\begin{array}{c}\text { Plantas } \\
\text { com declínio }\end{array}$ \\
\hline & & & & \multicolumn{2}{|c|}{$\%$} \\
\hline$N$ & 63 & 66 & $\mathrm{Fe}$ & 0 & 0 \\
\hline $\mathrm{P}$ & 70 & 74 & $\mathrm{Mn}$ & 10 & 0 \\
\hline $\mathrm{K}$ & 50 & 65 & $\mathrm{Cu}$ & 17 & 11 \\
\hline $\mathrm{Ca}$ & 47 & 38 & $\mathrm{Zn}$ & 73 & 58 \\
\hline $\mathrm{Mg}$ & 33 & - & B & 77 & 60 \\
\hline $\mathbf{S}$ & 67 & 72 & & & \\
\hline
\end{tabular}

Obs.: Foram amostradas 30 plantas sadias e 65 plantas com declínio.

Tabela 4 - Porcentagens de amostras foliares com deficiência (1985-1986).

\begin{tabular}{|c|c|c|c|c|c|}
\hline \multirow[t]{2}{*}{ Nutrientes } & $\begin{array}{c}\text { Plantas } \\
\text { sadias }\end{array}$ & $\begin{array}{c}\text { Plantas } \\
\text { com declínio }\end{array}$ & \multirow[t]{2}{*}{ Nutrientes } & $\begin{array}{c}\text { Plantas } \\
\text { sadias } \\
\end{array}$ & $\begin{array}{c}\text { Plantas } \\
\text { com declinio } \\
\end{array}$ \\
\hline & \multicolumn{2}{|c|}{$\%$} & & \multicolumn{2}{|c|}{$\%$} \\
\hline $\mathrm{N}$ & 0 & 0 & $\mathrm{Fe}$ & 0 & 0 \\
\hline $\mathrm{P}$ & 33 & 44 & $\mathrm{Mn}$ & 0 & 0 \\
\hline $\mathrm{K}$ & 0 & 22 & $\mathrm{Cu}$ & 20 & 6 \\
\hline $\mathrm{Ca}$ & 30 & 19 & $\mathrm{Zn}$ & 43 & 38 \\
\hline $\mathrm{Mg}$ & 10 & 9 & B & 63 & 71 \\
\hline$S$ & 0,5 & - & & & \\
\hline
\end{tabular}

Obs.: Foram amostradas 30 plantas sadias e 32 plantas com declínio. 
GIROTO (1990), coletando amostras de tecido de laranjeiras 'Valencia' sadias e com declínio, encontrou diferenças significativas entre os teores de fósforo, enxofre, boro e manganês nas folhas de árvores sadias ou com declínio. Os teores de fósforo e de manganês estavam mais altos nas árvores sadias, e os teores de enxofre e de boro, mais altos nas árvores com declínio. Foram utilizadas amostras de folhas de ramos terminais sem fruto, semelhante à metodologia e padrões apresentados por EMBLETON et al. (1973).

No presente experimento foram utilizadas amostras de folhas de ramos com frutos, segundo GRUPO PAULISTA DE ADUBAÇÃO E CALAGEM DOS CITROS (1990).

WUTSCHER \& HARDESTY ( 1979b), analisando diferentes tecidos de laranjeira 'Valencia' sobre limoeiro 'Rugoso', obtiveram os seguintes resultados: as folhas de árvores com "blight" apresentavam teores significativamente mais baixos do que árvores sadias quanto ao potássio, e teores significativamente mais altos quanto ao sódio, zinco e cloro. As baixas concentrações de potássio nas folhas estavam associadas a altas concentrações deste mineral no lenho de ramos e tronco. Os teores de alumínio nas folhas estavam ao redor de $25 \mathrm{ppm}$, não diferindo significativamente entre árvores sadias e afetadas.

WUTSCHER \& MCDONALD (1986), analisando seiva e tecidos de laranjeiras 'Hamlin' sobre limoeiro 'Rugoso da Flórida', encontraram os seguintes resultados: árvores com "blight" apresentavam teores foliares de magnésio, enxofre, sódio, manganês e cloro, significativamente maiores do que os teores em árvores sadias, enquanto que os teores de nitrogênio, potássio, cálcio, ferro, zinco, cobre e silício não diferiram significativamente entre plantas sadias ou afetadas. 
WUTSCHER (1988a), comparando folhas com sintomas visuais de "blight" e folhas normais, sadias, em uma mesma árvore, encontrou nas primeiras, teores significativamente mais baixos de cácio, magnésio, enxofre, manganês, zinco, boro e silício.

Muitas das alterações relatadas em plantas afetadas pelo declínio ( ou "blight" no caso da Flórida ) parecem ser respostas secundárias relacionadas tanto com déficit hídrico como com outros distúrbios decorrentes do declínio da planta (ALBRIGO, 1984). Anderson ${ }^{3}$, citado por ALBRIGO (1984) observou que a poda de raizes produziu alterações nos níveis de minerais nos tecidos, similares às causadas por "blight".

HIROCE \& CAETANO (1984) observam que, como os testes diagnósticos para declínio dos citros indicam menor absorção de água pelas plantas afetadas, a ocorrência de elevada porcentagem de folhas deficientes em potássio ( que é bastante móvel e dependente do fluxo de água pelo xilema ) entre as plantas com declínio, é bastante coerente. A deficiência de potássio pode ser mais uma condição secundária resultante de distúrbios metabólicos da planta.

${ }^{3}$ ANDERSON, C.A. Effect of trunk girdling, root pruning, and blight on sweet orange fruit quality and leaf mineral composition. HortScience, 15: 395, 1980. 


\subsubsection{Interpretação da análise foliar pelo Sistema Integrado de Diagnose e Recomendação ( DRIS )}

A forma mais frequente de interpretação da análise foliar em citros é através de faixas dos teores de nutrientes, onde estes são considerados deficientes, baixos, adequados, altos ou excessivos. Este critério leva à interpretação individual de cada nutriente, sem computar as relações entre eles.

O Sistema Integrado de Diagnose e Recomendação ( Diagnosis and Recommendation Integrated System, de onde vem a sigla DRIS ) foi originalmente proposto por Beaufils ${ }^{4}$, citado por BATAGLIA (1989), para identificação dos fatores limitantes da produtividade. Com o tempo, entretanto, vem se mostrando mais eficiente como uma forma alternativa de interpretação da análise da planta. A interpretação pelo DRIS consiste na obtenção de índices que revelam a relação de um nutriente com todos os demais analisados ( Tabela 5 ). O ponto fundamental para a obtenção destes índices, objetivando avaliar o estado nutricional da planta em termos principalmente qualitativos, é delinear relações entre nutrientes em uma população padrão que apresente desenvolvimento satisfatório e alta produção. Como os dados disponíveis de populações padrões vêm sendo coletados há poucos anos, e a técnica não está firmemente consolidada, recomenda-se que o DRIS seja utilizado como complemento, e não como substituto, dos demais critérios de interpretação de análise foliar em citros (BATAGLIA, 1989).

4BEAUFILS, E.R. Diagnosis and recommendation integrated system (DRIS). A general scheme for experimentation and calibration based on principles developed from research in plant nutrition. Soil Science Bull., University of Natal, South Africa, 1, 1973. 
Tabela 5 - Interpretação das faixas de valores de índices DRIS obtidos de análises de folhas de citros.

\begin{tabular}{cc}
$\begin{array}{c}\text { Faixa de valores } \\
\text { para índices DRIS }\end{array}$ & $\begin{array}{c}\text { Avaliação do teor } \\
\text { do nutriente }\end{array}$ \\
abaixo de -75 & deficiente (DF) \\
entre -75 e -25 & baixo (BA) \\
entre -25 e +25 & adequado (AD) \\
entre +25 e +75 & alto (AL) \\
acima de +75 & excessivo (EX) \\
\hline
\end{tabular}

Fonte : SANTOS, W.R. ${ }^{5}$

A interpretação pelo DRIS tem contribuído para a eliminação de muitos problemas nutricionais e de adubação, em soja, milho, trigo, batata, cana-de-açúcar, alfafa. Em alguns casos, a precisão do diagnóstico é maior pelo DRIS do que pelos critérios de faixas de suficiência ou níveis críticos, porém em outros casos, o DRIS não fornece todas as deficiências ou excessos de nutrientes. Recentemente, ao contrário de artigos anteriores, tem sido relatada a importância da padronização na amostragem de folhas, para maior eficiência da diagnose pelo DRIS.

5SANTOS, W.R. (Instituto Agronômico de Campinas) Comunicação pessoal, 1992. 
O DRIS utilizado em laranjeira 'Valencia', na Califórnia, resultou em dados que geralmente concordavam com as faixas de interpretação de teores de nutrientes, com a vantagem de que o DRIS refletia o balanço nutricional e fornecia a ordem em que os nutrientes provavelmente se tormariam limitantes (BÉEERLY et al, 1984).

SCHAFFER et al. (1988) utilizaram o DRIS para a identificaçăo de deficiências minerais associadas com um declínio de mangueiras, de etiologia desconhecida. As deficiências foram avaliadas a nível de pomares inteiros e não de árvores individualmente selecionadas. $\mathrm{O}$ desbalanço nutricional foi maior nos pomares com maior porcentagem de árvores em declínio, comparado com pomares sadios.

\subsection{Associação do declínio com agentes patogênicos}

A associação da presença de Fusarium spp. com árvores afetadas pelo declínio ou "blight" tem sido relatada por diversos autores ( BRLANSKY \& LEE, 1987; BURNETT et al., 1982; GRAHAM et al., 1983 ; GRAHAM et al., 1985; NEMEC et al., 1980 e NEMEC et al., $1989 \mathrm{~b}$ ), no entanto nenhum deles demonstrou uma relação causal com a anomalia. Fusarium solani, a espécie dominante, tem sido isolada de forma consistente a partir de lesões necróticas de raizes de plantas em declínio, entretanto este patógeno não tem causado lesões quando inoculado em raízes de limoeiro 'Rugoso', o porta-enxerto mais suscetivel utilizado na Flórida ( GRAHAM et al., 1983 ). A necrose das raízes principais não é a causa de declínio da copa das árvores. Fusarium solani pode ser considerado um parasita oportunista, sendo colonizador 
primário de raízes de citros aparentemente após a reserva de amido das raízes se esgotar, devido ao declínio da planta.

Bactérias restritas ao xilema, como Xylella fastidiosa, têm sido isoladas e testadas como causa do declínio dos citros ( GARDNER, J.M. et al., 1985; HOPKINS, 1988 e HOPKINS et al., 1991 ). Foi demonstrado que Xylella fastidiosa inoculada em citros pode produzir sintomas de "blight" ( HOPKINS, 1988 ), no entanto a anomalia denominada "blight" não foi totalmente reproduzida, já que não houve um número significativo de árvores que apresentassem testes positivos para todas as características de "blight". Um dos vetores de Xylella fastidiosa, uma cigarrinha de xilema, Oncometopia nigricans, foi utilizado com sucesso para transmitir uma linhagem de Xylella fastidiosa que causa mal de Pierce em videira, a partir de plantas cítricas com "blight" ( HOPKINS et al., 1991 ). Estes autores encontraram que a população de Oncometopia nigricans é mais abundante em pomares com alta incidência de "blight" do que em pomares com baixa incidência desta anomalia. LEE et al. (1984b) também citam um maior número de $O$. nigricans em pomares com alta incidência de "blight", entretanto eles colocam a possibilidade de que populações de $O$. nigricans sejam maiores nestas áreas altamente afetadas por "blight" devido ao ambiente mais favorável destes locais, proporcionado pela maior entrada de luz através das copas menos densas das árvores afetadas, e maior crescimento de ervas hospedeiras destas cigarrinhas ( $O$. nigricans requer a presença de outros hospedeiros já que não deposita ovos em citros ).

Quanto às possibilidades de transmissão do declínio, no Brasil, ou "blight" na Flórida, o método de enxertia de raízes obteve resultados aparentemente positivos ( TUCKER et al., 1984 ; NEMEC, 1988 ; ROSSETTI \& BERETTA, 1989; ROSSETTI et al., 1989 ; BERETTA et al., 1989a ; BERETTA et al., 1989b e 
BERETTA et al., 1989c ), enquanto que outros tipos de enxertia, de diversas outras partes da planta, não obtiveram nenhum resultado ( BERETTA, 1987; GUIRADO et al., 1988 ; ROSSETTI \& BERETTA, 1988 e WUTSCHER \& SMITH, 1988 ).

BERETTA et al. (1985) realizaram um experimento utilizando mudas de laranjeira Pera' sobre limoeiro 'Cravo', transferidas para vasos contendo solo obtido de covas de árvores com acentuado declínio, esterilizado ou não, ou solo de covas de árvores sadias. Após um ano, as mudas em vasos com solo proveniente de árvores com declínio apresentavam acentuada clorose foliar, mesmo nos tratamentos com solo esterilizado, e após dois anos, cortes histológicos demonstravam ocorrência de numerosas obstruções amorfas nos vasos do xilema, semelhantes às das plantas com declínio no campo.

A análise da concentração de zinco no tronco não revelou diferença significativa entre os tratamentos com solos de árvores sadias ou com declínio.

O experimento foi repetido com mudas de laranjeira 'Valencia' sobre 'Cravo', plantadas em solos de covas de plantas sadias ou com declínio. Os resultados aos dez meses mostravam menor desenvolvimento das mudas cultivadas em solo de covas de árvores com declínio. Os autores não citaram dados sobre a estrutura, ou fertilidade dos solos utilizados nos ensaios. Eles sugeriram uma possível associação do solo com a indução de obstruções amorfas características de plantas cítricas com declínio. 0 desenvolvimento de sintomas semelhantes aos do declínio em mudas cultivadas mesmo em solo esterilizado, proveniente de covas de árvores com declínio, seria uma razão suficientemente boa para uma investigação mais detalhada das propriedades deste solo. Uma lacuna nas investigações sobre a incidência do declínio dos citros, está relacionada à interrupção, por variados motivos, de ensaios que poderiam ser promissores quanto ao esclarecimento das causas desta moléstia. Experimentos conduzidos por grupo de 
pesquisadores com âmbito multidisciplinar também auxiliariam uma avaliação mais profunda desta anomalia complexa.

WUTSCHER (1988a) observou que alguns experimentos no passado, como o de SHANNON \& ZAPHRIR (1958), em que as raizes de citros são fracionadas em meios de crescimento distintos, são basicamente semelhantes à enxertia de raízes. Nestes experimentos constatou-se que desordens nutricionais podem ser rapidamente transferidas de um sistema radicular a outro, e para o enxerto acima deles. Em um experimento de transmissão de "blight" por enxertia de raizes, as radicelas das árvores receptoras com sintomas da anomalia, possuíam teores mais baixos de cálcio, magnésio, enxofre, ferro, zinco, cloro e molibdênio, do que as radicelas das árvores não enxertadas. A questão seria, no caso da união pela enxertia de raízes, do que está sendo transmitido, se um agente patogênico, desordens nutricionais ou metabólitos.

\subsection{Tentativas de controle e recuperação de plantas}

Os ensaios visando a recuperação de plantas com declínio no Brasil incluem : utilização de Bacillus subtilis para destruir (degradar) as obstruções amorfas dos vasos ; enxertias e enraizamento de copas ; interenxerto com cultivares tolerantes ; adição de compostos e tratamentos no solo, entre outros ensaios ( BERETTA \& ROSSETTI, 1988; GUIRADO et al., 1988; GUIRADO et al., 1989; ROSSETTI, 1983 e ROSSETTI \& BERETTA, 1988).

Na Flórida, TIMMER et al. (1985) não obtiveram recuperação de árvores afetadas por "blight", utilizando tratamentos com tetraciclina, tanto por inundação 
do solo como por injeção no tronco da árvore. Eles demonstraram que a tetraciclina evitou o acúmulo de zinco no lenho das plantas tratadas, em relação ao controle, no entanto, mesmo com a redução da concentração de zinco no lenho, os sintomas de "blight" como a senescência, continuaram a se desenvolver, em árvores em estágio inicial de declínio (altas concentrações de zinco no lenho e baixa absorção de água) e também em estágio de pré-declínio (altas concentrações de zinco no lenho mas absorção de água normal). Os autores sugeriram que a tetraciclina pode ser uma ferramenta útil na elucidação do papel do zinco no desenvolvimento da anomalia.

LEE et al. (1981) encontraram dificuldade para injetar compostos bactericidas no tronco de árvores afetadas por "blight", mesmo à alta pressão. Nenhum dos compostos injetados resultou em remissão dos sintomas da anomalia. $O$ método de tratamento do declínio por injeção de compostos no tronco parece pouco praticável em condições de pomares comerciais, pela extensão da área cultivada, que se encontra afetada pelo declínio, em nossas condições.

TAVARES et al. (1984) empregaram tratamentos em laranjeiras com 9 anos de idade, que incluem afrancamento; adubações com $30 \mathrm{~kg}$ de esterco de gado por planta; $20 \mathrm{~kg}$ de esterco de galinha por planta; $10 \mathrm{~kg}$ de torta de mamona por planta; 10 $\mathrm{kg}$ de Hiperhumus (produto comercial) por planta; e controle. Para cada tratamento foram utilizadas 4 plantas afetadas pelo declínio e 8 sadias, que receberam o tratamento em uma única vez. Após 14 meses, as árvores foram avaliadas quanto ao declínio. Nenhum dos tratamentos resultou em recuperação das plantas. A suposição dos autores é de que os resultados negativos estejam relacionados com a pequena quantidade de matéria orgânica aplicada.

WUTSCHER (1985) realizou tratamentos de árvores afetadas por "blight" com um composto de silicato de cálcio, contendo também outros minerais como 
fósforo, potássio, magnésio, ferro, manganês, enxofre, sódio, zinco, cobre, cloro e molibdênio. Testes de absorção de água pelas árvores tratadas, após seis e doze meses da aplicação do composto, mostravam diferenças significativas no volume absorvido, em relação às árvores não tratadas ( o volume absorvido pelas árvores não tratadas permaneceu baixo durante as avaliações, sendo que o volume absorvido pelas árvores tratadas aumentou significativamente ). A concentração de zinco no lenho de árvores tratadas era significativamente menor após doze meses do tratamento, enquanto que nas árvores não tratadas não houve alteração significativa durante o mesmo período.

A concentração de silício aumentou significativamente nas folhas de plantas tratadas, em relação ao controle, não havendo diferenças nos teores dos demais minerais.

O composto de silicato de cálcio não resultou em recuperação total das plantas afetadas, no entanto, os efeitos na absorção de água e no teor de zinco no lenho indicam uma melhoria nas condições das árvores. A anomalia denominada "blight" se desenvolve durante vários anos; é de se esperar que a recuperação também requeira um longo período para ser alcançada (WUTSCHER, 1985).

CHILDS (1981) adicionou aproximadamente $2 \mathrm{~kg}$ de montmorilonita por árvore ao ano, em um talhão de laranjeira 'Valencia' sobre limoeiro 'Rugoso' de 20 anos de idade, na Flótida, onde havia 1086 árvores aparentemente sadias e 293 com "blight". No talhão controle, não tratado, havia 1173 árvores aparentemente sadias e 242 com "blight".

Após 4 anos de tratamento, o número de árvores afetadas por "blight" no talhão tratado reduziu $68,9 \%$, enquanto que no talhão controle o número de árvores afetadas aumentou $57,6 \%$. Experimentos posteriores indicam resultados semelhantes com relação à adição de montmorilonita. 
A adição de $45 \mathrm{~kg}$ de húmus por árvore, em pomares afetados da Flórida (PINCKARD, 1982), resultou em maior crescimento e frutificação das árvores tratadas em relação ao controle. Análises de amostras do câmbio revelaram a ausência do declínio em árvores tratadas, enquanto que as não tratadas resultaram em teste positivo para o declínio.

A supressão de sintomas de declínio tais como paralisação do crescimento, obstruções dos vasos de xilema e acúmulo de zinco no lenho, em certos experimentos onde são utilizados compostos que elevam os teores de nutrientes do solo ou melhoram sua estrutura, levam à reflexão sobre quais condições aprimoradas por estes compostos estariam relacionadas com a recuperação de plantas com declínio, ou ainda, quais condições previamente existentes estariam relacionadas com o desenvolvimento do declinio.

A recomendação mais aceita até o momento é a de utilização de cultivares tolerantes como porta-enxertos, como medida de prevenção do declínio. Estes cultivares considerados tolerantes são aqueles que em observações de campo são pouco ou nada afetados pelo declínio, como é o caso das tangerineiras 'Sunki' e 'Cleopatra', da laranjeira 'Caipira' e do tangelo 'Orlando' ( BERETTA et al.,1988b; GUIRADO et al.,1988 e GUIRADO et al.,1991 ).

Smith6, citado por PRATES et al. ( 1983b), analisando folhas de laranjeira 'Valencia' com "blight",verificou severa deficiência de zinco nas folhas. Realizadas pulverizações com óxido de zinco, as folhas deixaram de mostrar sintomas de deficiência deste nutriente em poucas semanas. Nos cinco anos seguintes, árvores com declínio foram pulverizadas com zinco trềs vezes ao ano. Estas aplicações mantiveram as

${ }^{6} \mathrm{SMITH}$, P.F. History of citrus blight in Florida. Citrus Industry Magazine, 9: 13-19, 1974. 
árvores com maior enfolhamento e com folhas de coloração normal, no entanto não evitaram o murchamento característico do declínio. A floração e o lançamento de ramos mantiveram-se tardios e cada fluxo de brotação apresentava deficiência de zinco até que se procedesse a pulverização corretiva.

A adubação foliar tem a grande vantagem de trazer rápidos resultados para as plantas. Entretanto, para o zinco, que é pouco móvel na planta, a aplicação foliar surte efeito somente no fluxo de crescimento sucessivo à aplicação (DECHEN \& NEVES, 1988).

Tsui', citado por PRATES et al. ( 1983b ) verificou a essencialidade do zinco para a síntese do triptofano, um precursor do ácido indolilacético, uma auxina. PRATES et al.(1983b) sugerem que, uma vez que a síntese do ácido indolilacético é inibida em plantas com baixos níveis de zinco, como as com declínio, o subdesenvolvimento pode estar relacionado com baixos teores de auxinas endógenas, responsáveis pela promoção do crescimento vegetal.

Reguladores vegetais como as giberelinas, auxinas e citocininas foram utilizados com a finalidade de promover o crescimento vegetal e retardar a senescência, característica do declínio ( PRATES et al.,1983b). Os tratamentos aplicados em laranjeiras 'Pera' sobre limoeiro 'Cravo', com sintomas acentuados de declínio, de 10 anos de idade, foram os seguintes: 1) controle; 2) ácido giberélico (GA) a 100 ppm; 3) GA a 100 ppm + ácido 2,4-diclorofenoxiacético (2,4-D) a 10 ppm; 4) GA a 50 ppm + 2,4-D a $10 \mathrm{ppm}$; 5) citocinina $+\mathrm{GA}_{4}+\mathrm{GA}_{7}$ ( produto comercial da Abbott, Promalin ) a $50 \mathrm{ppm}$; 6) Promalin a $100 \mathrm{ppm}$. Houve uma recuperação das plantas tratadas com ácido giberélico + ácido 2,4-diclorofenoxiacético, com maior enfolhamento e boa brotação, até

${ }^{7}$ TSUI, C. The role of zinc in auxin synthesis in the tomato plant. American Journal of Botany, 35: 172-179, 1948. 
aproximadamente oito meses após a aplicação. Nas avaliações seguintes as plantas cítricas voltaram a mostrar sintomas iniciais de declinio, com murchamento unilateral acentuado. $O$ uso de citocininas não resultou em diferenças significativas na produção, tamanho ou qualidade de frutos. Não foi possível a prevenção de "blight", ou inibição do desenvolvimento de sintomas em árvores no estágio inicial de definhamento, ou recuperação de árvores severamente afetadas (WHEATON \& YOUNG, 1981).

PRATES et al. (1988) utilizaram reguladores vegetais como giberelinas e auxinas, e um fertilizante composto de aminoácidos, vitaminas, carboidratos e minerais como nitrogênio, magnésio, enxofre, boro, manganês, molibdênio e zinco, em plantas com acentuado declínio unilateral. A recuperação das plantas foi satisfatória somente após seis meses da aplicação, no entanto não foram observadas diferenças na absorção de água pelo método de injeção com seringa. 


\section{MATERIAL E MÉTODOS}

\subsection{Caracterização do local do experimento}

O experimento, instalado em 14 de junho de 1989, foi conduzido em um pomar de laranjeiras na Fazenda Urutuba, município de Estiva, próximo a Mogi-Guaçu, Estado de São Paulo. O pomar não era irrigado, e apresentava uma produção média de $150 \mathrm{~kg}$ de frutos/árvore.

Segundo a classificação de Köppen, o clima da região se enquadra no tipo "Cwa" (mesotérmico, subtropical úmido com estiagem de inverno). A temperatura do mês mais quente apresenta média superior a $22^{\circ} \mathrm{C}$, e a média do mês mais frio é inferior a $18^{\circ} \mathrm{C}$. A precipitação média anual está entre 1100 e $1700 \mathrm{~mm}$. O total das chuvas no mês mais seco não ultrapassa $30 \mathrm{~mm}$. A estação seca se situa entre abril e setembro. O mês mais chuvoso está entre dezembro e fevereiro.

A Tabela 6 apresenta os dados climatológicos do posto meteorológico da Empresa Champion Papel e Celulose, situado no município de Mogi-Guaçu, a aproximadamente 20 quilômetros da área experimental, dados estes relativos ao periodo de realização do ensaio. Observa-se que a precipitação durante o período experimental 
Tabela 6 - Dados climatológicos do posto meteorológico da Empresa Champion Papel e Celulose.

\begin{tabular}{|c|c|c|c|c|c|c|c|}
\hline \multirow[b]{2}{*}{ MES/ANO } & \multirow{2}{*}{$\begin{array}{c}\text { PRECIPITAÇAO } \\
\text { (mm) }\end{array}$} & \multirow{2}{*}{$\begin{array}{l}\text { DIAS DE } \\
\text { CHUVA }\end{array}$} & \multicolumn{2}{|c|}{ UMMADE REI_ATIVA (\%) } & \multicolumn{3}{|c|}{ TEMPERATURA $\left({ }^{\circ} \mathrm{C}\right)$} \\
\hline & & & MAXIMA & MÁNIMA & MAXXMAA & Ḿ́Nma & M自DIA \\
\hline Jun/89 & 21 & 5 & 89 & 44 & 28 & 6 & 16 \\
\hline $\mathrm{Jul} / 89$ & 77 & 4 & 89 & 32 & 29 & 3 & 15 \\
\hline $\mathrm{Ag} / 89$ & 23 & 4 & 88 & 41 & 30 & 6 & 17 \\
\hline Set/89 & 72 & 11 & 89 & 37 & 33 & 7 & 19 \\
\hline Out/89 & 26 & 2 & 89 & 43 & 33 & 11 & 20 \\
\hline Nov/89 & 138 & 10 & 90 & 40 & 31 & 10 & 21 \\
\hline Dez/89 & 232 & 12 & 90 & 37 & 33 & 13 & 22 \\
\hline $\operatorname{Jan} / 90$ & 174 & 18 & 90 & 49 & 34 & 18 & 24 \\
\hline Fev/90 & 136 & 11 & 90 & 45 & 33 & 16 & 24 \\
\hline Mar/90 & 106 & 11 & 90 & 49 & 33 & 16 & 23 \\
\hline $\mathrm{Abr} / 90$ & 24 & 8 & 89 & 45 & 32 & 14 & 22 \\
\hline Mai/90 & 34 & 6 & 89 & 47 & 28 & 2 & 17 \\
\hline Jun/90 & 5 & 1 & 89 & 25 & 28 & 2 & 16 \\
\hline $\mathrm{Jul} / 90$ & 50 & 6 & 89 & 41 & 28 & 0 & 16 \\
\hline $\mathrm{Ag} / 90$ & 55 & 5 & 89 & 40 & 30 & 2 & 17 \\
\hline Set/90 & 72 & 6 & 89 & 22 & 33 & 5 & 18 \\
\hline Out $/ 90$ & 56 & 5 & 90 & 35 & 34 & 12 & 22 \\
\hline Nov/90 & 68 & 11 & 90 & 44 & 36 & 15 & 24 \\
\hline Dez/90 & 142 & 9 & 90 & 43 & 34 & 10 & 23 \\
\hline
\end{tabular}


foi menor que a precipitação média anual para a região ( em 1990, por exemplo, um total de $920 \mathrm{~mm}$ de chuva, comparados aos $1400 \mathrm{~mm}$, média regional ).

Reuther ${ }^{1}$, citado por ORTOLANI et al. (1991), calcula que laranjais adultos irrigados necessitem de 762 a $1245 \mathrm{~mm}$ de água por ano, para um bom desenvolvimento e produção. As necessidades hídricas dos citros variam com a radiação solar, a temperatura do ar, o vento, a umidade do ar, a combinação enxerto/ portaenxerto, as características do solo, o espaçamento da cultura, e outros tantos fatores da planta e do ambiente.

Para a maior parte das espécies de citros, temperaturas ao redor de $12^{\circ} \mathrm{C}$ causam sensível redução no metabolismo, que chega a quase paralisação a $5^{\circ} \mathrm{C}$. A taxa de crescimento aumenta progressivamente acima de $12^{\circ} \mathrm{C}$, até uma taxa máxima por volta de $25^{\circ} \mathrm{C}$ a $31^{\circ} \mathrm{C}$; acima desta temperatura a taxa de crescimento diminui gradativamente, praticamente cessando a $38^{\circ}$ a $40^{\circ} \mathrm{C}$.

A classe de solo do pomar deste ensaio é Latossolo Vermelho-Amarelotextura média.

Os tratos culturais de rotina, no pomar, compreendiam a aplicação do adubo 19.10.19, duas vezes ao ano, no outono e na primavera, na quantidade de $1,5 \mathrm{~kg} /$ árvore a cada aplicą̧ão. Foram efetuadas calagens nos anos de 1987, 1988 e 1989, aplicando-se $1250 \mathrm{~kg} /$ ha de calcáreo dolomítico. Em 1990 não foi realizada calagem.

Pulverizações foliares com nutrientes como boro, magnésio, manganês, enxofre, zinco, além de nitrogênio, fósforo e potássio, eram realizadas a cada ano, no início da primavera.

1REUTHER, W. Climate and citrus behavior. In: REUTHER, W.,ed. The Citrus Industry. Berkeley, University of California, 1973. v.3, cap.9, p.280-337. 
Principalmente durante a estação mais quente do ano, era realizado o controle fitossanitário, com fungicidas, acaricidas e inseticidas. $O$ controle de formigas era efetuado 4 vezes por ano, com iscas formicidas.

O controle de ervas daninhas era efetuado mecanicamente.

\subsection{Cultivar e seleção de árvores utilizadas}

As árvores utilizadas foram de laranjeira 'Pera', clone premunizado, enxertadas sobre limoeiro 'Cravo', com 18 anos de idade, selecionadas por apresentarem sintomas iniciais de declínio dos citros, e no caso do tratamento controle sem declínio, por não apresentarem quaisquer sintomas.

\subsection{Teste de absorção de água pelo tronco}

Para a diferencią̧ão de árvores com e sem declínio também foi utilizado o teste de absorção de água pelo tronco, em 14 de junho de 1989. Este teste consiste em perfurar o tronco da laranjeira a aproximadamente $30 \mathrm{~cm}$ acima da regiăo de enxertia com uma broca de $1 / 8$ de polegada, a $3 \mathrm{~cm}$ de profundidade. Nesta perfuração se conecta a extremidade de uma seringa de $20 \mathrm{ml}$, sem agulha, na qual se completam $10 \mathrm{ml}$ de água, e com o auxílio de uma alavanca, pressiona-se a água para 
o interior do tronco (LEE et al., 1984a). Encontra-se uma boa ilustração deste método em texto de GUIRADO et al. (1991).

As árvores sadias devem absorver $10 \mathrm{ml}$ de água em menos de 10 segundos, sendo que as árvores com sintomas de declínio, neste experimento, inicialmente não absorveram qualquer volume.

\subsection{Delineamento experimental}

$O$ delineamento experimental foi inteiramente casualizado, com sete tratamentos e seis repetições. Cada parcela se constituiu de uma árvore.

\subsection{Tratamentos empregados}

Os tratamentos utilizados no experimento se encontram na Tabela 7.

\subsection{Aplicação dos tratamentos}

Os produtos foram aplicados em pulverizações foliares, com exceção de Biofix e Aminofértil-2, aplicados no solo a $8 \mathrm{ml}$ e 81 por planta, respectivamente. Os demais foram pulverizados a um volume de 10 litros de solução por árvore, molhando toda a copa. 
Tabela 7 - Tratamentos empregados e suas respectivas doses.

\begin{tabular}{|c|c|c|c|}
\hline Tratamento & Condição da árvore & Produto aplicado & Dose \\
\hline $\mathrm{D}$ & com declínio & controle & \\
\hline \multirow[t]{2}{*}{$\mathrm{GA}+2,4-\mathrm{D}$} & com declínio & ácido giberélico + & $50 \mathrm{ppm}$ \\
\hline & & ácido 2,4-diclorofenoxiacético & $8 \mathrm{ppm}$ \\
\hline \multirow[t]{2}{*}{$\mathrm{GA}+\mathrm{NAA}$} & com declínio & ácido giberélico + & $50 \mathrm{ppm}$ \\
\hline & & ácido naftalenacético & $20 \mathrm{ppm}$ \\
\hline \multirow[t]{3}{*}{ GREX } & com declínio & ácido giberélico + & 50 ppm \\
\hline & & ácido naftalenacético + & 20 ppm \\
\hline & & Grex-Citrus & $30 \mathrm{ml} /$ planta \\
\hline \multirow[t]{2}{*}{ AGB } & com declínio & Biofix $(1)+$ & $8 \mathrm{ml} /$ planta \\
\hline & & Agromil & 500 ppm \\
\hline \multirow[t]{2}{*}{ AM } & com declínio & Aminofértil-2(1) + & $81 /$ planta \\
\hline & & Aminofértil-1 & $5000 \mathrm{ppm}$ \\
\hline SD & sem declínio & controle & \\
\hline
\end{tabular}

Obs. : (1)Produto aplicado no solo. 
A composição dos produtos aplicados é apresentada na Tabela 8:

Tabela 8 - Composição dos produtos aplicados às árvores do ensaio.

\begin{tabular}{|c|c|c|c|}
\hline Produto & Formulação (em \%) & Produto & Formulação (em \%) \\
\hline \multirow[t]{8}{*}{ Grex-Citrus } & 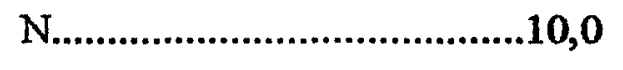 & Aminofértil-1 & N....................10,0 \\
\hline & 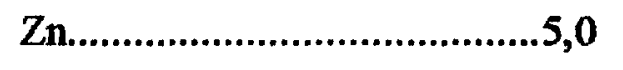 & & $\mathrm{K}_{2} \mathrm{O} \ldots \ldots \ldots \ldots \ldots \ldots \ldots \ldots \ldots$ \\
\hline & Mn & & $\mathrm{Zn} \ldots \ldots \ldots \ldots \ldots \ldots . . . . . . . . . .0$ \\
\hline & Mg & & Mn....................2,0 \\
\hline & Fe & & В................... \\
\hline & В & & Aminoácidos.....8,0 \\
\hline & & & S..................., \\
\hline & & & Mat.orgânica...40,0 \\
\hline \multirow[t]{12}{*}{ Biofix } & 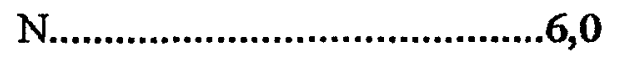 & & \\
\hline & 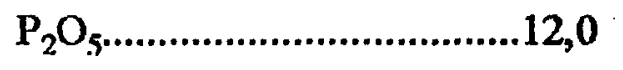 & & \\
\hline & $\mathrm{K}_{2} \mathrm{O}$ & Aminofértil-2 & N........................ \\
\hline & Ácido.húmico............................,0 & & $\mathrm{K}_{2} \mathrm{O} \ldots \ldots \ldots \ldots \ldots \ldots, \ldots$ \\
\hline & $\mathrm{Zn}$ & & $\operatorname{Mg} \ldots \ldots \ldots \ldots \ldots \ldots . . . . . .1,5$ \\
\hline & Mn. & & S...................... 7,6 \\
\hline & $\mathrm{Cu}$ & & В..........................,5 \\
\hline & Mg & & $\mathrm{Zn} \ldots \ldots \ldots \ldots \ldots \ldots . . . . . . . . .3$ \\
\hline & Fe & & $\mathrm{Cu} \ldots \ldots \ldots \ldots \ldots \ldots, 01$ \\
\hline & 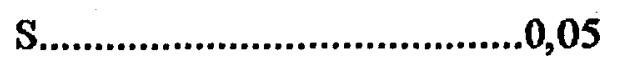 & & Fe..................0,04 \\
\hline & Mo & & Mn..................1,0 \\
\hline & & & Mat.orgânica...40,0 \\
\hline
\end{tabular}

Agromil Extrato de sementes de citros..50,0

Propilenoglicol........................50,0 
As épocas de aplicação foram em :

1a aplicação : 07 de julho de 1989;

2a aplicação : 20 de outubro de 1989 ;

3 a aplicação : 19 de fevereiro de 1990;

4a aplicação : 13 de junho de 1990;

totalizando 4 aplicações com intervalos de aproximadamente 4 meses entre elas.

\subsection{Coleta de dados}

\subsubsection{Análises foliares}

No início do ensaio, em 14 de junho de 1989, foram coletadas amostras de folhas de ramos com frutos, a altura de aproximadamente $1,70 \mathrm{~m}$ do solo, por toda a circunferência da copa de cada uma das árvores do experimento. Foram enviadas ao laboratório, para análise, segundo os métodos do Instituto Agronômico de Campinas, duas amostras para cada árvore, sendo que, dos resultados obtidos a partir destas amostras, foi calculada a média das concentrações dos minerais analisados, fornecendo uma avaliação nutricional individual para as 42 árvores do ensaio.

Uma segunda coleta de amostras de folhas foi realizada em 02 de abril de 1990, visto ser a época recomendada para comparação com os padrões nutricionais disponíveis, como as faixas de interpretação de teores de macro e 
micronutrientes nas folhas de citros, geradas na primavera, com seis meses de idade, de ramos com frutos, segundo GRUPO PAULISTA DE ADUBAÇÃO E CALAGEM DOS CITROS (1990). A metodologia foi semelhante à da primeira coleta, com a finalidade de avaliar possíveis alterações provocadas por três aplicações dos tratamentos, no estado nutricional das plantas.

\subsubsection{Indices DRIS}

O Sistema Integrado de Diagnose e Recomendação (DRIS) é um critério alternativo para a interpretação da análise foliar em plantas, desenvolvido originalmente para a seringueira, por Beaufils2, citado por BATAGLIA \& DECHEN (1986) e por BATAGLIA (1989). Este critério permite averiguar a existência de desequilibrio entre os diversos nutrientes minerais.

Através do estabelecimento de padrões para as diversas relações entre nutrientes, por processamento em sistema computacional, é possível comparar os dados das análises foliares das plantas em interesse, com dados de plantas em bom estado e com boa produção. Para cada nutriente é calculado um índice, considerando as relações deste nutriente com os demais e comparando estas relações com as relações

${ }^{2}$ BEAUFILS, E.R. Diagnosis and recommendation integrated system (DRIS). A general scheme for experimentation and calibration based on principles developed from research in plant nutrition. Soil Science Bull., University of Natal, South Africa, 1, 1973. 
médias de uma população padrão. Índices com valores negativos indicam deficiência e positivos indicam excesso, enquanto que valores próximos de zero indicam equilíbrio, como mostra a Tabela 5. O índice de balanço nutricional é calculado pela média dos valores absolutos dos índices de todos os nutrientes avaliados. Esta técnica deve permitir tanto identificar desequilibrios entre os nutrientes como colocá-los em ordem crescente de deficiência, e avaliar, através do balanço nutricional, o estado nutricional geral da planta.

Foram utilizados na interpretação pelo DRIS os resultados da análise foliar das amostras coletadas em 02 de abril de 1990, e a população padrão se constituiu das árvores sadias do experimento.

\subsubsection{Análises de solo}

Na mesma época da primeira análise foliar, foram retiradas amostras de solo, em 16 de junho de 1989, sob cada copa das 42 plantas envolvidas no experimento, em dois pontos da projeção da copa (na linha e na entrelinha), formando uma amostra composta para cada nível de profundidade. As faixas de profundidade foram de 0 a $20 \mathrm{~cm}$, de 20 a $40 \mathrm{~cm}$, e de 40 a $60 \mathrm{~cm}$, totalizando três amostras compostas por árvore. Os métodos de análise de solo seguiram o sistema adotado pelo Instituto Agronômico de Campinas (RAIJ et al.,1987).

Seguindo o mesmo esquema da primeira coleta, em 27 de novembro de 1990, foram retiradas novamente amostras de solo sob cada árvore, possibilitando uma avaliação dos efeitos das quatro aplicações dos produtos utilizados no ensaio. 


\subsubsection{Análise do teor de zinco no lenho}

Diversos artigos anteriormente publicados citam como sintomatologia típica do declínio dos citros, o elevado acúmulo de sais de zinco no lenho da árvore, logo acima da região de enxertia (ROSSETTI \& BERETTA, 1988; WUTSCHER, 1981; WUTSCHER et al., 1977; WUTSCHER et al., 1980 e YOUNG et al., 1980).

Para determinar o acúmulo de zinco nas árvores do ensaio, foram retiradas amostras do lenho de cada árvore, em 02 de abril de 1990.

As amostras foram retiradas a aproximadamente $20 \mathrm{~cm}$ acima da região de enxertia, utilizando-se um formão, cortando-se um quadrado de $2 \times 2 \mathrm{~cm}$ e $1 \mathrm{~cm}$ de profundidade, desprezando-se a casca, e remetidas para análise do teor de zinco.

Este método é uma adaptação do empregado por WUTSCHER et al. (1977), no qual são efetuadas duas perfurações no tronco a aproximadamente $20 \mathrm{~cm}$ acima da região de enxertia, e $2,5 \mathrm{~cm}$ de profundidade, em lados opostos do tronco, com broca de $1 / 2$ polegada, e também são utilizadas amostras onde a casca é desprezada.

\subsubsection{Teste de absorção de água pelo tronco}

Ao término das aplicações dos tratamentos, em 26 de outubro de 1990, juntamente com a última atribuição de notas pela aparência visual das árvores, foram repetidos os testes de absorção de água por injeção no tronco, pelo mesmo método já descrito anteriormente (ítem 3.3), utilizado para diferenciação de árvores com e sem declínio, no início do experimento. 


\subsubsection{Atribuição de notas}

Foi utilizado um sistema de atribuição de notas para as árvores envolvidas no experimento, de acordo com a avaliação visual das plantas. Sistemas de atribuição de notas têm sido utilizados de forma semelhante em vários experimentos (PRATES et al., 1983b; PRATES et al., 1988 e WUTSCHER, 1984). O valor das notas variou de 1 a 5 , significando : 1,árvore morta; 2,senescente ou podada; 3,árvore com declínio bilateral; 4,árvore com declínio unilateral; e 5,árvore sadia.

No início do ensaio, as notas atribuídas às árvores, em 14 de junho de 1989, foram : nota 5 para as árvores do tratamento 7, sem declínio, e nota 4 para as restantes, com declínio unilateral moderado, condição esta selecionada para iniciar o experimento.

As avaliações visuais seguintes ocorreram em : 20 de outubro de 1989; 02 de abril de 1990; e 26 de outubro de 1990.

\subsection{7. Índice de área foliar}

O índice de área foliar (LAF) de 8 árvores do ensaio foi determinado pelo método de fotografias hemisféricas.

As fotografias foram tiradas em 31 de janeiro de 1991, com câmara Nikon $F$ aparelhada com lente olho-de-peixe Fisheye NIKKOR $(1: 5,6 ; f=10 \mathrm{~mm}$; 180 -OP), e filmes Pan F marca ILFORD de alto contraste. 
As fotografias foram obtidas com céu nublado, ainda utilizando-se filtro L1A (skylight).

Para este ensaio foi selecionada a abertura f/8 e velocidades de 30 ou 60 , indicadas pelo fotômetro.

A câmara fotográfica foi nivelada sobre plataforma de madeira de $30 \mathrm{~cm}$ por $50 \mathrm{~cm}$, rente ao solo abaixo da copa da laranjeira, a uma distância de aproximadamente $50 \mathrm{~cm}$ do tronco, com a lente direcionada para $90^{\circ}$ do plano do terreno.

Para cada árvore amostrada, foram tiradas quatro fotografias, sendo duas de cada hemisfério da copa da planta, para seleção da fotografia de melhor definição para cada hemisfério.

O método, baseado na medida da frequência de aberturas na copa, consiste na utilização de uma equação para o IAF, definida por Leong et al. ${ }^{3}$, citados por BERNARDES (1989), para a seringueira :

$$
\mathrm{IAF}=-\frac{1}{0,91} \ln [\mathrm{gB}]
$$

sendo:

${ }^{3}$ LEONG, W.; LEMEUR, R.; YOON, P.K. Characterisation of leaf area index and canopy light penetration of Hevea brasiliensis Muell. Arg. by hemispherical photography. Journal of the Rubber Research Institute of Malasia, Kuala Lumpur, 30 (2): 80-90, 1982. 


$$
\mathrm{g} B=\frac{\text { comprimento de arcos de céu }}{\text { comprimento da circunferéncia }} .
$$

Esta relação (gB) é calculada através de circunferência traçada com um raio de $52,7 \mathrm{~mm}$ sobre as fotografias ampliadas em papel de tamanho $18 \mathrm{~cm}$ por $24 \mathrm{~cm}$, sendo copiados em papel vegetal os segmentos de arco desta circunferência, que interceptam as aberturas na copa, e agrupados para medição em curvímetro.

Os comprimentos dos segmentos de arco de céu utilizados na equação do IAF foram obtidos a partir da média entre os comprimentos medidos com curvímetro e os comprimentos calculados através dos ângulos formados pelos mesmos arcos.

A média entre os índices de área foliar dos dois hemisférios forneceu o IAF da árvore.

As árvores fotografadas foram as de número $1,2,3$ (tratamento $D$ ) ; 7, 8, 11 (tratamento GA+2,4-D) ; e 39, 40 (tratamento SD).

\subsubsection{Correlação notas-índice de área foliar}

Obtidos os índices de área foliar (IAF) das oito árvores do ensaio, através do método de fotografias hemisféricas, procedeu-se a análise da regressão : IAF em função da nota. As notas utilizadas para a regressão foram as da taltima avaliação visual, de 26 de outubro de 1990, para as mesmas oito árvores fotografadas. 


\subsection{Análise estatística}

\subsubsection{Análises foliares e de solo}

Usualmente, com a finalidade de reduzir a variabilidade decorrente de erro experimental, recorre-se ao controle local do experimento, obtendo-se estimativas não tendenciosas dos efeitos dos tratamentos.

Quando as fontes de erro são difíceis ou impossíveis de serem eliminadas pelo controle local, uma alternativa seria o controle estatístico, que permite remover tais fontes. Através da análise de covariância, a variável dependente pode ser ajustada de forma a eliminar os efeitos de variáveis que não possam ser controladas e que representem fonte de variação.

Neste experimento, os dados obtidos a partir das últimas análises de folhas e de solo, podem ser influenciados pela condição já existente no início, antes da aplicação dos tratamentos, revelada pelas primeiras análises foliares e de solo. A análise de covariância e o teste de Tukey, ao nível de 5\% de probabilidade, foram realizados, considerando os dados das segundas análises como variáveis dependentes a serem ajustadas a fim de anular os efeitos das variáveis auxiliares (dados das primeiras análises).

\subsubsection{Textura do solo}

As porcentagens de areia e de argila obtidas na primeira análise de solo, foram avaliadas através de análise de variância com aplicação do teste $F$. 


\subsubsection{Concentração de zinco no lenho}

Procedeu-se a análise de variância dos dados de concentração de zinco, com aplicação do teste $\mathrm{F}$.

\subsubsection{Absorção de água pelo tronco}

Foi efetuada análise de variância para os dados de volume de água absorvida no segundo teste de absorção de água pelo tronco, e aplicado o teste de Tukey.

\subsubsection{Notas pela aparência visual}

As notas obtidas a partir da $2 \stackrel{a}{\text {, }}$ 3a e 4 a avaliações visuais das plantas afetadas pelo declínio, foram submetidas à análise de variância com aplicação de teste $F$.

\subsubsection{Regressão IAF-notas}

Utilizou-se o teste $\mathrm{F}$ aplicado à análise de variância da regressão linear, índices de área foliar em função das notas atribuídas pela avaliação visual. 


\section{RESULTADOS E DISCUSSÃO}

\subsection{Análises foliares}

Foram obtidos a partir das análises foliares de junho de 1989 e de abril de 1990, os teores de nitrogênio, fósforo, potássio, cálcio, magnésio, enxofre, boro, zinco, manganês, ferro, cobre e alumínio (Tabelas 9 a 12).

\subsubsection{Nitrogênio (N)}

Os tratamentos controle com declínio (D); Agromil+Biofix (AGB) e Aminofértil-1+Aminofértil-2 (AM) não diferem significativamente entre si, segundo a análise de covariância e o teste de Tukey ao nível de 5\% de probabilidade, como mostra a Tabela 10. AM apresenta maior média, diferindo significativamente dos tratamentos com ácido giberélico+ ácido 2,4-diclorofenoxiacético (GA+2,4-D); ácido giberélico + ácido naftalenacético (GA+NAA); ácido giberélico + ácido naftalenacético + Grex-Citrus (GREX); e do controle sem declínio, ou plantas sadias (SD). Os tratamentos $D ; G A+2,4-D ; G A+N A A$ e $A G B$ não diferem significativamente entre si, sendo que $D$ apresenta média significativamente maior do que as dos tratamentos GREX e SD. Os tratamentos GA+2,4-D; GA+NAA; AGB e SD não apresentam diferença significativa 
entre si, sendo que a média do tratamento AGB é significativamente maior do que a do tratamento GREX. Este último não difere significativamente dos tratamentos $G A+2,4-D$; GA+NAA e SD.

Tabela 9 - Médias e análise de variância das concentrações de nitrogênio , fósforo , potássio , cálcio, magnésio e enxofre, em porcentagem, para as análises foliares de 14/06/89.

\begin{tabular}{|c|c|c|c|c|c|c|}
\hline \multirow{3}{*}{$\frac{\text { Tratamentos }}{1}$} & $\mathrm{~N}$ & $\mathrm{P}$ & $\mathrm{K}$ & $\mathrm{Ca}$ & $\mathrm{Mg}$ & $S$ \\
\hline & \multicolumn{6}{|c|}{$\%$} \\
\hline & $2,2 a b$ & 0,12 bc & 1,0 & 3,2 & 0,39 & $0,35 \mathrm{a}$ \\
\hline 2 & $2,1 a b$ & $0,12 \mathrm{bc}$ & 0,9 & 3,6 & 0,44 & $0,23 \quad b$ \\
\hline 3 & $1,8 \quad b$ & $0,12 b c$ & 0,9 & 3,5 & 0,43 & $0,22 \quad b$ \\
\hline 4 & $2,1 \mathrm{ab}$ & $0,10 \quad \mathrm{c}$ & 0,9 & 3,3 & 0,44 & $0,28 \mathrm{ab}$ \\
\hline 5 & $2,2 a b$ & $0,18 \mathrm{a}$ & 1,0 & 3,1 & 0,43 & $0,29 a b$ \\
\hline 6 & $2,4 a$ & $0,15 a b$ & 1,0 & 3,1 & 0,39 & $0,27 \mathrm{ab}$ \\
\hline 7 & $2,3 \mathrm{a}$ & $0,12 \mathrm{bc}$ & 1,0 & 3,2 & 0,38 & $0,26 \mathrm{ab}$ \\
\hline F (Trat.) & $3,57^{* 2 * 3}$ & $6,13^{* * *}$ & $0,60^{\text {ns }}$ & 2,69 ns & $2,56^{\mathrm{ns}}$ & $3,72^{\text {*** }}$ \\
\hline C. V. $(\%)$ & 12,68 & 18,81 & 15,51 & 8,92 & 9,43 & 20,16 \\
\hline
\end{tabular}

Obs.1: as médias de uma mesma coluna, seguidas de letras distintas, diferem significativamente entre si, pelo teste de Tukey ao nivel de $5 \%$ de probabilidade.

Obs.2: $* *=$ significativo ao nivel de $1 \%$ de probabilidade; ns = não significativo. 
Tabela 10 - Médias e análise de covariância das concentrações de nitrogênio , fósforo , potássio, cálcio, magnésio e enxofre, em porcentagem, para as análises foliares de 02/04/90.

\begin{tabular}{|c|c|c|c|c|c|c|}
\hline \multirow[b]{2}{*}{ Tratamentos } & $N$ & $\mathrm{P}$ & $\mathrm{K}$ & $\mathrm{Ca}$ & $\mathrm{Mg}$ & $S$ \\
\hline & \multicolumn{6}{|c|}{$\%$} \\
\hline 1 & $1,9 \mathbf{a ~ b}$ & 0,12 & 1,1 & $3,7 \quad b c$ & 0,27 & 0,26 \\
\hline 2 & 1,8 bc d & 0,13 & 1,0 & 4,3 a & 0,33 & 0,25 \\
\hline 3 & $1,8 \mathrm{bcd}$ & 0,12 & 1,0 & $3,9 \quad \mathrm{ab}$ & 0,31 & 0,26 \\
\hline 4 & 1,7 & 0,13 & 0,9 & $\mathrm{bc}$ & 0,34 & 0,24 \\
\hline 5 & $1,9 \mathrm{abc}$ & 0,12 & 1,0 & 3,6 & 0,35 & 0,25 \\
\hline 6 & $2,0 \mathrm{a}$ & 0,12 & 1,1 & 3,4 & 0,28 & 0,26 \\
\hline 7 & $\mathrm{~cd}$ & 0,12 & 1,2 & 3,4 & 0,30 & 0,25 \\
\hline F (Trat.) & $6,21 * *$ & $0,49 \mathrm{~ns}$ & $1,89 \mathrm{~ns}$ & $5,44^{* 2+3}$ & $1,54 \mathrm{~ns}$ & $0,68 \mathrm{~ns}$ \\
\hline C. V. $(\%)$ & 4,89 & 7,51 & 11,02 & 6,61 & 12,29 & 8,54 \\
\hline
\end{tabular}

Obs.1: as médias de uma mesma coluna, seguidas de letras distintas, diferem significativamente entre si, pelo teste de Tukey ao nivel de $5 \%$ de probabilidade.

Obs.2: $* *=$ significativo ao nivel de $1 \%$ de probabilidade; ns = não significativo.

O tratamento com GREX apresenta média de teores de nitrogênio nas folhas, significativamente menor do que a do controle com declínio, enquanto que o tratamento com AM apresenta média significativamente maior do que a do controle sem 
declínio. O controle com declínio apresenta média significativamente maior do que a do controle sem declínio.

Todos os tratamentos apresentam teores avaliados como deficientes, pelo critério de faixas de interpretação de teores de nutrientes nas folhas para citros (GRUPO PAULISTA DE ADUBAÇÃO E CALAGEM DOS CITROS, 1990).

\subsubsection{Fósforo (P) e potássio (K)}

Os tratamentos não apresentam diferença significativa entre si , pelo teste $\mathrm{F}$ ao nível de $5 \%$ de probabilidade (Tabela 10).

Pelo critério de faixas de interpretação, os teores de fósforo estão na faixa de teores adequados, em todos os tratamentos; e os teores de potássio são avaliados como baixos, em todos os tratamentos.

\subsubsection{Cálcio (Ca)}

Os tratamentos GA+2,4-D e GA+NAA não diferem significativamente entre si, sendo a média de GA+2,4-D significativamente maior do que as de $D$; GREX; AGB; AM e SD. Os tratamentos D; GA+NAA; GREX e AGB não diferem significativamente entre si, sendo que a média de GA+NAA é significativamente maior do que as de $\mathrm{AM}$ e SD. Os tratamentos $\mathrm{D}$; GREX; $\mathrm{AGB}$; $\mathrm{AM}$ e $\mathrm{SD}$ não apresentam diferença significativa entre si (Tabela 10). 
O tratamento GA+2,4-D proporcionou a maior média de teores de cálcio nas folhas, só não diferindo significativamente da média de GA+NAA. Os tratamentos controle, e aqueles que receberam fertilizantes, não diferiram entre si, quanto ao teor de cálcio nas folhas.

Em todos os tratamentos os teores são considerados adequados, pelo critério de faixas de suficiência de nutrientes para citros.

\subsubsection{Magnésio (Mg) e enxofre (S)}

Os tratamentos não diferem significativamente entre si, pelo teste $\mathrm{F}$ a $5 \%$ de probabilidade (Tabela 10 ).

Pelo critério de faixas de suficiência, os tratamentos GA+2,4-D; GA+NAA; GREX; AGB e SD apresentam teores adequados de magnésio, enquanto que os tratamentos D e AM apresentam teores baixos.

Quanto aos teores de enxofre nas folhas, são considerados adequados em todos os tratamentos, pelo critério de faixas de interpretação.

\subsubsection{Boro (B)}

O tratamento AM apresenta a maior média, pelo teste de Tukey a 5\% de probabilidade, diferindo significativamente dos demais, os quais não diferem significativamente entre si, conforme a Tabela 12.

Todos os tratamentos apresentam teores adequados de boro, com exceção de AM, para o qual o teor é excessivo, pelo critério de faixas de interpretação. 
Este resultado pode ser explicado pelo alto teor de boro do fertilizante Aminofértil-1 $(1,0 \%)$ somado ao teor de boro de Aminofértil-2 $(0,5 \%)$, ambos aplicados neste tratamento.

Tabela 11 - Médias e análise de variância das concentrações de boro, zinco, manganês, ferro, cobre e alumínio, para as análises foliares de 14/06/89.

\begin{tabular}{ccccccc}
\hline Tratamentos & $\mathrm{B}$ & $\mathrm{Zn}$ & $\mathrm{Mn}$ & $\mathrm{Fe}$ & $\mathrm{Cu}$ & $\mathrm{Al}$ \\
\hline 1 & $49 \mathrm{ab}$ & $64 \mathrm{a}$ & $49 \mathrm{a}$ & $228 \mathrm{ab}$ & 30 & 191 \\
2 & $51 \mathrm{ab}$ & $66 \mathrm{a}$ & $41 \mathrm{ab}$ & $228 \mathrm{ab}$ & 28 & 178 \\
3 & $43 \mathrm{~b}$ & $55 \mathrm{ab}$ & $34 \mathrm{ab}$ & $204 \mathrm{~b}$ & 26 & 130 \\
4 & $47 \mathrm{ab}$ & $40 \mathrm{~b}$ & $33 \mathrm{~b}$ & $221 \mathrm{ab}$ & 23 & 181 \\
5 & $52 \mathrm{ab}$ & $46 \mathrm{ab}$ & $39 \mathrm{ab}$ & $212 \mathrm{~b}$ & 20 & 194 \\
6 & $57 \mathrm{a}$ & $39 \mathrm{~b}$ & $30 \mathrm{~b}$ & $238 \mathrm{ab}$ & 28 & 210 \\
7 & $46 \mathrm{ab}$ & $47 \mathrm{ab}$ & $40 \mathrm{ab}$ & $258 \mathrm{a}$ & 28 & 222 \\
\hline F (Trat.) & $2,34 *$ & $5,68 * *$ & $3,08 *$ & $3,25 * *$ & $0,47 \mathrm{~ns}$ & $1,63 \mathrm{~ns}$ \\
C.V. (\%) & 14,65 & 21,93 & 22,53 & 10,45 & 50,58 & 30,04 \\
\hline
\end{tabular}

Obs.l: as médias de uma mesma coluna, seguidas de letras distintas, diferem significativamente entre si, pelo teste de Tukey ao nível de 5\% de probabilidade.

Obs.2: $* *=$ significativo ao nivel de $1 \%$ de probabilidade;

* = significativo ao nivel de $5 \%$ de probabilidade;

ns = não significativo. 
Tabela 12 - Médias e análise de covariância das concentrações de boro, zinco, manganês, ferro, cobre e alumínio, para as análises foliares de 02/04/90.

\begin{tabular}{|c|c|c|c|c|c|c|c|}
\hline Tratamentos & & $\mathrm{B}$ & $\mathrm{Zn}$ & $\mathrm{Mn}$ & $\mathrm{Fe}$ & $\mathrm{Cu}$ & $\mathrm{Al}$ \\
\hline 1 & 81 & $b$ & $44 \mathrm{~b}$ & $39 a b$ & 203 & 29 & 229 \\
\hline 2 & 77 & $b$ & $36 \mathrm{bc}$ & 28 & 185 & 22 & 244 \\
\hline 3 & 81 & $b$ & $33 \mathrm{bc}$ & 32 bc & 202 & 25 & 262 \\
\hline 4 & 85 & $\mathrm{~b}$ & $70 \mathrm{a}$ & $48 \mathrm{a}$ & 197 & 19 & 318 \\
\hline 5 & 82 & b & $27 \quad \mathrm{c}$ & $30 \mathrm{bc}$ & 201 & 25 & 295 \\
\hline 6 & $268 \mathrm{a}$ & & $71 \mathrm{a}$ & $45 \mathrm{a}$ & 195 & 28 & 272 \\
\hline 7 & 79 & $\mathrm{~b}$ & $29 \quad \mathrm{c}$ & $32 \mathrm{bc}$ & 208 & 26 & 298 \\
\hline $\mathrm{F}$ (Trat.) & 158,8 & $1 * *$ & $40,40 * *$ & $16,25 *$ & $0,63 \mathrm{~ns}$ & $1,86^{\mathrm{ns}}$ & $1,99 \mathrm{~ns}$ \\
\hline C.V. $(\%)$ & 11,52 & & 15,34 & 14,46 & 11,73 & 26,05 & 21,50 \\
\hline
\end{tabular}

Obs.1: as médias de uma mesma coluna, seguidas de letras distintas, diferem significativamente entre si, pelo teste de Tukey ao nivel de 5\% de probabilidade.

Obs.2: $* *=$ significativo ao nivel de $1 \%$ de probabilidade; $\mathrm{ns}=$ não significativo.

\subsubsection{Zinco (Zn)}

Os tratamentos GREX e AM não diferem significativamente entre si, pelo teste de Tukey a $5 \%$ de probabilidade, sendo que apresentam médias significativamente maiores em relação a todos os demais. $D ; G A+2,4-D$ e GA+NAA não diferem entre si, sendo que $D$ apresenta média significativamente maior do que AGB e SD. GA+2,4-D; GA+NAA; AGB e SD não apresentam diferença 
significativa entre si (Tabela 12). O tratamento AGB apresenta média significativamente menor do que a do controle com declínio. $O$ controle com declínio apresenta média significativamente maior do que a do controle sem declínio.

Considera-se que os tratamentos D; GA+2.4-D; GA+NAA; AGB e SD apresentam teores adequados, segundo a faixa de interpretação, sendo que os tratamentos GREX e AM apresentam teores altos. Os produtos aplicados tanto em GREX como em AM possuem altas concentrações de zinco, justificando os valores encontrados nas análises foliares.

\subsubsection{Manganês (Mn)}

Os tratamentos $D$; GREX e $A M$ não diferem significativamente entre si. GREX e AM apresentam médias significativamente maiores do que as de GA+2,4D; GA+NAA; AGB e SD. Estes tratamentos não diferem significativamente entre si. D; GA+NAA; AGB e SD não apresentam diferença significativa entre si. $O$ tratamento $\mathrm{D}$ apresenta média significativamente maior do que a de GA+2,4-D (Tabela 12). Os produtos aplicados em GREX e AM são uma fonte considerável de manganês para as plantas. As médias destes tratamentos são significativamente maiores do que a do controle sem declínio. Os controles não diferem entre si.

Os teores são considerados adequados para todos os tratamentos, segundo as faixas de suficiência. 


\subsubsection{Ferro (Fe), cobre (Cu) e alumínio (Al)}

Com relação a estes minerais, os tratamentos não apresentam diferença significativa entre si, pelo teste $\mathrm{F}$ ao nivel de $5 \%$ de probabilidade, como mostra a Tabela 12.

Os teores de ferro encontram-se altos em todos os tratamentos, segundo as faixas de interpretação, o que é de se esperar, pela abundância deste micronutriente nos solos de nossa região.

Os teores de cobre são considerados excessivos em todos os tratamentos, pelo critério de faixas de concentração.

Quanto às concentrações de alumínio nas folhas, WUTSCHER \& HARDESTY (1979b), analisando árvores de laranjeira 'Valencia' sobre limoeiro 'Rugoso', de 16 anos de idade, encontraram valores ao redor de $25 \mathrm{ppm}$. No presente ensaio, as médias de tratamentos variam entre 229 e 318 ppm de aluminio, teores comparáveis aos encontrados nas raizes, por WUTSCHER \& HARDESTY (1979b).

Diversos autores encontraram diferenças significativas nos teores foliares de minerais, comparando plantas sadias e com declínio. PRATES et al. (1983a) e PRATES et al. (1984b) encontraram maior porcentagem de amostras foliares deficientes em potássio, em plantas com declínio, em relação às sadias. WUTSCHER \& HARDESTY (1979b) também relataram teores significativamente menores de potássio, e significativamente maiores de sódio, zinco e cloro, em árvores com "blight". As baixas concentrações de potássio nas folhas estavam associadas a altas concentrações deste mineral no lenho de ramos e tronco. WUTSCHER \& MCDONALD (1986) encontraram teores significativamente maiores de magnésio, enxofre, sódio, manganês e cloro, em árvores com "blight". 
PRATES et al. (1985) e PRATES et al. (1989) não encontraram correlação significativa entre deficiências minerais e incidência de declínio.

Os distúrbios no estado nutricional das plantas, quando correlacionados com a ocorrência do declínio, conforme relato dos autores acima citados, parecem variar com as condições internas e externas da planta, mais como uma consequência de distúrbios metabólicos primários. O prejuízo na absorção pelas raízes e transporte pelo xilema, características do declínio, levam a um desequilíbrio do desenvolvimento vegetal, e alterações no estado nutricional dependeriam principalmente das condições de solo e de clima, e das características da planta. Possivelmente por estas razões são encontradas grandes variações no estado nutricional de plantas envolvidas em experimentos com declínio, dependendo da localização, cultivares, épocas do ano e outros fatores. 


\subsection{9. Índices DRIS}

Os índices DRIS obtidos a partir da análise foliar de abril de 1990, para os nutrientes nitrogênio, fósforo, potássio, cálcio, magnésio, enxofre, boro, ferro, manganês e zinco, e os índices de balanço nutricional, são apresentados nas Tabelas 13 a 23 .

Tabela 13 - Índices DRIS para o nitrogênio, da análise foliar de abril de 1990.

\begin{tabular}{|c|c|c|c|c|c|c|c|}
\hline \multirow[b]{2}{*}{ Tratamentos } & \multicolumn{6}{|c|}{ Repetições } & \multirow[b]{2}{*}{ Médias } \\
\hline & 1 & 2 & 3 & 4 & 5 & 6 & \\
\hline $\mathrm{D}$ & -4 & 12 & 29 & 11 & 13 & 18 & 13 \\
\hline $\mathrm{GA}+2,4-\mathrm{D}$ & 19 & -9 & 11 & 5 & -4 & -12 & 2 \\
\hline $\mathrm{GA}+\mathrm{NAA}$ & 12 & -2 & 1 & -5 & -1 & -10 & -1 \\
\hline GREX & -16 & -25 & -16 & -8 & -4 & -19 & -15 \\
\hline $\mathrm{AGB}$ & 2 & 19 & 10 & 17 & 27 & 31 & 18 \\
\hline $\mathrm{AM}$ & 9 & 9 & 7 & 19 & 2 & 3 & 8 \\
\hline $\mathrm{SD}$ & -5 & -18 & -12 & 14 & 9 & 7 & -1 \\
\hline
\end{tabular}


Tabela 14 - Índices DRIS para o fósforo, da análise foliar de abril de 1990.

\begin{tabular}{|c|c|c|c|c|c|c|c|}
\hline \multirow[b]{2}{*}{ Tratamentos } & \multicolumn{6}{|c|}{ Repetições } & \multirow[b]{2}{*}{ Médias } \\
\hline & 1 & 2 & 3 & 4 & 5 & 6 & \\
\hline D & -6 & 2 & -7 & -14 & 10 & 0 & -2 \\
\hline $\mathrm{GA}+2,4-\mathrm{D}$ & 3 & 2 & -1 & -4 & 0 & 15 & 2 \\
\hline $\mathrm{GA}+\mathrm{NAA}$ & -1 & 20 & -10 & -11 & 4 & 2 & 1 \\
\hline GREX & -12 & 21 & 29 & -7 & 9 & -4 & 6 \\
\hline AGB & 0 & -15 & 20 & -2 & 6 & -4 & 1 \\
\hline $\mathrm{AM}$ & -33 & -1 & -12 & 8 & -2 & -14 & -9 \\
\hline SD & -12 & 21 & 9 & 0 & -5 & -17 & -1 \\
\hline
\end{tabular}

Tabela 15 - Índices DRIS para o potássio, da análise foliar de abril de 1990.

\begin{tabular}{cccccccc}
\hline & \multicolumn{7}{c}{ Repetiços } \\
\cline { 2 - 6 } Tratamentos & 1 & 2 & 3 & 4 & 5 & 6 & Médias \\
\hline D & 14 & -12 & -36 & -28 & -25 & -27 & -19 \\
GA+2,4-D & 13 & -17 & -70 & -29 & -37 & -22 & -27 \\
GA+NAA & -29 & -28 & -14 & -51 & -27 & -48 & -33 \\
GREX & -36 & -85 & -28 & -7 & -73 & -49 & -46 \\
NOB & -28 & -47 & -23 & -19 & 5 & -13 & -21 \\
AM & -32 & -32 & -13 & 1 & -55 & -20 & -25 \\
SD & -29 & -5 & 10 & -3 & 26 & -5 & -1 \\
\hline
\end{tabular}


Tabela 16 - Índices DRIS para o cálcio, da análise foliar de abril de 1990.

\begin{tabular}{cccccccc}
\hline & \multicolumn{7}{c}{ Repetiç̃̃es } \\
\cline { 2 - 6 } Tratamentos & 1 & 2 & 3 & 4 & 5 & 6 & Médias \\
\hline D & 3 & -7 & 13 & 17 & 29 & 3 & 10 \\
GA+2,4-D & 21 & 49 & 27 & 42 & 53 & 49 & 40 \\
GA+NAA & 24 & 24 & 17 & 41 & 31 & 14 & 25 \\
GREX & 2 & -1 & -8 & 12 & 5 & 12 & 4 \\
AGB & 25 & 20 & 0 & 6 & -9 & 0 & 7 \\
AM & 7 & -5 & -27 & -34 & -1 & -29 & -15 \\
SD & 13 & 6 & -3 & 11 & -26 & -3 & 0 \\
\hline
\end{tabular}

Tabela 17 - Índices DRIS para o magnésio, da análise foliar de abril de 1990.

\begin{tabular}{|c|c|c|c|c|c|c|c|}
\hline \multirow[b]{2}{*}{ Tratamentos } & \multicolumn{6}{|c|}{ Repetições } & \multirow[b]{2}{*}{ Médias } \\
\hline & 1 & 2 & 3 & 4 & 5 & 6 & \\
\hline D & -26 & -7 & -12 & -15 & -5 & 7 & -10 \\
\hline $\mathrm{GA}+2,4-\mathrm{D}$ & -13 & 4 & 10 & 23 & 11 & -1 & 6 \\
\hline GA+NAA & 1 & -2 & 3 & 2 & 5 & 7 & 3 \\
\hline GREX & 15 & -2 & 16 & 8 & 8 & .10 & 9 \\
\hline AGB & 20 & 9 & -1 & 1 & 29 & 17 & 12 \\
\hline $\mathrm{AM}$ & 0 & 0 & -14 & -8 & -10 & -22 & -9 \\
\hline SD & 13 & 17 & -5 & 14 & -45 & -4 & -2 \\
\hline
\end{tabular}


Tabela 18 - Índices DRIS para o enxofre, da análise foliar de abril de 1990.

\begin{tabular}{cccccccc}
\hline & \multicolumn{7}{c}{ Repetiç̃es } \\
\cline { 2 - 6 } Tratamentos & 1 & 2 & 3 & 4 & 5 & 6 & Médias \\
\hline D & -22 & 12 & -23 & 19 & -17 & -10 & -7 \\
GA+2,4-D & -3 & 18 & -25 & -24 & -7 & 14 & -4 \\
GA+NAA & -11 & 1 & 17 & 18 & -26 & 4 & 0 \\
GREX & -9 & 16 & -71 & -49 & -25 & -45 & -30 \\
AGB & -32 & -7 & -11 & -1 & 23 & 8 & -3 \\
AM & -12 & -37 & -33 & -23 & -16 & -4 & -21 \\
SD & -2 & 3 & 4 & -8 & 21 & -14 & 1 \\
\hline
\end{tabular}

Tabela 19 - Índices DRIS para o boro, da análise foliar de abril de 1990.

\begin{tabular}{cccccccc}
\hline & \multicolumn{7}{c}{ Repetiç̃es } \\
\cline { 2 - 6 } Tratamentos & 1 & 2 & 3 & 4 & 5 & 6 & Médias \\
\hline D & 5 & -7 & -17 & -4 & -12 & -2 & -6 \\
GA+2,4-D & -2 & -2 & 1 & -14 & -11 & -22 & -8 \\
GA+NAA & -12 & -1 & 6 & -10 & 1 & 3 & -2 \\
GREX & -7 & -1 & -13 & 2 & -10 & 4 & -4 \\
AGB & 5 & 1 & -6 & 8 & -2 & 3 & 2 \\
AM & 53 & 49 & 64 & 53 & 52 & 47 & 53 \\
SD & 18 & -3 & 2 & -6 & -11 & 4 & 1 \\
\hline
\end{tabular}


Tabela 20 - Índices DRIS para o ferro, da análise foliar de abril de 1990.

\begin{tabular}{cccccccc}
\hline & \multicolumn{7}{c}{ Repetiç̃̃es } \\
\cline { 2 - 6 } Tratamentos & 1 & 2 & 3 & 4 & 5 & 6 & Médias \\
\hline D & -8 & -8 & -5 & -18 & -23 & -6 & -11 \\
GA+2,4-D & -25 & -22 & -7 & 1 & -8 & -22 & -14 \\
GA+NAA & 5 & -15 & -21 & -3 & -2 & 3 & -6 \\
GREX & -11 & -20 & -6 & -17 & -12 & -14 & -13 \\
AGB & 5 & 3 & -8 & -13 & -15 & 0 & -5 \\
AM & -38 & -37 & -34 & -50 & -40 & -24 & -37 \\
SD & 13 & -7 & -6 & 4 & 1 & 0 & 1 \\
\hline
\end{tabular}

Tabela 21 - Índices DRIS para o manganês, da análise foliar de abril de 1990.

\begin{tabular}{cccccccc}
\hline & \multicolumn{7}{c}{ Repetiç̃̃es } \\
\cline { 2 - 6 } Tratamentos & 1 & 2 & 3 & 4 & 5 & 6 & Médias \\
\hline D & 24 & 4 & 21 & 0 & 7 & -10 & 8 \\
GA+2,4-D & -23 & -20 & 20 & -11 & -6 & -22 & -10 \\
GA+NAA & -10 & 5 & -8 & -3 & 13 & 16 & 2 \\
GREX & 16 & 28 & 31 & 10 & 32 & 28 & 24 \\
AGB & 5 & 19 & -3 & 0 & -11 & -14 & -1 \\
AM & 4 & 3 & 6 & -1 & 14 & 7 & 6 \\
SD & -11 & -15 & 1 & -8 & 18 & 23 & 1 \\
\hline
\end{tabular}


Tabela 22 - Índices DRIS para o zinco, da análise foliar de abril de 1990.

\begin{tabular}{|c|c|c|c|c|c|c|c|}
\hline \multirow[b]{2}{*}{ Tratamentos } & \multicolumn{6}{|c|}{ Repetições } & \multirow[b]{2}{*}{ Médias } \\
\hline & 1 & 2 & 3 & 4 & 5 & 6 & \\
\hline$D$ & 20 & 11 & 37 & 33 & 24 & 26 & 25 \\
\hline $\mathrm{GA}+2,4-\mathrm{D}$ & 10 & -4 & 34 & 12 & 9 & 23 & 14 \\
\hline GA+NAA & 21 & -3 & 10 & 21 & 3 & 9 & 10 \\
\hline GREX & 58 & 70 & 66 & 55 & 70 & 77 & 66 \\
\hline AGB & -2 & -1 & 22 & 5 & -53 & -26 & -9 \\
\hline $\mathrm{AM}$ & 42 & 52 & 56 & 35 & 57 & 55 & 50 \\
\hline $\mathrm{SD}$ & 3 & 0 & 1 & -17 & 12 & 8 & 1 \\
\hline
\end{tabular}

Tabela 23 - Índices de balanço nutricional, obtidos a partir da análise foliar de abril de 1990.

\begin{tabular}{cccccccc}
\hline & \multicolumn{7}{c}{ Repeticões } \\
\cline { 2 - 6 } Tratamentos & 1 & 2 & 3 & 4 & 5 & 6 & Médias \\
\hline D & 13 & 8 & 20 & 16 & 16 & 11 & 14 \\
GA+2,4-D & 13 & 15 & 21 & 16 & 15 & 20 & 17 \\
GA+NAA & 13 & 10 & 11 & 16 & 11 & 12 & 12 \\
GREX & 18 & 27 & 28 & 18 & 25 & 26 & 24 \\
AGB & 12 & 14 & 10 & 7 & 18 & 12 & 12 \\
AM & 23 & 22 & 27 & 23 & 25 & 22 & 24 \\
SD & 12 & 10 & 5 & 8 & 17 & 8 & 10 \\
\hline
\end{tabular}


Todos os tratamentos apresentam média de índices DRIS para o nitrogênio, fósforo, magnésio e manganês, na faixa correspondente a teor adequado, pelo critério de interpretação de valores de índices DRIS (Tabela 5).

Pelo DRIS, os tratamentos GA+2,4-D; GA+NAA e GREX apresentam índices correspondentes a teor baixo de potássio; os demais tratamentos apresentam índices correspondentes a teor adequado. $O$ tratamento $\mathrm{GA}+2,4-\mathrm{D}$ apresenta índice correspondente a teor alto de cálcio, e os demais tratamentos, a teor adequado. Os índices para o enxofre são considerados na faixa de teores adequados em quase todos os tratamentos, com exceção de GREX, que apresenta índice relativo a teor baixo. Praticamente todos os tratamentos apresentam índices relativos a teor adequado de boro, com exceção do tratamento AM, que apresenta índice correspondente a teor alto. Os índices para o ferro estão na faixa de teores considerados adequados em quase todos os tratamentos. $\mathrm{O}$ tratamento $\mathrm{AM}$ apresenta índice na faixa de teor baixo. Praticamente todos os tratamentos apresentam índices relativos a teores adequados de zinco, com exceção dos tratamentos GREX e AM, onde o teor é considerado alto, pelos índices apresentados.

Quanto aos índices de balanço nutricional (BN), a interpretação é de que valores mais altos indicam maior desequilibrio entre nutrientes na planta, já que estes índices são obtidos a partir da média dos valores absolutos dos índices de cada nutriente. Podemos verificar que o tratamento GA+2,4-D apresenta índice de BN ligeiramente elevado, em relação ao controle de árvores sadias, em consequência principalmente do indice baixo para o potássio e elevado para o cálcio. $O$ tratamento GREX apresenta índice de BN elevado também pelo baixo índice para o potássio, e pelo índice elevado para o zinco. $O$ tratamento AM apresenta índices altos para o boro e para o zinco, resultando em um alto índice de $\mathrm{BN}$. 


\subsection{Análises de solo}

A partir das análises de solo de junho de 1989 e de novembro de 1990, foram obtidos os seguintes dados: $\mathrm{pH}$; porcentagem de saturação por bases (V \%); capacidade de troca catiônica (CTC); porcentagem de matéria orgânica; teores de fósforo $(\mathrm{P})$, potássio $(\mathrm{K})$, cálcio $(\mathrm{Ca})$ e magnésio $(\mathrm{Mg})$; acidez potencial $(\mathrm{H}+\mathrm{Al})$; relações cálcio/magnésio $(\mathrm{Ca} / \mathrm{Mg})$, cálcio/potássio $(\mathrm{Ca} / \mathrm{K})$ e magnésio/potássio $(\mathrm{Mg} / \mathrm{K})$; e porcentagem de areia e de argila (Tabelas 24 a 36 ).

\subsubsection{Porcentagem de saturação por bases (V\%)}

Houve diferença significativa entre os tratamentos, quanto a porcentagem de saturação por bases, pela análise de covariância e teste de Tukey ao nível de $5 \%$ de probabilidade, na faixa de profundidade de 0 a $20 \mathrm{~cm}$ da superficie do solo, como mostra a Tabela 25. O tratamento AGB apresenta maior média, não diferindo entretanto dos tratamentos D; GA+2,4-D; GREX; AM e SD. O tratamento GA+NAA apresenta menor média, não diferindo significativamente de $D$; GA+2,4-D; GREX ; AM e SD. Com base nestes resultados da análise estatística, pode-se verificar que apenas a média de AGB difere da média de GA+NAA, sendo significativamente maior do que esta última. As médias de ambos tratamentos não diferem dos controles, com ou sem declínio, sendo que estes não diferem entre si. Como são médias consideradas altas, de modo geral, segundo os padrões para interpretação de resultados de análise de solo para citros (GRUPO PAULISTA DE ADUBAÇÃO E CALAGEM DOS CITROS,1990), as diferenças parecem não influenciar o estado das plantas. 
Nas faixas de profundidade de 20 a $40 \mathrm{~cm}$, e de 40 a $60 \mathrm{~cm}$, não houve diferenças significativas entre os tratamentos, pelo teste $\mathrm{F}$ ao nível de $5 \%$ de probabilidade.

Tabela 24 - Médias e análise de variância da porcentagem de saturação por bases (V\%), e dos teores de fósforo, em ppm, das amostras de solo de junho de 1989.

\begin{tabular}{|c|c|c|c|c|c|c|}
\hline \multirow[b]{2}{*}{ Tratamentos } & \multicolumn{3}{|c|}{$\begin{array}{c}\text { V\% } \\
\text { Profundidade }\end{array}$} & \multicolumn{3}{|c|}{$\begin{array}{c}\text { Fósforo } \\
\text { Profundidade }\end{array}$} \\
\hline & $0-20 \mathrm{~cm}$ & $20-40 \mathrm{~cm}$ & $40-60 \mathrm{~cm}$ & $0-20 \mathrm{~cm}$ & $20-40 \mathrm{~cm}$ & $40-60 \mathrm{~cm}$ \\
\hline $\mathrm{D}$ & $52 a b$ & $32 \mathrm{ab}$ & $29 \mathrm{ab}$ & 18,7 & 4,6 & 4,5 \\
\hline $\mathrm{GA}+2,4-\mathrm{D}$ & $51 \mathrm{ab}$ & $32 \mathrm{ab}$ & $25 \mathrm{ab}$ & 23,4 & 5,2 & 3,3 \\
\hline $\mathrm{GA}+\mathrm{NAA}$ & $51 \mathrm{ab}$ & $26 a b$ & $24 \mathrm{ab}$ & 20,7 & 6,4 & 5,4 \\
\hline GREX & $57 \mathrm{a}$ & $37 \mathrm{ab}$ & $30 \mathrm{ab}$ & 19,7 & 6,1 & 4,8 \\
\hline AGB & $58 \mathrm{a}$ & $44 \mathrm{a}$ & $36 a$ & 21,6 & 6,0 & 4,7 \\
\hline $\mathrm{AM}$ & $47 \mathrm{ab}$ & $28 \mathrm{ab}$ & $25 \mathrm{ab}$ & 18,7 & 8,2 & 6,1 \\
\hline SD & $31 \mathrm{~b}$ & $14 \mathrm{~b}$ & $12 \mathrm{~b}$ & 23,2 & 4,9 & 3,9 \\
\hline F (Trat.) & $3,36 * *$ & $3,05 * *$ & $2,38 *$ & $0,38 \mathrm{~ns}$ & $1,72^{\mathrm{ns}}$ & $1,42 \mathrm{~ns}$ \\
\hline C.V. $(\%)$ & 23,85 & 43,01 & 44,72 & 37,40 & 38,78 & 40,38 \\
\hline
\end{tabular}

Obs.1: as médias de uma mesma coluna, seguidas de letras distintas, diferem significativamente entre si, pelo teste de Tukey ao nivel de $5 \%$ de probabilidade.

Obs. $2: * *=$ significativo a $1 \%$ de probabilidade;

$*=$ significativo a $5 \%$ de probabilidade;

ns = não significativo. 
Tabela 25 - Médias e análise de covariância da porcentagem de saturação por bases (V\%), e dos teores de fósforo, em ppm, das amostras de solo de novembro de 1990.

\begin{tabular}{ccccccc}
\hline & \multicolumn{3}{c}{$\begin{array}{c}\text { V\% } \\
\text { Profundidade }\end{array}$} & \multicolumn{3}{c}{$\begin{array}{c}\text { Fósforo } \\
\text { Profundidade }\end{array}$} \\
\cline { 2 - 7 } Tratamentos & $0-20 \mathrm{~cm}$ & $20-40 \mathrm{~cm}$ & $40-60 \mathrm{~cm}$ & $0-20 \mathrm{~cm}$ & $20-40 \mathrm{~cm}$ & $40-60 \mathrm{~cm}$ \\
\hline D & $73 \mathrm{a} \mathrm{b}$ & 63 & 54 & 8,3 & 5,0 & 2,1 \\
GA+2,4-D & $70 \mathrm{a} \mathrm{b}$ & 58 & 44 & 3,2 & 1,9 & 1,7 \\
GA+NAA & $62 \quad \mathrm{~b}$ & 55 & 52 & 3,7 & 3,7 & 2,0 \\
GREX & $82 \mathrm{ab}$ & 76 & 65 & 8,2 & 4,0 & 3,3 \\
AGB & $85 \mathrm{a}$ & 75 & 69 & 10,1 & 5,4 & 3,4 \\
AM & $76 \mathrm{a} \mathrm{b}$ & 62 & 56 & 8,9 & 6,2 & 3,0 \\
SD & $69 \mathrm{a} \mathrm{b}$ & 64 & 46 & 5,2 & 4,6 & 2,6 \\
\hline F (Trat.) & 2,42 * & $1,24 \mathrm{~ns}$ & $1,05 \mathrm{~ns}$ & $2,57 \mathrm{~ns}$ & $1,28 \mathrm{~ns}$ & $2,03 \mathrm{~ns}$ \\
C.V. (\%) & 14,40 & 22,81 & 28,50 & 58,54 & 67,17 & 41,46 \\
\hline
\end{tabular}

Obs.1: as médias de uma mesma coluna, seguidas de letras distintas, diferem significativamente entre si, pelo teste de Tukey ao nivel de $5 \%$ de probabilidade.

Obs. $2: *=$ significativo a $5 \%$ de probabilidade;

ns = não significativo.

Quanto aos demais parâmetros, ou seja, pH ; CTC (capacidade de troca catiônica); porcentagem de matéria orgânica; teores de fósforo, de potássio, de cálcio e de magnésio; acidez potencial e relaçõ̉es $\mathrm{Ca} / \mathrm{Mg}$ (cálcio/magnésio), $\mathrm{Ca} / \mathrm{K}$ (cálcio/potássio) e $\mathrm{Mg} / \mathrm{K}$ (magnésio/potássio), os tratamentos não apresentam 
diferenças significativas entre si, pela análise de covariância e teste $\mathrm{F}$ ao nível de $5 \%$ de probabilidade, em nenhuma faixa de profundidade do solo (Tabelas 25 a 35).

Tabela 26 - Médias e análise de variância dos índices de $\mathrm{pH}$ do solo, em $\mathrm{CaCl}_{2}$, e da capacidade de troca catiônica (CTC), em meq $/ 100 \mathrm{~cm}^{3}$ de solo, obtidos a partir de amostras retiradas em junho de 1989.

\begin{tabular}{ccccccc}
\hline & \multicolumn{3}{c}{$\begin{array}{c}\mathrm{pH} \\
\text { Profundidade }\end{array}$} & \multicolumn{4}{c}{ CTC } \\
\cline { 2 - 7 } Tratamentos & $0-20 \mathrm{~cm}$ & $20-40 \mathrm{~cm}$ & $40-60 \mathrm{~cm}$ & $0-20 \mathrm{~cm}$ & $20-40 \mathrm{~cm}$ & $40-60 \mathrm{~cm}$ \\
\hline D & 4,8 & 4,4 & 4,4 & $4,1 \mathrm{~b}$ & $3,3 \mathrm{~b}$ & $3,7 \mathrm{~b}$ \\
GA+2,4-D & 5,2 & 4,5 & 4,2 & $5,1 \mathrm{ab}$ & $4,0 \mathrm{~b}$ & $3,9 \mathrm{ab}$ \\
GA+NAA & 4,8 & 4,2 & 4,1 & $3,9 \mathrm{~b}$ & $3,2 \mathrm{~b}$ & $3,1 \mathrm{~b}$ \\
GREX & 4,9 & 4,6 & 4,3 & $4,0 \mathrm{~b}$ & $3,4 \mathrm{~b}$ & $3,0 \mathrm{~b}$ \\
AGB & 5,0 & 4,7 & 4,4 & $5,3 \mathrm{ab}$ & $3,7 \mathrm{~b}$ & $3,3 \mathrm{~b}$ \\
AM & 4,7 & 4,4 & 4,3 & $5,5 \mathrm{ab}$ & $4,4 \mathrm{ab}$ & $4,2 \mathrm{ab}$ \\
SD & 4,6 & 4,2 & 4,2 & $6,5 \mathrm{a}$ & $6,0 \mathrm{a}$ & $5,9 \mathrm{a}$ \\
\hline F (Trat.) & $1,28 \mathrm{~ns}$ & $0,98 \mathrm{~ns}$ & $0,86 \mathrm{~ns}$ & 4,59 k** & 5,22 *** & 4,30 *** \\
C.V. (\%) & 8,80 & 9,70 & 7,91 & 22,58 & 25,90 & 30,27 \\
\hline
\end{tabular}

Obs.1: as médias de uma mesma coluna, seguidas de letras distintas, diferem significativamente entre si, pelo teste de Tukey ao nivel de $5 \%$ de probabilidade.

Obs.2: $* *$ = significativo a $1 \%$ de probabilidade; ns = não significativo. 
Estes resultados diferem dos relatados por WUTSCHER (1989b) e WUTSCHER \& LEE (1988), que encontraram valores significativamente mais altos de pH do solo correlacionados com a ocorrência de "blight", na Flórida. Por outro lado, WUTSCHER \& HARDESTY (1979b), não encontraram diferẹç̧as significativas na CTC, no $\mathrm{pH}$, e nos teores dos minerais fósforo, potássio, cálcio, magnésio, sódio, ferro, manganês, zinco, cobre e molibdênio em solos sob árvores sadias ou com "blight".

Tabela 27 - Médias e análise de covariância dos índices de $\mathrm{pH}$ do solo, em $\mathrm{CaCl}_{2}$, da capacidade de troca catiônica (CTC), em meq $100 \mathrm{~cm}^{3}$ de solo, obtidos a partir de amostras retiradas em novembro de 1990.

\begin{tabular}{ccccccc}
\hline & \multicolumn{3}{c}{$\begin{array}{c}\mathrm{pH} \\
\text { Profundidade }\end{array}$} & & \multicolumn{3}{c}{$\begin{array}{c}\text { CTC } \\
\text { Profundidade }\end{array}$} \\
\cline { 2 - 7 } Tratamentos & $0-20 \mathrm{~cm}$ & $20-40 \mathrm{~cm}$ & $40-60 \mathrm{~cm}$ & $0-20 \mathrm{~cm}$ & $20-40 \mathrm{~cm}$ & $40-60 \mathrm{~cm}$ \\
\hline D & 5,5 & 5,2 & 5,0 & 4,6 & 3,5 & 3,1 \\
GA+2,4-D & 5,3 & 5,0 & 4,5 & 4,4 & 3,5 & 3,2 \\
GA+NAA & 4,9 & 4,8 & 4,6 & 3,9 & 3,8 & 3,2 \\
GREX & 5,5 & 5,4 & 4,9 & 4,8 & 3,9 & 2,9 \\
AGB & 5,6 & 5,2 & 5,0 & 5,4 & 4,1 & 3,4 \\
AM & 5,1 & 4,8 & 4,7 & 4,8 & 3,4 & 3,2 \\
SD & 4,8 & 4,7 & 4,4 & 4,8 & 4,0 & 3,4 \\
\hline F (Trat.) & $1,46 \mathrm{~ns}$ & $0,44 \mathrm{~ns}$ & $0,29 \mathrm{~ns}$ & $1,32 \mathrm{~ns}$ & $0,54 \mathrm{~ns}$ & $0,30 \mathrm{~ns}$ \\
C.V.(\%) & 8,82 & 13,05 & 12,91 & 18,60 & 25,78 & 24,31 \\
\hline
\end{tabular}

Obs.: ns = não significativo. 
Tabela 28 - Médias e análise de variância da porcentagem de matéria orgânica, e dos teores de potássio, em meq/100 $\mathrm{cm}^{3}$ de solo, das amostras retiradas em junho de 1989.

\begin{tabular}{ccccccc}
\hline & \multicolumn{3}{c}{$\begin{array}{c}\text { Matéria orgânica } \\
\text { Profundidade }\end{array}$} & & \multicolumn{3}{c}{$\begin{array}{c}\text { Potássio } \\
\text { Profundidade }\end{array}$} \\
\cline { 2 - 7 } Tratamentos & $0-20 \mathrm{~cm}$ & $20-40 \mathrm{~cm}$ & $40-60 \mathrm{~cm}$ & $0-20 \mathrm{~cm}$ & $20-40 \mathrm{~cm}$ & $40-60 \mathrm{~cm}$ \\
\hline D & 1,0 & 0,8 & 0,8 & $0,12 \mathrm{ab}$ & $0,09 \mathrm{ab}$ & 0,06 \\
GA+2,4-D & 1,0 & 0,9 & 0,8 & $0,17 \mathrm{ab}$ & $0,10 \mathrm{ab}$ & 0,07 \\
GA+NAA & 1,0 & 0,9 & 0,8 & $0,18 \mathrm{a}$ & $0,11 \mathrm{a}$ & 0,08 \\
GREX & 1,2 & 1,0 & 0,8 & $0,11 \mathrm{~b}$ & $0,06 \mathrm{ab}$ & 0,04 \\
AGB & 1,2 & 0,8 & 0,7 & $0,14 \mathrm{ab}$ & $0,08 \mathrm{ab}$ & 0,04 \\
AM & 1,2 & 1,0 & 0,9 & $0,12 \mathrm{ab}$ & $0,05 \mathrm{~b}$ & 0,06 \\
SD & 1,2 & 0,9 & 0,8 & $0,16 \mathrm{ab}$ & $0,08 \mathrm{ab}$ & 0,06 \\
\hline F (Trat.) & $0,78 \mathrm{~ns}$ & $0,53 \mathrm{~ns}$ & $1,24 \mathrm{~ns}$ & $2,92 *$ & $2,42 *$ & $1,82 \mathrm{~ns}$ \\
C.V. (\%) & 25,57 & 24,31 & 21,91 & 26,81 & 38,20 & 37,26 \\
\hline
\end{tabular}

Obs.1: as médias de uma mesma coluna, seguidas de letras distintas, diferem significativamente entre si, pelo teste de Tukey ao nível de $5 \%$ de probabilidade.

Obs.2: * = significativo a 5\% de probabilidade; ns = não significativo. 
Tabela 29 - Médias e análise de covariância da porcentagem de matéria orgânica, e dos teores de potássio, em meq/100 $\mathrm{cm}^{3}$ de solo, das amostras retiradas em novembro de 1990.

\begin{tabular}{|c|c|c|c|c|c|c|}
\hline \multirow[b]{2}{*}{ Tratamentos } & \multicolumn{3}{|c|}{$\begin{array}{c}\text { Matéria orgânica } \\
\text { Profundidade } \\
\end{array}$} & \multicolumn{3}{|c|}{$\begin{array}{c}\text { Potássio } \\
\text { Profundidade }\end{array}$} \\
\hline & $0-20 \mathrm{~cm}$ & $20-40 \mathrm{~cm}$ & $40-60 \mathrm{~cm}$ & $0-20 \mathrm{~cm}$ & $20-40 \mathrm{~cm}$ & $40-60 \mathrm{~cm}$ \\
\hline $\mathrm{D}$ & 1,5 & 1,4 & 1,3 & 0,09 & 0,04 & 0,03 \\
\hline $\mathrm{GA}+2,4-\mathrm{D}$ & 1,7 & 1,4 & 1,4 & 0,06 & 0,04 & 0,03 \\
\hline $\mathrm{GA}+\mathrm{NAA}$ & 1,4 & 1,4 & 1,3 & 0,07 & 0,04 & 0,03 \\
\hline GREX & 1,8 & 1,4 & 1,3 & 0,10 & 0,06 & 0,03 \\
\hline $\mathrm{AGB}$ & 1,8 & 1,6 & 1,5 & 0,13 & 0,07 & 0,06 \\
\hline AM & 1,8 & 1,6 & 1,5 & 0,12 & 0,06 & 0,04 \\
\hline $\mathrm{SD}$ & 1,8 & 1,6 & 1,4 & 0,11 & 0,06 & 0,03 \\
\hline F (Trat.) & $0,46 \mathrm{~ns}$ & $0,68 \mathrm{~ns}$ & $3,02^{n s}$ & $1,11 \mathrm{~ns}$ & $0,99 \mathrm{~ns}$ & $2,50 \mathrm{~ns}$ \\
\hline C.V. $(\%)$ & 17,44 & 18,76 & 11,95 & 75,09 & 62,07 & 48,38 \\
\hline
\end{tabular}

Obs.: ns = não significativo.

Os teores de potássio no solo são considerados de baixos a muito baixos, de acordo com os padrões para interpretação de resultados de análise de solo para citros (GRUPO PAULISTA DE ADUBAÇÃo E CALAGEM DOS CITROS,1990). Os baixos teores de potássio encontrados também nas folhas indicam que tanto a adubação de solo como a foliar não estão suprindo as necessidades das plantas que se desenvolvem em solos carentes em potássio. 
Tabela 30 - Médias e análise de variância dos teores de cálcio, e de magnésio, em meq/100 $\mathrm{cm}^{3}$ de solo, das amostras retiradas em junho de 1989 .

\begin{tabular}{|c|c|c|c|c|c|c|}
\hline \multirow[b]{2}{*}{ Tratamentos } & \multicolumn{3}{|c|}{$\begin{array}{c}\text { Cálcio } \\
\text { Profundidade }\end{array}$} & \multicolumn{3}{|c|}{$\begin{array}{c}\text { Magnésio } \\
\text { Profundidade }\end{array}$} \\
\hline & $0-20 \mathrm{~cm}$ & $20-40 \mathrm{~cm}$ & $40-60 \mathrm{~cm}$ & $0-20 \mathrm{~cm}$ & $20-40 \mathrm{~cm}$ & $40-60 \mathrm{~cm}$ \\
\hline D & 1,6 & $0,7 \mathrm{ab}$ & 0,7 & $0,4 \mathrm{ab}$ & 0,2 & 0,3 \\
\hline $\mathrm{GA}+2,4-\mathrm{D}$ & 1,7 & $0,8 \mathrm{ab}$ & 0,7 & $0,5 \mathrm{ab}$ & 0,3 & 0,2 \\
\hline GA+NAA & 1,3 & $0,5 \mathrm{~b}$ & 0,5 & $0,4 \mathrm{ab}$ & 0,2 & 0,2 \\
\hline GREX & 1,6 & $0,8 \mathrm{ab}$ & 0,5 & $0,6 \mathrm{ab}$ & 0,4 & 0,3 \\
\hline AGB & 2,1 & $1,0 \mathrm{a}$ & 0,7 & $0,8 \mathrm{a}$ & 0,5 & 0,4 \\
\hline $\mathrm{AM}$ & 1,7 & $0,6 a b$ & 0,5 & $0,6 \mathrm{ab}$ & 0,3 & 0,2 \\
\hline SD & 1,3 & $0,5 \mathrm{~b}$ & 0,5 & $0,3 \quad b$ & 0,2 & 0,2 \\
\hline F (Trat.) & $2,24^{\mathrm{ns}}$ & $3,08 *$ & $1,46^{\mathrm{ns}}$ & $2,52 *$ & $2,23 \mathrm{~ns}$ & $1,17^{\mathrm{ns}}$ \\
\hline C.V. $(\%)$ & 25,31 & 37,48 & 37,42 & 38,69 & 54,59 & 68,38 \\
\hline
\end{tabular}

Obs.1: as médias de uma mesma coluna, seguidas de letras distintas, diferem significativamente entre si, pelo teste de Tukey ao nivel de $5 \%$ de probabilidade.

Obs.2: * = significativo a $5 \%$ de probabilidade; ns = não significativo. 
Tabela 31 - Médias e análise de covariância dos teores de cálcio, e de magnésio, em meq $/ 100 \mathrm{~cm}^{3}$ de solo, das amostras retiradas em novembro de 1990 .

\begin{tabular}{ccccccc}
\hline & \multicolumn{3}{c}{$\begin{array}{c}\text { Cálcio } \\
\text { Profundidade }\end{array}$} & \multicolumn{3}{c}{$\begin{array}{c}\text { Magnésio } \\
\text { Profundidade }\end{array}$} \\
\cline { 2 - 7 } Iratamentos & $0-20 \mathrm{~cm}$ & $20-40 \mathrm{~cm}$ & $40-60 \mathrm{~cm}$ & $0-20 \mathrm{~cm}$ & $20-40 \mathrm{~cm}$ & $40-60 \mathrm{~cm}$ \\
\hline D & 2,6 & 1,6 & 1,2 & 0,8 & 0,7 & 0,6 \\
GA+2,4-D & 2,2 & 1,4 & 0,9 & 0,8 & 0,7 & 0,4 \\
GA+NAA & 1,6 & 1,6 & 1,1 & 0,7 & 0,6 & 0,6 \\
GREX & 2,7 & 1,9 & 1,1 & 1,2 & 1,1 & 0,9 \\
AGB & 3,2 & 2,0 & 1,5 & 1,2 & 1,0 & 0,8 \\
AM & 2,5 & 1,4 & 1,2 & 1,1 & 0,7 & 0,6 \\
SD & 2,5 & 1,8 & 1,1 & 0,8 & 0,8 & 0,6 \\
\hline F (Trat.) & $1,95 \mathrm{~ns}$ & $0,60 \mathrm{~ns}$ & $0,59 \mathrm{~ns}$ & $0,80 \mathrm{~ns} \cdots$ & $0,77 \mathrm{~ns}$ & $0,70 \mathrm{~ns}$ \\
C.V. (\%) & 25,78 & 44,88 & 48,28 & 32,66 & 51,38 & 60,57 \\
\hline
\end{tabular}

Obs.: $\mathbf{n s}=$ não significativo.

Os teores de cálcio e de magnésio são considerados btimos, e satisfazem a recomendação de que sejam mantidos a no mínimo $40 \%$ e $10 \%$ da CTC, respectivamente (GRUPO PAULISTA DE ADUBAÇÃO E CALAGEM DOS CITROS, 1990). 
Tabela 32 - Médias e análise de variância da acidez potencial no solo ( $\mathrm{H}+\mathrm{Al}$ ), em meq $/ 100 \mathrm{~cm}^{3}$ de solo, e da relação cálcio/magnésio, das amostras retiradas em junho de 1989.

\begin{tabular}{cccccccc}
\hline & \multicolumn{3}{c}{$\begin{array}{c}\mathrm{H}+\mathrm{Al} \\
\text { Profundidade }\end{array}$} & \multicolumn{3}{c}{$\begin{array}{c}\text { Ca/Mg } \\
\text { Profundidade }\end{array}$} \\
\cline { 2 - 7 } Tratamentos & $0-20 \mathrm{~cm}$ & $20-40 \mathrm{~cm}$ & $40-60 \mathrm{~cm}$ & $0-20 \mathrm{~cm}$ & $20-40 \mathrm{~cm}$ & $40-60 \mathrm{~cm}$ \\
\hline D & $2,0 \mathrm{~b}$ & $2,3 \mathrm{~b}$ & $2,7 \mathrm{~b}$ & 3,9 & 3,5 & 2,8 \\
GA+2,4-D & $2,6 \mathrm{ab}$ & $2,7 \mathrm{~b}$ & $2,9 \mathrm{~b}$ & 3,5 & 3,0 & 2,8 \\
GA+NAA & $1,9 \mathrm{~b}$ & $2,3 \mathrm{~b}$ & $2,4 \mathrm{~b}$ & 3,1 & 3,1 & 3,0 \\
GREX & $1,7 \mathrm{~b}$ & $2,2 \mathrm{~b}$ & $2,1 \mathrm{~b}$ & 2,6 & 2,1 & 1,8 \\
AGB & $2,3 \mathrm{~b}$ & $2,1 \mathrm{~b}$ & $2,1 \quad \mathrm{~b}$ & 2,8 & 2,2 & 2,0 \\
AM & $3,1 \mathrm{ab}$ & $3,5 \mathrm{ab}$ & $3,4 \mathrm{ab}$ & 2,9 & 2,4 & 3,0 \\
SD & $4,6 \mathrm{a}$ & $5,2 \mathrm{a}$ & $5,2 \mathrm{a}$ & 3,4 & $\cdots$ & 2,8 & 3,2 \\
\hline F (Trat.) & $4,28 * *$ & $5,52 * *$ & $4,78 * *$ & $2,10 \mathrm{~ns}$ & $2,28 \mathrm{~ns}$ & $1,12 \mathrm{~ns}$ \\
C.V. (\%) & 45,43 & 39,90 & 40,51 & 24,88 & 30,27 & 47,07 \\
\hline
\end{tabular}

Obs.1: as médias de uma mesma coluna, seguidas de letras distintas, diferem significativamente entre si, pelo teste de Tukey ao nivel de $5 \%$ de probabilidade.

Obs.2: $* *=$ significativo a $1 \%$ de probabilidade;

ns = não significativo. 
Tabela 33 - Médias e análise de covariância da acidez potencial no solo ( $\mathrm{H}+\mathrm{Al}$ ), em meq $/ 100 \mathrm{~cm}^{3}$ de solo, e da relação cálcio/magnésio, das amostras retiradas em novembro de 1990.

\begin{tabular}{ccccccc}
\hline & \multicolumn{3}{c}{$\begin{array}{c}\mathrm{H}+\mathrm{Al} \\
\text { Profundidade }\end{array}$} & \multicolumn{3}{c}{$\begin{array}{c}\text { Ca/Mg } \\
\text { Profundidade }\end{array}$} \\
\cline { 2 - 7 } Tratamentos & $0-20 \mathrm{~cm}$ & $20-40 \mathrm{~cm}$ & $40-60 \mathrm{~cm}$ & $0-20 \mathrm{~cm}$ & $20-40 \mathrm{~cm}$ & $40-60 \mathrm{~cm}$ \\
\hline D & 1,2 & 1,2 & 1,4 & 3,4 & 2,4 & 2,0 \\
GA+2,4-D & 1,2 & 1,4 & 1,8 & 3,1 & 2,5 & 2,6 \\
GA+NAA & 1,4 & 1,6 & 1,5 & 2,4 & 2,8 & 2,3 \\
GREX & 0,9 & 0,9 & 1,0 & 2,4 & 1,9 & 1,4 \\
AGB & 0,8 & 1,0 & 1,0 & 2,8 & 2,1 & 2,0 \\
AM & 1,1 & 1,2 & 1,3 & 2,2 & 2,0 & 1,9 \\
SD & 1,5 & 1,3 & 1,7 & 3,1 & 2,4 & 2,0 \\
\hline F (Trat.) & $1,88 \mathrm{~ns}$ & $1,73 \mathrm{~ns}$ & $2,16 \mathrm{~ns}$ & $1,06 \mathrm{~ns}$ & $0,55 \mathrm{~ns}$ & $0,87 \mathrm{~ns}$ \\
C.V. (\%) & 35,28 & 35,56 & 32,43 & 29,53 & 36,02 & 45,02 \\
\hline
\end{tabular}

Obs.: ns = não significativo.

Na segunda época de amostragem de solo das 42 árvores do ensaio, três amostras resultaram em níveis tóxicos de alumínio $\left(>0,5 \mathrm{meq} / 100 \mathrm{~cm}^{3}\right)$ abaixo de $40 \mathrm{~cm}$ de profundidade. Duas amostras apresentaram níveis tóxicos de alumínio abaixo de 20 $\mathrm{cm}$ de profundidade, e apenas uma amostra resultou em niveis tóxicos de alumínio nas três profundidades de solo analisadas. Estes dados diferem bastante da primeira época de amostragem, quando aproximadamente $40 \%$ das amostras abaixo de $20 \mathrm{~cm}$ apresentavam concentrações tóxicas de alumínio. Mesmo havendo uma melhoria das condições do sola, 
o desenvolvimento radicular foi prejudicado durante um período de tempo. Restaria avaliar as consequências para as plantas, decorrentes deste fator.

Tabela 34 - Médias e análise de variância das relações cálcio/potássio e magnésio/potássio, obtidas a partir das amostras de solo de junho de 1989.

\begin{tabular}{|c|c|c|c|c|c|c|}
\hline \multirow[b]{2}{*}{ Tratamentos } & \multicolumn{3}{|c|}{$\begin{array}{c}\mathrm{Ca} / \mathrm{K} \\
\text { Profundidade } \\
\end{array}$} & \multicolumn{3}{|c|}{$\begin{array}{c}\mathrm{Mg} / \mathrm{K} \\
\text { Profundidade } \\
\end{array}$} \\
\hline & $0-20 \mathrm{~cm}$ & $20-40 \mathrm{~cm}$ & $40-60 \mathrm{~cm}$ & $0-20 \mathrm{~cm}$ & $20-40 \mathrm{~cm}$ & $40-60 \mathrm{~cm}$ \\
\hline $\mathrm{D}$ & 12,2 & $8,2 a b$ & $9,8 a b$ & 3,1 & 2,5 & $4,0 \mathrm{ab}$ \\
\hline $\mathrm{GA}+2,4-\mathrm{D}$ & 11,1 & $8,6 \mathrm{ab}$ & $10,4 \mathrm{ab}$ & 3,5 & 3,2 & $3,6 \mathrm{ab}$ \\
\hline $\mathrm{GA}+\mathrm{NAA}$ & 7,6 & $4,6 \quad b$ & $6,1 b$ & 2,4 & 1,6 & $2,2 \quad b$ \\
\hline GREX & 16,2 & $12,4 \mathrm{ab}$ & $10,9 a b$ & 6,3 & 6,1 & $6,6 \mathrm{ab}$ \\
\hline AGB & 16,6 & $13,8 \mathrm{a}$ & $16,6 \mathrm{a}$ & 6,0 & 6,3 & $9,6 \mathrm{a}$ \\
\hline $\mathrm{AM}$ & 15,2 & $11,5 \mathrm{ab}$ & $8,7 a b$ & 6,1 & 5,7 & $4,7 \mathrm{ab}$ \\
\hline $\mathrm{SD}$ & 8,6 & $7,3 \mathrm{ab}$ & $8,8 \mathrm{ab}$ & 2,7 & 2,9 & $2,8 \mathrm{ab}$ \\
\hline F (Trat.) & $1,82^{n s}$ & $3,08 *$ & $2,74 *$ & $1,75 \mathrm{~ns}$ & $2,39 \mathrm{~ns}$ & $2,59 *$ \\
\hline C.V. $(\%)$ & 52,93 & 47,53 & 47,17 & 74,64 & 72,73 & 84,51 \\
\hline
\end{tabular}

Obs.1: as médias de uma mesma coluna, seguidas de letras distintas, diferem significativamente entre si, pelo teste de Tukey ao nivel de $5 \%$ de probabilidade.

Obs. $2:{ }^{*}=$ significativo a $5 \%$ de probabilidade; $\mathrm{ns}=$ não significativo. 
Tabela 35 - Médias e análise de covariância das 'relações cálcio/potássio e magnésio/potássio, obtidas a partir das amostras de solo de novembro de 1990.

\begin{tabular}{|c|c|c|c|c|c|c|}
\hline \multirow[b]{2}{*}{ Tratamentos } & \multicolumn{3}{|c|}{$\begin{array}{c}\mathrm{Ca} / \mathrm{K} \\
\text { Profundidade }\end{array}$} & \multicolumn{3}{|c|}{$\begin{array}{c}\mathrm{Mg} / \mathrm{K} \\
\text { Profundidade }\end{array}$} \\
\hline & $0-20 \mathrm{~cm}$ & $20-40 \mathrm{~cm}$ & $40-60 \mathrm{~cm}$ & $0-20 \mathrm{~cm}$ & $20-40 \mathrm{~cm}$ & $40-60 \mathrm{~cm}$ \\
\hline $\mathrm{D}$ & 34,0 . & 34,2 & 31,5 & 10,6 & 15,3 & 16,4 \\
\hline $\mathrm{GA}+2,4-\mathrm{D}$ & 39,2 & 36,0 & 25,7 & 15,6 & 17,8 & 13,1 \\
\hline $\mathrm{GA}+\mathrm{NAA}$ & 36,8 & 33,8 & 40,6 & 17,8 & 13,8 & 27,1 \\
\hline GREX & 33,7 & 36,2 & 33,1 & 15,8 & 22,6 & 27,3 \\
\hline AGB & 35,0 & 32,6 & 31,4 & 12,6 & 17,6 & 18,2 \\
\hline $\mathrm{AM}$ & 29,8 & 30,8 & 31,8 & 14,2 & 14,8 & 16,7 \\
\hline SD & 33,3 & 37,4 & 28,8 & 10,4 & 16,7 & 14,4 \\
\hline F (Trat.) & $0,40^{\mathrm{ns}}$ & $0,26^{\mathrm{ns}}$ & $0,64 \mathrm{~ns}$ & $0,78 \mathrm{~ns}$ & $0,23^{n s}$ & $0,93 \mathrm{~ns}$ \\
\hline C.V. $(\%)$ & 62,19 & 60,24 & 66,49 & 70,32 & 72,79 & 83,90 \\
\hline
\end{tabular}

Obs.: ns = não significativo. 


\subsubsection{Textura do solo}

Os tratamentos não apresentam diferenças significativas entre si, pelo teste $F$ ao nível de $5 \%$ de probabilidade, em nenhuma das faixas de profundidade do solo, com relação às porcentagens de areia e de argila, obtidas na primeira análise de solo (Tabela 36).

Tabela 36 - Médias e análise de variância da porcentagem de areia e de argila, nas amostras de solo retiradas no início do experimento, em junho de 1989.

\begin{tabular}{|c|c|c|c|c|c|c|}
\hline \multirow[b]{3}{*}{ Tratamentos } & \multirow{2}{*}{\multicolumn{3}{|c|}{$\begin{array}{c}\text { Areia } \\
\% \\
\text { Profundidade } \\
\end{array}$}} & \multirow{2}{*}{\multicolumn{3}{|c|}{$\begin{array}{c}\text { Argila } \\
\% \\
\text { Profundidade } \\
\end{array}$}} \\
\hline & & & & & & \\
\hline & $0-20 \mathrm{~cm}$ & $20-40 \mathrm{~cm}$ & $40-60 \mathrm{~cm}$ & $0-20 \mathrm{~cm}$ & $20-40 \mathrm{~cm}$ & $40-60 \mathrm{~cm}$ \\
\hline $\mathrm{D}$ & 62 & 59 & 60 & 29 & 33 & 32 \\
\hline $\mathrm{GA}+2,4-\mathrm{D}$ & 66 & 66 & 60 & 27 & 27 & 33 \\
\hline $\mathrm{GA}+\mathrm{NAA}$ & 62 & 60 & 59 & 28 & 31 & 32 \\
\hline GREX & 62 & 62 & 60 & 25 & 29 & 30 \\
\hline $\mathrm{AGB}$ & 61 & 60 & 58 & 28 & 30 & 31 \\
\hline $\mathrm{AM}$ & 62 & 59 & 58 & 27 & 30 & 31 \\
\hline SD & 61 & 60 & 57 & 28 & 30 & 33 \\
\hline F (Trat.) & $1,40^{\mathrm{ns}}$ & $1,47^{\mathrm{ns}}$ & $1,49 \mathrm{~ns}$ & $1,16^{\mathrm{ns}}$ & $0,84^{\mathrm{ns}}$ & $0,62^{\mathrm{ns}}$ \\
\hline C.V. $(\%)$ & 5,28 & 8,35 & 4,87 & 12,36 & 17,10 & 10,53 \\
\hline
\end{tabular}

Obs.: ns $=$ não significativo. 


\subsection{Teor de zinco no lenho}

Os tratamentos não diferem significativamente entre si, quanto ao teor de zinco no lenho, pelo teste $\mathrm{F}$ ao nível de $5 \%$ de probabilidade (Tabela 37 ).

Tabela 37 - Teores de zinco no lenho, em ppm, obtidos de amostras a $20 \mathrm{~cm}$ acima da região de enxertia, em abril de 1990, e análise de variância.

\begin{tabular}{cccccccc}
\hline & \multicolumn{7}{c}{ Repetições } \\
\cline { 2 - 6 } Tratamentos & 1 & 2 & 3 & 4 & 5 & 6 & Médias \\
\hline D & 12 & 11 & 9 & 44 & 17 & 14 & 17,8 \\
GA+2,4-D & 9 & 6 & 11 & 19 & 15 & 8 & 11,3 \\
GA+NAA & 12 & 7 & 10 & 8 & 10 & 7 & 9,0 \\
GREX & 13 & 6 & 8 & 8 & 7 & 7 & 8,2 \\
AGB & 10 & 9 & 15 & 15 & 19 & 7 & 12,5 \\
AM & 10 & 8 & 8 & 13 & 21 & 19 & 13,2 \\
SD & 8 & 6 & 11 & 8 & 9 & 9 & 8,5 \\
\hline F (Trat.) & & & & & & & 1,89 ns \\
C.V. (\%) & & & & & & & 53,05 \\
\hline
\end{tabular}

Obs.: ns = não significativo. 
Os teores médios de zinco encontrados neste ensaio, são semelhantes aos relatados por GIROTO (1990) em laranjeiras sadias 'Valencia' sobre limoeiro 'Cravo', no município de Barretos, Estado de São Paulo. Por outro lado, são comparáveis aos valores encontrados em árvores com declínio, pela maioria dos pesquisadores que realizaram análise do teor de zinco no lenho de citros, relacionando-o com a anomalia (BRLANSKY et al.,1984; LIMA, 1984; ROSSETTI, 1981; WUTSCHER, 1989a; WUTSCHER \& HARDESTY, 1979b; WUTSCHER et al., 1977 e YOUNG et al., 1980).

Uma variação grande nas concentrações de zinco no lenho de plantas cítricas é observada de um local para outro, como foi relatado por WUTSCHER et al. (1977) e confirmado pelos trabalhos posteriores. Portanto, é recomendável comparar plantas sadias e afetadas em um mesmo local. WUTSCHER et al. (1977) relataram que em 4 dos 10 locais avaliados por estes autores, não houve diferenças significativas no teor de zinco entre árvores sadias e afetadas.

A análise do teor de zinco no tronco de árvores do mesmo talhão onde foi realizado o presente ensaio, na Fazenda Urutuba, em 1982 (sete anos antes), resultou em médias de 7,2 ppm para árvores com sintomas iniciais de declínio e 3,9 ppm para árvores sadias (PRATES et al., 1984a). Pode-se observar pelos resultados do presente trabalho, que as árvores apresentam teores médios um tanto mais elevados do que aquelas com sintomas iniciais de declínio, em 1982.

WUTSCHER (1985) cita uma sazonalidade normal no teor de zinco no lenho tanto de plantas sadias como em declínio, havendo uma redução no verão.

Em levantamento por um período de 12 anos, WUTSCHER (1989a) obteve teores que permaneceram entre 14 e 20 ppm para árvores com "blight", e entre 2 e 3 ppm para sadias. 
A avaliação quantitativa do teor de zinco no lenho relacionado ao declínio de plantas cítricas, tem sido, como pode-se verificar pelos resultados obtidos, uma questão não bem estabelecida. As concentrações variam com o local, época e cultivar, entre outros fatores, e não estão correlacionadas com a severidade do declínio. Portanto, torna-se difícil chegar a uma idéia sobre o desenvolvimento do declínio relacionando-o a padrões quantitativos do acúmulo de zinco no tronco. Parece mais apropriado buscar uma teoria com respeito às razões para as diferenças de concentrações entre árvores sadias ou não, quando significativas, considerando os casos que se constituem em exceções, e as condições em que ocorrem.

\subsection{Teste de absorção de água pelo tronco}

A média de volume de água absorvida pelas árvores do tratamento SD (árvores sadias) é significativamente maior do que as médias dos demais tratamentos (árvores com declínio), pelo teste de Tukey ao nível de $5 \%$ de probabilidade, conforme mostra a Tabela 38, referente aos resultados do segundo teste de absorção de água pelo tronco, realizado ao término das aplicações dos tratamentos, em outubro de 1990. As médias de volume absorvido por árvores com declínio não diferem significativamente entre si. 
Tabela 38 - Volume de água absorvida, em mililitros/10 segundos, no teste de absorção de água realizado em outubro de 1990, e análise de variância.

\begin{tabular}{|c|c|c|c|c|c|c|c|}
\hline \multirow[b]{2}{*}{ Tratamentos } & \multicolumn{6}{|c|}{ Repetições } & \\
\hline & 1 & 2 & 3 & 4 & 5 & 6 & Médias \\
\hline $\mathrm{D}$ & 2,8 & 0 & 0 & 1,3 & 0 & 1,0 & 0,85 \\
\hline $\mathrm{GA}+2,4-\mathrm{D}$ & 3,3 & 0 & 1,3 & 0,7 & 0 & 2,0 & 1,22 \\
\hline $\mathrm{GA}+\mathrm{NAA}$ & 6,2 & 1,3 & 0 & 0,3 & 0 & 0 & 1,30 \\
\hline GREX & 0,3 & 5,0 & 1,7 & 1,3 & 0 & 2,7 & 1,83 \\
\hline $\mathrm{AGB}$ & 1,3 & 0 & 10,0 & 0,7 & 2,7 & 2,0 & 2,78 \\
\hline $\mathrm{AM}$ & 8,3 & 2,0 & 6,2 & 0,3 & 0,3 & 8,3 & 4,23 \\
\hline $\mathrm{SD}$ & 10,0 & 10,0 & 10,0 & 10,0 & 10,0 & 10,0 & $10,00 \mathrm{a}$ \\
\hline F (Trat.) & & & & & & & $10,86 *$ \\
\hline C.V. $(\%)$ & & & & & & & 75,53 \\
\hline
\end{tabular}

Obs.1: as médias de uma mesma coluna, seguidas de letras distintas, diferem significativamente entre si, pelo teste de Tukey a $5 \%$ de probabilidade.

Obs.2: ${ }^{* *}=$ significativo a $1 \%$ de probabilidade.

Estes resultados estão de acordo com os obtidos por PRATES et al. (1984a) em pomar de 'Valencia'/Cravo' e 'Pera'/Cravo', onde as árvores sadias absorviam $10 \mathrm{ml}$ de água em menos de 10 segundos, enquanto que as árvores com declínio não absorviam nada ou chegavam a absorver até $2 \mathrm{mi}$ de água em 10 segundos. Também 
concordam com os valores estabelecidos pelo método diagnóstico para declínio dos citros (LEE et al., 1984a).

As árvores do tratamento SD aparentemente se encontram em um estágio chamado por TIMMER et al. (1985), de pré-declínio, quando as árvores apresentam altas concentrações de zinco no lenho, no entanto absorvem água normalmente pelo tronco. Estes resultados concordam com os relatados por YOUNG et al. (1980), de que o acúmulo de zinco no lenho antecede a redução da translocação de água pelo xilema.

\subsection{Avaliação visual das árvores}

As notas atribuídas às árvores pelo seu estágio de declínio, nas três avaliações visuais durante o experimento, encontram-se nas Tabelas 39 a 41 . Não houve diferença significativa entre tratamentos, em nenhuma das épocas de avaliação, pelo teste F a $5 \%$ de probabilidade. A partir das notas, do volume de água absorvida pelo tronco, e do teor de zinco no lenho, demonstrou-se que nenhum dos tratamentos levou à recuperação das plantas com declínio. Convém notar que as árvores do tratamento SD (controle sem declínio) mantiveram nota 5 , indicativo de árvore sadia, durante todas as avaliações.

Deve-se enfatizar que as respostas de uma planta a um regulador vegetal podem variar com a espécie e a variedade. Mesmo uma determinada variedade pode apresentar respostas diferentes sob diferentes condições ambientais. Estas diferenças no 
efeito hormonal podem ser explicadas por variações nas fases de desenvolvimento ou fisiológicas, diferenças nas condições ambientais, no estado nutricional e na absorção, translocação, inativação, ou interação dos reguladores e dos hormônios endógenos (WEAVER, 1972).

Frequentemente encontra-se uma baixa correlação entre as concentrações endógenas de hormônios vegetais e as ações destes nas plantas (MARSCHNER, 1986). Também a aplicação de reguladores vegetais apresenta uma variação muito grande entre a ação esperada e a que realmente ocorre, em frequentes ocasiões, principalmente em plantas perenes. A razão para esta baixa correlação entre a ação hormonal e a concentração celular é que geralmente apenas uma fração da quantidade total do hormônio vegetal é fisiologicamente ativa, sendo o restante, ao menos temporariamente, inativado por ligações químicas ( conjugações com compostos orgânicos ), por compartimentação, ou por metabolismo ( geralmente oxidação ). No entanto, a razão principal é o requerimento de receptores nos sítios de ação do hormônio, o que esclarece certos efeitos inesperados de reguladores aplicados em plantas.

GARDNER, F.P. et al.(1985) afirmam que as respostas da planta às auxinas variam amplamente, dependendo da sensibilidade do órgão ou tecido. Alguns órgãos em especial, como frutos, sementes e folhas, são, com maior frequência, objeto de estudos com aplicação de reguladores vegetais, e geralmente respondem a estas aplicações. Também há respostas positivas a giberelinas, por exemplo, em plantas geneticamente anãs. Considerando-se a planta inteira, diversas espécies não respondem a giberelinas exógenas, por apresentarem níveis endógenos suficientes para seu desenvolvimento ou por requererem auxinas.

A sensibilidade dos tecidos e órgãos para responder ao regulador vegetal varia ao longo de sua diferenciação ou maturação (MARSCHNER, 1986). Embora em 
alguns casos os reguladores vegetais têm sido utilizados com sucesso em culturas, sua aplicação em larga escala está ainda limitada pelas dificuldades em predizer seus efeitos com suficiente precisão.

Tabela 39- Notas obtidas da avaliação visual de 20 de outubro de 1989, e análise de variância.

\begin{tabular}{llllllll}
\hline & \multicolumn{7}{c}{ Repetiç̃̃es } \\
\cline { 2 - 7 } Tratamentos & $\mathbf{1}$ & 2 & 3 & 4 & 5 & 6 & Médias \\
\hline D & 4 & 3 & 3 & 4 & 4 & 4 & 3,67 \\
GA+2,4-D & 4 & 3 & 3 & 4 & 3 & 4 & 3,50 \\
GA+NAA & 4 & 3 & 4 & 3 & 4 & 4 & 3,67 \\
GREX & 4 & 4 & 3 & 3 & 3 & 4 & 3,50 \\
AGB & 4 & 4 & 4 & 4 & 3 & 4 & 3,83 \\
AM & 4 & 4 & 4 & 3 & 3 & 4 & 3,67 \\
\hline F (Trat.) & & & & & & & 0,36 ns \\
C. V. (\%) & & & & & & 14,04 \\
\hline
\end{tabular}

Obs.: ns = não significativo. 
Tabela 40 - Notas obtidas da avaliação visual de 02 de abril de 1990, e análise de variância.

\begin{tabular}{llllllll}
\hline & \multicolumn{7}{c}{ Repetiçóes } \\
\cline { 2 - 7 } Tratamentos & 1 & 2 & 3 & 4 & 5 & 6 & Médias \\
\hline D & 4 & 3 & 3 & 4 & 3 & 4 & 3,50 \\
GA+2,4-D & 4 & 2 & 2 & 4 & 3 & 4 & 3,17 \\
GA+NAA & 3 & 2 & 4 & 3 & 3 & 3 & 3,00 \\
GREX & 3 & 4 & 4 & 3 & 2 & 3 & 3,17 \\
AGB & 4 & 3 & 4 & 3 & 2 & 4 & 3,33 \\
AM & 4 & 4 & 4 & 3 & 3 & 4 & 3,67 \\
\hline F (Trat.) & & & & & & & 0,68 ns \\
C.V. (\%) & & & & & & 21,98 \\
\hline
\end{tabular}

Obs.: ns = não significativo.

Tabela 41 - Notas obtidas da avaliação visual de 26 de outubro de 1990 , e análise de variância.

\begin{tabular}{llllllll}
\hline & \multicolumn{7}{c}{ Repetições } \\
\cline { 2 - 7 } Tratamentos & 1 & 2 & 3 & 4 & 5 & 6 & Médias \\
\hline D & 4 & 3 & 3 & 4 & 3 & 4 & 3,50 \\
GA+2,4-D & 4 & 2 & 3 & 4 & 3 & 4 & 3,33 \\
GA+NAA & 4 & 3 & 4 & 3 & 3 & 2 & 3,17 \\
GREX & 4 & 4 & 4 & 3 & 3 & 4 & 3,67 \\
AGB & 4 & 4 & 4 & 4 & 2 & 4 & 3,67 \\
AM & 4 & 4 & 4 & 3 & 3 & 4 & 3,67 \\
\hline F (Trat.) & & & & & & & 0,59 ns \\
C.V. (\%) & & & & & & 19,28 \\
\hline
\end{tabular}

Obs.: ns = não significativo . 
Considerando-se não apenas as diferenças entre médias de tratamentos, referentes às notas atribuídas na última avaliação visual, em 26 de outubro de 1990 (Tabela 36), mas o número de plantas que mantiveram nota 4 , em cada tratamento, observa-se que os tratamentos que incluiam fertilizantes (GREX; AGB e AM) apresentaram maior número de árvores com nota 4 (de 4 a 5 árvores) do que os tratamentos controle com declínio; GA+2,4-D e GA+NAA, sem fertilizantes (de 2 a 3 árvores). Não é um resultado analisado estatisticamente, entretanto, sugere que a experimentação por um período de tempo mais prolongado, com maiores doses dos fertilizantes, possa contribuir com maiores informações sobre a resposta de plantas com declínio à adição de reguladores vegetais e fertilizantes.

\section{6. Índice de área foliar ( IAF )}

Os índices de área foliar obtidos pelo método de fotografias hemisféricas, para as oito árvores fotografadas, encontram-se na Tabela 42. 
Tabela 42- IAF calculado pelo método de fotografias hemisféricas e notas correspondentes para oito árvores do ensaio.

\begin{tabular}{cccc}
\hline Arvore & Tratamento & IAF & Nota \\
\hline 08 & GA+2,4-D & 0,79 & 2 \\
11 & GA+2,4-D & 1,54 & 3 \\
02 & D & 1,53 & 3 \\
03 & D & 1,33 & 3 \\
01 & D & 1,60 & 4 \\
07 & GA+2,4-D & 1,51 & 4 \\
40 & SD & 2,68 & 5 \\
39 & SD & 2,11 & 5 \\
\hline
\end{tabular}

\subsection{Correlação notas - indices de área foliar (}

O teste $\mathrm{F}$ foi significativo a $0,2 \%$ para a regressão $\mathrm{IAF}$ = função ( nota ), indicando que há uma correlação significativa entre os valores de notas e de IAF (Quadro 1).

Quadro 1 - Quadro da análise de variância da regressão linear IAF = função (notas).

\begin{tabular}{lccccc}
\hline \multicolumn{1}{c}{ Causas da variação } & G.L. & S.Q. & Q.M. & Valor de F & Pr $>$ F \\
\hline Regressão & 1 & 1,7561 & 1,7561 & 25,98 & 0,0022 \\
Resíduo & 6 & 0,4055 & 0,0676 & & \\
\hline Total & 7 & 2,1616 & & & \\
\hline
\end{tabular}


Não foi possível fotografar as árvores, em todas as épocas de avaliação visual, ou ao menos árvores de todos os tratamentos em uma determinada época, portanto não foi realizada análise de variância das médias de índices de área foliar (IAF).

A correlação notas - IAF foi testada com o objetivo de avaliar se o sistema de atribuição de notas através da avaliação visual é válido. Pelo número de árvores fotografadas, pode-se dizer que aparentemente a avaliação visual fornece um dado razoável sobre a condição da copa da árvore.

O método de fotografias hemisféricas é bastante promissor na avaliação de copas de árvores envolvidas em ensaios, principalmente quando afetadas pelo declínio, que causa sintomas apreciáveis na copa dos citros. 


\section{CONCLUSÕES}

Considerando os resultados apresentados, o período de duração do experimento, e as condições em que o experimento foi conduzido, concluiu-se que :

a. Nenhum dos tratamentos empregados resulta em recuperação das laranjeiras com declínio.

b. O tratamento com ácido giberélico+ácido 2,4-diclorofenoxiacético apresenta teor foliar de cálcio mais elevado e teor foliar de manganês mais baixo, em relação ao controle com declínio.

c. O tratamento com ácido giberélico+ácido naftalenacético+Grex-Citrus apresenta menor teor de nitrogênio nas folhas, e maior teor de zinco, em relação ao controle com declínio.

d. O tratamento com Agromil+Biofix apresenta teor mais baixo de zinco nas folhas, em relação ao controle com declínio. 
e. O tratamento com Aminofértil-1+Aminofértil-2 apresenta maiores teores de boro e de zinco nas folhas, em relação ao controle com declínio.

f. O tratamento controle com declínio apresenta maiores teores de nitrogênio e de zinco nas folhas, em relação ao controle sem declínio.

g. O tratamento controle sem declínio apresenta maior volume de água absorvida pelo tronco, em relação ao controle com declínio, e a todos os demais tratamentos, também com declínio.

h. Os tratamentos não apresentam diferença no teor de zinco no lenho, em relação aos controles, e estes não apresentam diferença no teor de zinco no lenho, entre si.

i. Os índices de área foliar calculados pelo método de fotografias hemisféricas estão significativamente correlacionados com as notas atribuídas pela avaliação visual das árvores. 


\section{REFERÊNCIAS BIBLIOGRÁFICAS}

ALBRIGO, L.G. Xylem plugging and mineral status of blight affected citrus trees - a review. In : INTERNATIONAL CITRUS CONGRESS, 6., São Paulo, 1984. Proceedings of the International Society of Citriculture. São Paulo, Editorial Committee, 1984. v.2, p.303-306.

ALLMARAS, R.R.; KRAFT, J.M.; MILLER, D.E. Effects of soil compaction and incorporated crop residue on root health. Annual Review of Phytopathology, 26: 219-243, 1988.

ARRUDA, S.T.; PRATES, H.S.; GHILLARDI, A.A. Aspectos econômicos do declínio de citros em São Paulo. Laranja, Cordeirópolis, 7(2):377-402, 1986.

BATAGLIA, O.C. Dris - Citros - Uma alternativa para avaliar a nutrição das plantas. Laranja, Cordeirópolis, 10(2): 565-574, 1989.

BATAGLIA, O.C. \& DECHEN, A.R. Critérios alternativos para diagnose foliar. In : SIMPÓSIO AVANÇADO DE QUÍMICA E FERTILIDADE DO SOLO, 1. Piracicaba, 1986. Anais. Campinas, Fundação Cargill, 1986. p.115-136. 
BERETTA, M.J.G. Declínio de plantas cítricas. Informações Agronômicas, Piracicaba, 35:3-6, set. 1986.

BERETTA, M.J.G. Declínio de plantas cítricas - pesquisas recentes. Laranja, Cordeirópolis, 8(1): 83-93, dez. 1987.

BERETTA, M.J.G. \& ROSSETTI, V. Declinio: transmission, etiology, citology and recovery. In : INTERNATIONAL SYMPOSIUM OF CITRUS CANKER, DECLINIO/BLIGHT AND SIMILAR DISEASES, São Paulo, 1987. Proceedings. Campinas, Fundação Cargill, 1988. p.338-348.

BERETTA, M.J.G.; BRLANSKY, R.H.; LEE, R.F. A comparison of histochemical staining reactions of the xylem occlusions in trees affected by citrus blight and declinio. Plant Disease, 72(12):1058-1060, dez. 1988a.

BERETTA, M.J.G.; ROSSETTI, V.; POMPEU JÚNIOR, J.; TEÓFILO SOBRINHO, J. Comportamento de porta-enxertos em relação ao declínio de cítricas no Estado de São Paulo. Laranja, Cordeirópolis, 9(2):311-325, nov. 1988 b.

BERETTA, M.J.G.; ROSSETTI, V.; TEIXEIRA, A.R.R.; SEMPIONATO, O. Aplicação dos testes diagnósticos para declínio em plantas cítricas submetidas à transmissão por enxertia de aproximação de raízes. Laranja, Cordeirópolis, $10(2)$ : 335-346, 1989a. 
BERETTA, M.J.G.; MORAES, W.B.C.; BRLANSKY, R.H.; LEE, R.F.; TIMMER, L.W. Clorose foliar de mudas de citros envasadas, em presença de terra de pomar com declínio-II. Fitopatologia Brasileira, 10(2): 332, jun. 1985.

BERETTA, M.J.G.; TEIXEIRA, A.R.R.; ROSSETTI, V.; BRLANSKY, R.H.; LEE, R.F. Acúmulo de zinco em plantas jovens submetidas a transmissão experimental de declínio. In : CONGRESSO PAULISTA DE FITOPATOLOGIA, 12., Araras, 1989. Summa Phytopathologica. Jaguariúna, CNPDA/EMBRAPA, 1989b. v. 15(1):30.

BERETTA, M.J.G.; TEIXEIRA, A.R.R.; ROSSETTI, V.; VEGAS, A.; OCHOA, F.; ROMERO, G.; MENDT, R. Ocorrência de obstruções amorfas no xilema em plantas jovens submetidas a transmissão experimental de declínio. In : CONGRESSO PAÚlISTA DE FITOPATOLOGIA, 12., Araras, 1989. Summa Phytopathologica. Jaguariúna, CNPDA/EMBRAPA, 1989c. v.15(1): 31.

BERNARDES, M.S. Efeito de métodos químicos de indução de copa no desenvolvimento da seringueira ( Hevea brasiliensis Muell. Arg. cv. RRIM 600 ). Piracicaba, 1989. 192p. ( Mestrado - Escola Superior de Agricultura "Luiz de Queiroz"/USP )

BEVERLY, R.B.; STARK, J.G.; OJALA, J.G.; EMBLETON, T.W. Nutrient diagnosis of 'Valencia' oranges by DRIS. Journal of the American Society for Horticultural Science, 109 (5): 649-654, 1984. 
BRLANSKY, R.H. \& LEE, R.F. Pesquisa sobre o blight dos citros na Flórida. Laranja, Cordeirópolis, 8(1): 97-99, dez. 1987.

BRLANSKY, R.H.; LEE, R.F.; COLLINS, M.H. Structural comparison of xylem occlusions in the trunk of citrus trees with blight and other decline diseases. Phytopathology, 75:145-150, 1985.

BRLANSKY, R.H.; TIMMER, L.W.; LEE, R.F.; GRAHAM, J.H. Relationship of xylem plugging to reduced water uptake and symptom development in citrus trees with blight and blightlike declines. Phytopathology, 74(11): 1325-1328, 1984.

BURNETT, H.C.; NEMEC, S.; PATTERSON, M. A review of Florida citrus blight and its association with soil edaphic factors, nutrition and Fusarium solani. Tropical Pest Management, 28(4): 416-422, dez. 1982.

CASTRO, P.R.C. Declínio : uma anomalia fisiológica dos citros. Laranja, Cordeirópolis, 12(2): 381-400, 1991.

CHILDS, J.F.L. Florida citrus blight. Part I. Some causal relations of citrus blight. Plant Disease Reporter, 63(7):560-564, jul. 1979.

CHILDS, J.F.L. Control of citrus blight disease. Proceedings of the Florida State Horticultural Society, 94:25-28, 1981. 
COHEN, M. Diagnosis of young tree decline, blight and sand hill decline of citrus by measurement of water uptake using gravity injection. Plant Disease Reporter, 58 : 801-805, 1974.

COHEN, M. Trees with citrus blight. Citrus Industry, 63(2): 21-27, fev. 1982.

DECHEN, A.R. \& NEVES, C.S.V.J. Aplicação foliar de nutrientes em citros. Laranja, Cordeirópolis, 9(1): 65-92, nov. 1988.

EMBLETON, T.W.; JONES, W.W.; LABANAUSKAS, C.K.; REUTHER, W. Leaf analysis as a diagnostic tool and guide to fertilization. In : REUTHER, W., ed. The Citrus Industry. Berkeley, University of California, 1973. v.3, cap.6, p.183-210.

GARDNER, F.P.; PEARCE, R.B.; MTCHELL, R.L. Physiology of crop plants. Ames, The Iowa State University Press, 1985. 327p.

GARDNER, J.M.; CHANDLER, J.L.; FELDMAN, A.W. Growth responses and vascular plugging of citrus inoculated with rhizobacteria and xylem-resident bacteria. Plant and Soil, 86(3): 333-345, 1985.

GIROTO, E.J. Correlações de nutrientes em tecidos de laranjeiras ( Citrus sinensis (L.) Osbeck cv. Valencia ) e o declínio dos citros. Lavras, 1990. 77p. (MestradoEscola Superior de Agricultura de Lavras ) 
GRAHAM, J.H.; TIMMER, L.W.; YOUNG, R.H. Necrosis of major roots in relation to citrus blight. Plant Disease, 67(11): 1273-1276, 1983.

GRAHAM, J.H.; BRLANSKY, R.H.; TIMMER, L.W.; LEE, R.F.; MARAIS, L.J.; BENDER, G.S. Comparison of citrus tree declines with necrosis of major roots and their association with Fusarium solani. Plant Disease, 69(12): 1055-1058, 1985.

GRUPO PAULISTA DE ADUBAÇÃO E CALAGEM DOS CTTROS. Recomendações de adubação e calagem para citros no Estado de São Paulo. 2. ed. Cordeirópolis, Estação Experimental Sylvio Moreira / IAC, 1990. 14p. (Suplemento Laranja, Cordeirópolis, 11 (3) : 1990)

GUIRADO, N. \& SILVERIO, J.L. Leprose e declínio : problemas sérios da citricultura paulista. Laranja, Cordeirópolis, 13 (2) : 541-552, 1992.

GUIRADO, N.; MÜLLER, G.W.; PRATES, H.S. Declínio dos citros. In : RODRIGUEZ, O., ed. Citricultura Brasileira. 2.ed. Campinas, Fundação Cargill, 1991. v.2, p.722-734.

GUIRADO, N.; PRATES, H.S.; MÜLLER, G.W. Studies on the brazilian citrus decline carried out in the Instituto Agronômico, Campinas. In: INTERNATIONAL SYMPOSIUM OF CITRUS CANKER, DECLINIO/BLIGHT AND SIMILAR DISEASES, São Paulo, 1987. Proceedings. Campinas, Fundação Cargill, 1988. p.329-337, 
GUIRADO, N.; COSTA, A.S.; MÜLLER, G.W.; PRÁTES, H.S. Utilização de interenxertos tolerantes ao declínio dos citros em combinações suscetíveis à doença como possível medida de controle. In: CONGRESSO PAULISTA DE FITOPATOLOGIA, 12., Araras, 1989. Summa Phytopathologica. Jaguariúna, CNPDA/EMBRAPA, 1989. vol.15(1):42.

HIROCE, R. \& CAETANO, A.A. Levantamento nutricional de pomares cítricos pela análise química foliar. Laranja, Cordeirópolis, 5 : 265-276, nov. 1984.

HOPKINS, D.L. Production of diagnostic symptoms of blight in citrus inoculated with Xylella fastidiosa. Plant Disease, 72(5): 432-435, 1988.

HOPKINS, D.L.; BISTLINE, F.W.; RUSSO, L.W.; THOMPSON, C.M. Seasonal fluctuation in the occurence of Xylella fastidiosa in root and stem extracts from citrus with blight. Plant Disease, 75(2): 145-147, 1991.

LEE, R.F.; MARAIS, L.J.; TIMMER, L.W.; GRAHAM, J.H. Syringe injection of water into the trunk: a rapid diagnostic test for citrus blight. Plant Disease, 68(6):511-513, jun. 1984a.

LEE, R.F.; TIMMER, L.W.; ALBRIGO, L.G.; TUCKER, D.P.H. Citrus blight : attempts to get remission of symptoms by chemotherapy. Proceedings of the Florida State Horticultural Society, 94 : 21-25, jun. 1981. 
LEE, R.F.; TIMMER, L.W.; ALLEN, J.C.; TUCKER, D.P.H. Sharpshooter populations in blight-affected Florida citrus groves. In : INTERNATIONAL CITRUS CONGRESS, 6., São Paulo, 1984. Proceedings of the International Society of Citriculture. São Paulo, Editorial Committee, 1984b. v.2, p.376-379.

LIMA, J.E.O. Estudo sobre o declínio dos citros na região de Mogi-Guaçu, SP. Laranja, Cordeirópolis, 4 :173-187, 1983.

LIMA, J.E.O. Comparação entre declínio, colapso, gomose e tristeza. Laranja, Cordeirópolis, 5 : 399-401, nov. 1984.

MAGALHÃES, A.C. Considerações sobre a fisiologia do sistema radicular : o caso das plantas cítricas. Laranja, Cordeirópolis, 9(2): 401-404, nov. 1988.

MARAIS, L.J. Citrus blight : world research review. Citrograph, 75(5): 119-124, mar. 1990.

MARSCHNER, H. Mineral nutrition of higher plants. Orlando, Academic Press, 1986. 674p.

MOREIRA, C.S. Manejo do solo em pomar cítrico. Laranja, Cordeirópolis, 9(2): 423435, nov. 1988. 
NEMEC, S. Oxygen, temperature and water potential in shallow and deep soils of a citrus grove with blight. Proceedings of the Soil and Crop Science Society of Florida, 42 : 85-90, 1983.

NEMEC, S. Florida citrus blight. In : INTERNATIONAL CITRUS CONGRESS, 6., Tel Aviv, 1988. Proceedings. Rehovot, Israel, Balaban Publishers, 1988. v.2, p.1023-1029.

NEMEC, S.; BAKER, R.; BURNETT, H. Pathogenicity of Fusarium solani to citrus roots and its possible role in blight etiology. Proceedings of the Florida State Horticultural Society, 93 : 36-41, 1980.

NEMEC, S.; BURNETT, H.C.; PATTERSON, M. Root distribution and loss on blighted and healthy citrus trees. Proceedings of the Soil and Crop Science Society of Florida, $41:$ 91-96, 1983.

NEMEC, S.; MYHRE, D.; BURNETT, H. Stress responses in citrus induced with soil applications of urea, ammonium nitrate, and ammonium hydroxide. Proceedings of the Soil and Crop Science Society of Florida, $48: 111-117,1989 \mathrm{a}$.

NEMEC, S.; ZABLOTOWICZ, R.M.; CHANDLER, J.L. Distribution of Fusarium spp. and selected microflora in citrus soils and rhizospheres associated with healthy and blight-diseased citrus in Florida. Phytophylactica, 21(2): 141-146, $1989 \mathrm{~b}$. 
NEMEC, S.; CALVERT, D.; ALLEN, L.H.; FISKELL, F. Features of shallow soils with clay pans that are conductive to citrus blight. In : INTERNATIONAL CITRUS CONGRESS, 6., São Paulo, 1984. Proceedings of the International Society of Citriculture. São Paulo, Editorial Committee, 1984. v.2, p.398-401.

ORTOLANI, A.A.; PEDRO JÚNIOR, M.J.; ALFONSI, R.R. Agroclimatologia e o cultivo dos citros. In : RODRIGUEZ, O.,ed. Citricultura brasileira. 2.ed. Campinas, Fundação Cargill, 1991. v.1, p.153-195.

PINCKARD, J.A. Suppression of citrus young tree decline with humus. Plant Disease, 66(4):311-312, abr. 1982.

POMPEU JÚNIOR, J. Porta-enxertos. In : RODRIGUEZ, O., ed. Citricultura brasileira. 2.ed. Campinas, Fundação Cargill, 1991. v.1, p.265-280.

PRATES, H.S. Declínio de citros no Estado de São Paulo. Laranja, Cordeirópolis, 9(1):201-207, nov. 1988.

PRATES, H.S. Levantamento do declínio em pomares cítricos do Estado de São Paulo. In : CONGRESSO PAULISTA DE FITOPATOLOGIA, 12., Araras, 1989. Summa Phytopathologica. Jaguariúna, CNPDA/EMBRAPA, 1989. v.15(1): 13.

PRATES, H.S.; GUIRADO, N.; MÜLLER, G.W. Declínio dos citros no Estado de São Paulo. Laranja, Cordeirópolis, 5 : 195-222, nov. 1984a. 
PRATES, H.S.; TRANI, P.E.; BATAGLIA, O. Diagnose foliar e declínio em citros. In: CONGRESSO PAULISTA DE FITOPATOLOGIA, 12., Araras, 1989. Summa Phytopathologica. Jaguariúna, CNPDA/EMBRAPA, 1989. vol.15(1):14.

PRATES, H.S.; TRANI, P.E.; BATAGLIA, O.C.; HIROCE, R. Estudo comparativo dos níveis de nutrientes em folhas de plantas sadias e plantas com sintomas de "declínio" em pomares cítricos do Estado de São Paulo. Summa Phytopathologica, 9(1-2):68, jan./jun. 1983a.

PRATES, H.S.; TRANI, P.E.; HIROCE, R.; BATAGLIA, O.C. Estudo comparativo dos níveis de nutrientes em folhas de plantas aparentemente sadias e plantas com sintomas de "declínio" de pomares cítricos do Estado de São Paulo. Summa Phytopathologica, 10(1-2):76-77, jan./jun. 1984b.

PRATES, H.S.; TRANI, P.E.; HIROCE, R.; GUIRADO, N. Estudo comparativo dos níveis de nutrientes em pomares cítricos afetados pelo declínio, no Estado de São Paulo. Fitopatologia Brasileira, 10(2):333, jun. 1985.

PRATES, H.S.; CASTRO, P.R.C.; GUIRADO, N.; MELOTTO, E.; MÜLLER, G.W. Remissão de sintomas iniciais do declínio de citros pela aplicação de reguladores vegetais. Anais da Escola Superior de Agricultura "Luiz de Queiroz", Piracicaba, 45(1):229-240, 1988. 
PRATES, H.S.; CASTRO, P.R.C.; SOUZA, W.; DIONISIO, A.; APPEZZATO, B. Ação de reguladores vegetais no declínio dos citros. Summa Phytopathologica, Piracicaba, 9(3-4):220-229, jul./dez. 1983b.

RAIJ, B. van; QUAGGIO, J.A.; CANTARELLA, H.; FERREIRA, M.E.; LOPES, A.S.; BATAGLIA, O.C. Análise quimica do solo para fins de fertilidade. Campinas, Fundação Cargill, 1987. 170 p.

ROSSETTI, V. Declinio de plantas citricas; trabalhos realizados pelo Instituto Biológico de 1978 a 1981. São Paulo, Instituto Biológico, 1981. 13p.

ROSSETTI, V. Tentativas experimentais para a recuperação de plantas afetadas pelo declínio dos citros. Laranja, Cordeirópolis, 4 : 165-171, 1983.

ROSSETTI, V. Declínio e "blight": pesquisas. Laranja, Cordeirópolis, 5:225-235, nov. 1984.

ROSSETTI, V. \& BERETTA, M.J.G. Declinio of citrus trees in Brazil. In: INTERNATIONAL SYMPOSIUM OF CITRUS CANKER, DECLINIO/BLIGHT AND SIMILAR DISEASES, São Paulo, 1987. Proceedings. Campinas, Fundação Cargill, 1988. p.262-273. 
ROSSETTI, V. \& BERETTA, M.J.G. Declínio de plantas cítricas : possível transmissão experimental. In: CONGRESSO PAULISTA DE FITOPATOLOGIA, 12.,Araras, 1989. Summa Phytopathologica. Jaguariúna, CNPDA/EMBRAPA, 1989. v.15(1): 30 .

ROSSETTI, V.; BERETTA, M.J.G.; TEIXEIRA, A.R.R. Transmissão experimental do declínio em plantas cítricas jovens. Laranja, Cordeirópolis, 10(2): 347-358, 1989.

ROSSETTI, V.; REBOUÇAS, J.T.S.; LEFÈVRE, A.F.V. Declínio de plantas cítricas : pesquisas sobre a resistência elétrica de tecido de plantas afetadas por declínio. Fitopatologia Brasileira, 10(2): 333, jun. 1985.

SCHAFFER, B.; LARSON, K.D.; SNYDER, G.H.; SANCHEZ, C.A. Identification of mineral deficiencies associated with mango decline by DRIS. HortScience, 23(3-I) : 617-619, 1988.

SHANNON, L.M. \& ZAPHRIR, J. The relative influence of two citrus rootstock species upon plant growth and upon the inorganic composition of the scion. Proceedings of the American Society for Horticultural Science, 71 : 257-264, jun. 1958.

SYVERTSEN, J.P.; BAUSHER, M.G.; ALBRIGO, L.G. Water relations and related leaf characteristics of healthy and blight affected citrus trees. Journal of the American Society for Horticultural Science, 105(3):431-434, 1980. 
TAVARES, E.D.; BATISTA, F.A.S.; MELO, M.B.; TRINDADE, J.; ROSSETTI, V.; SILVA, L.M.S. Adubação orgânica e afrancamento na recuperação de plantas cítricas com declínio. In : CONGRESSO BRASILEIRO DE FRUTICULTURA, 7., Florianópolis, 1983. Anais. Florianópolis, SBF/EMPASC, 1984. p.295-300.

TEÓFILO SOBRINHO, J. \& FIGUEIREDO, J.O. Diversificação do uso de portaenxertos na citricultura paulista. Laranja, Cordeirópolis, $5:$ 403-417, nov. 1984.

TIMMER, L.W.; GRAHAM, J.H.; LEE, R.F. Effect of tetracycline treatment on the development of citrus blight symptoms. Proceedings of the Florida State Horticultural Society, $98:$ : 3-6, 1985.

TUBELIS, A.; PRATES, H.S.; SALIBE, A.A. Comportamento do "declínio" nos pomares cítricos do Estado de São Paulo. Laranja, Cordeirópolis, 9(1):187-199, nov. $1988 b$.

TUCKER, D.P.H.; LEE, R.F.; TIMMER, L.W.; ALBRIGO, L.G.; BRLANSKY, R.H. Experimental transmission of citrus blight. Plant Disease, 68(11): 979-980, nov. 1984.

WEAVER, R.J. Plant growth substances in agriculture. San Francisco, W.H. Freeman and Company, 1972. 594p.

WHEATON, T.A. \& YOUNG, R. Cytex not effective in research trials. Citrus Industry Magazine, 62(8): 31-34, ag. 1981. 
WUTSCHER, H.K. Seasonal changes in zinc and water-soluble phenolics in the outer trunk wood of healthy and blight-affected sweet orange trees. HortScience, 16(2):157-158, abr. 1981.

WUTSCHER, H.K. The effect of trunk injections on blight-affected citrus trees. In : INTERNATIONAL CITRUS CONGRESS, 6., São Paulo, 1984. Proceedings of the International Society of Citriculture. São Paulo, Editorial Committee, 1984. v.2, p.394-396.

WUTSCHER, H.K. Positive effect of basic slag application on citrus blight-affected 'Hamlin' orange trees. Proceedings of the Florida State Horticultural Society, 98 : 1-3, 1985.

WUTSCHER, H.K. Comparison of soil, leaf and feeder root nutrient levels in the citrus blight-free and citrus blight-affected areas of a 'Hamlin' orange grove. Proceedings of the Florida State Horticultural Society, 99 : 74-77, 1986.

WUTSCHER, H.K. Citrus blight : a horticultural perspective. In : INTERNATIONAL SYMPOSIUM OF CITRUS CANKER, DECLINIO/BLIGHT AND SIMILAR DISEASES, São Paulo, 1987. Proceedings. Campinas, Fundação Cargill, 1988a. p.395-405.

WUTSCHER, H.K. Nutritional and soil factors affecting trees with citrus blight. In : INTERNATIONAL CITRUS CONGRESS, 6., Tel Aviv, 1988. Proceedings. Rehovot, Israel, Balaban Publishers, 1988b. v.2, p.1013-1021. 
WUTSCHER, H.K. Long-term patterns of water uptake in syringe injection and wood zinc levels of blight-affected orange trees. Proceedings of the Florida State Horticultural Society, $102: 24-27,1989$ a.

WUTSCHER, H.K. Soil pH and extractable elements under blight-affected and healthy citrus trees on six Florida soils. Journal of the American Society for Horticultural Science, 114(4): 611-614, jul. 1989b.

WUTSCHER, H.K. \& HARDESTY, C.A. Ammonium, nitrite, and nitrate nitrogen levels in the soil under blight-affected and healthy citrus trees. Communications in Soil Science and Plant Analysis, 10(12): 1495-1503, 1979a.

WUTSCHER, H.K. \& HARDESTY, C.A. Concentrations of 14 elements in tissues of blight-affected and healthy 'Valencia' orange trees. Journal of the American Society for Horticultural Science, 104 : 9-11, $1979 b$.

WUTSCHER, H.K. \& LEE, O.N. Soil pH and extractable mineral elements in and around an isolated citrus blight site. Proceedings of the Florida State Horticultural Society, 101 : 70-72, 1988.

WUTSCHER, H.K. \& MCDONALD, R.E. Mineral elements and organic acids in branch and root xylem sap of healthy and blight-affected sweet orange trees. Journal of the American Society for Horticultural Science, 111(3): 426-429, mai. 1986. 
WUTSCHER, H.K. \& SMITH, P.F. Failure to propagate citrus blight in reconstituted trees. Proceedings of the Florida State Horticultural Society, 101 : 62-63, 1988.

WUTSCHER, H.K.; COHEN, M.; YOUNG, R.H. Zinc and water-soluble phenolic levels in the wood for the diagnosis of citus blight. Plant Disease Reporter, 61(7):572-576, jul. 1977.

WUTSCHER, H.K.; SCHWARZ, R.E.; CAMPIGLIA,H.G.; MOREIRA, C.S.; ROSSETTI, V. Blightlike citrus tree declines in South America and South Africa. HortScience, 15(5): 588-590, out. 1980.

YOUNG, R.H.; WUTSCHER, H.K.; ALBRIGO, L.G. Relationships between water translocation and zinc accumulation in citrus trees with and without blight. Journal of the American Society for Horticultural Science, 105(3):444-447, 1980. 